\title{
Mobile technologies to support healthcare provider to healthcare provider communication and management of care (Review)
}

Gonçalves-Bradley DC, J Maria AR, Ricci-Cabello I, Villanueva G, Fønhus MS, Glenton C, Lewin S, Henschke N, Buckley BS, Mehl GL, Tamrat T, Shepperd S

Gonçalves-Bradley DC, J Maria AR, Ricci-Cabello I, Villanueva G, Fønhus MS, Glenton C, Lewin S, Henschke N, Buckley BS, Mehl GL, Tamrat T, Shepperd S.

Mobile technologies to support healthcare provider to healthcare provider communication and management of care. Cochrane Database of Systematic Reviews 2020, Issue 8. Art. No.: CD012927.

DOI: 10.1002/14651858.CD012927.pub2.

www.cochranelibrary.com 
TABLE OF CONTENTS

HEADER

ABSTRACT

PLAIN LANGUAGE SUMMARY

SUMMARY OF FINDINGS

BACKGROUND

OBJECTIVES

METHODS

RESULTS

Figure 1.

Figure 2.

Figure 3.

DISCUSSION

AUTHORS' CONCLUSIONS

ACKNOWLEDGEMENTS

REFERENCES

CHARACTERISTICS OF STUDIES

DATA AND ANALYSES

Analysis 1.1. Comparison 1: Mobile technologies used by primary care providers to consult with a hospital-based specialist compared to usual care: Providers' adherence to recommended practice, guidelines or protocols, Outcome 1: Providers' adherence to recommended guidelines

Analysis 2.1. Comparison 2: Mobile technologies used by primary care providers to consult with a hospital-based specialist compared to usual care: Time between presentation and management of the health condition, Outcome 1: Time between presentation and management

Analysis 3.1. Comparison 3: Mobile technologies used by primary care providers to consult with a hospital-based specialist compared to usual care: Healthcare use, Outcome 1: Healthcare use

Analysis 3.2. Comparison 3: Mobile technologies used by primary care providers to consult with a hospital-based specialist compared to usual care: Healthcare use, Outcome 2: Referred for clinic follow-up or clinical examination, 3 to 12 months followup

Analysis 3.3. Comparison 3: Mobile technologies used by primary care providers to consult with a hospital-based specialist compared to usual care: Healthcare use, Outcome 3: Referred for clinic follow-up or clinical examination, 3 to 12 months followup

Analysis 4.1. Comparison 4: Mobile technologies used by primary care providers to consult with a hospital-based specialist compared to usual care: Participant's healthcare status and well-being, Outcome 1: Health-related quality of life

Analysis 4.2. Comparison 4: Mobile technologies used by primary care providers to consult with a hospital-based specialist compared to usual care: Participant's healthcare status and well-being, Outcome 2: Clinical course

Analysis 5.1. Comparison 5: Mobile technologies used by primary care providers to consult with a hospital-based specialist compared to usual care: Acceptability or satisfaction, Outcome 1: Healthcare provider satisfaction with the intervention .......

Analysis 5.2. Comparison 5: Mobile technologies used by primary care providers to consult with a hospital-based specialist compared to usual care: Acceptability or satisfaction, Outcome 2: Participant satisfaction with care

Analysis 6.1. Comparison 6: Mobile technologies used by primary care providers to consult with a hospital-based specialist compared to usual care: Costs, Outcome 1: Costs

Analysis 7.1. Comparison 7: Mobile technologies used by primary care providers to consult with a hospital-based specialist compared to usual care: Technical difficulties, Outcome 1: Technical difficulties

Analysis 8.1. Comparison 8: Mobile technologies for use in the emergency department compared to usual care: Time between presentation and management of the health condition, Outcome 1: Time between presentation and management

Analysis 9.1. Comparison 9: Mobile technologies for use in the emergency department compared to usual care: Healthcare use, Outcome 1: Healthcare use

Analysis 10.1. Comparison 10: Mobile technologies for use in the emergency department compared to usual care: Technical difficulties, Outcome 1: Technical difficulties

Analysis 11.1. Comparison 11: Mobile technologies used by community health workers or home-care workers compared to usual care: Healthcare use, Outcome 1: Healthcare use

Analysis 12.1. Comparison 12: Mobile technologies used by community health workers or home-care workers compared to usual care: Participant's healthcare status and well-being, Outcome 1: Participant healthcare status and well-being 
Analysis 13.1. Comparison 13: Mobile technologies used by community health workers or home-care workers compared to usual care: Acceptability or satisfaction, Outcome 1: Participant satisfaction with care

Analysis 14.1. Comparison 14: Mobile technologies used by community health workers or home-care workers compared to usual care: Costs, Outcome 1: Costs

Analysis 15.1. Comparison 15: Mobile technologies used by community health workers or home-care workers compared to usual care: Technical difficulties, Outcome 1: Technical difficulties

ADDITIONAL TABLES

APPENDICES

HISTORY

CONTRIBUTIONS OF AUTHORS

DECLARATIONS OF INTEREST

SOURCES OF SUPPORT

DIFFERENCES BETWEEN PROTOCOL AND REVIEW 
[Intervention Review]

\section{Mobile technologies to support healthcare provider to healthcare provider communication and management of care}

Daniela C Gonçalves-Bradley ${ }^{1}$, Ana Rita J Maria², Ignacio Ricci-Cabello ${ }^{3}$, Gemma Villanueva4, Marita S Fønhus ${ }^{5}$, Claire Glenton 5 , Simon Lewin ${ }^{5,6}$, Nicholas Henschke ${ }^{4}$, Brian S Buckley 7 , Garrett L Mehl${ }^{8}$, Tigest Tamrat ${ }^{8}$, Sasha Shepperd ${ }^{1}$

${ }^{1}$ Nuffield Department of Population Health, University of Oxford, Oxford, UK. 2Nova Medical School, Faculdade de Ciências Médicas, Lisbon, Portugal. ${ }^{3}$ Primary Care Research Unit, Instituto de Investigación Sanitaria Illes Balears, Palma de Mallorca, Spain. ${ }^{4}$ Cochrane Response, Cochrane, London, UK. ${ }^{5}$ Norwegian Institute of Public Health, Oslo, Norway. ${ }^{6}$ Health Systems Research Unit, South African Medical Research Council, Cape Town, South Africa. ${ }^{7}$ Department of Surgery, University of the Philippines, Manila, Philippines. 8Department of Sexual and Reproductive Health, World Health Organization, Geneva, Switzerland

Contact address: Daniela C Gonçalves-Bradley, daniela.bradley@ndph.ox.ac.uk.

Editorial group: Cochrane Effective Practice and Organisation of Care Group.

Publication status and date: New, published in Issue 8, 2020.

Citation: Gonçalves-Bradley DC, J Maria AR, Ricci-Cabello I, Villanueva G, Fønhus MS, Glenton C, Lewin S, Henschke N, Buckley BS, Mehl GL, Tamrat T, Shepperd S. Mobile technologies to support healthcare provider to healthcare provider communication and management of care. Cochrane Database of Systematic Reviews 2020, Issue 8. Art. No.: CD012927. DOI: 10.1002/14651858.CD012927.pub2.

Copyright ( $\subseteq 2020$ The Authors. Cochrane Database of Systematic Reviews published by John Wiley \& Sons, Ltd. on behalf of The Cochrane Collaboration. This is an open access article under the terms of the Creative Commons Attribution Licence, which permits use, distribution and reproduction in any medium, provided the original work is properly cited.

\section{A B S T R A C T}

\section{Background}

The widespread use of mobile technologies can potentially expand the use of telemedicine approaches to facilitate communication between healthcare providers, this might increase access to specialist advice and improve patient health outcomes.

\section{Objectives}

To assess the effects of mobile technologies versus usual care for supporting communication and consultations between healthcare providers on healthcare providers' performance, acceptability and satisfaction, healthcare use, patient health outcomes, acceptability and satisfaction, costs, and technical difficulties.

\section{Search methods}

We searched CENTRAL, MEDLINE, Embase and three other databases from 1 January 2000 to 22 July 2019. We searched clinical trials registries, checked references of relevant systematic reviews and included studies, and contacted topic experts.

\section{Selection criteria}

Randomised trials comparing mobile technologies to support healthcare provider to healthcare provider communication and consultations compared with usual care.

\section{Data collection and analysis}

We followed standard methodological procedures expected by Cochrane and EPOC. We used the GRADE approach to assess the certainty of the evidence. 


\section{Main results}

We included 19 trials (5766 participants when reported), most were conducted in high-income countries. The most frequently used mobile technology was a mobile phone, often accompanied by training if it was used to transfer digital images. Trials recruited participants with different conditions, and interventions varied in delivery, components, and frequency of contact. We judged most trials to have high risk of performance bias, and approximately half had a high risk of detection, attrition, and reporting biases. Two studies reported data on technical problems, reporting few difficulties.

\section{Mobile technologies used by primary care providers to consult with hospital specialists}

We assessed the certainty of evidence for this group of trials as moderate to low.

Mobile technologies:

- probably make little or no difference to primary care providers following guidelines for people with chronic kidney disease (CKD; 1 trial, 47 general practices, 3004 participants);

- probably reduce the time between presentation and management of individuals with skin conditions, people with symptoms requiring an ultrasound, or being referred for an appointment with a specialist after attending primary care ( 4 trials, 656 participants);

- may reduce referrals and clinic visits among people with some skin conditions, and increase the likelihood of receiving retinopathy screening among people with diabetes, or an ultrasound in those referred with symptoms ( 9 trials, 4810 participants when reported);

- probably make little or no difference to patient-reported quality of life and health-related quality of life (2 trials, 622 participants) or to clinician-assessed clinical recovery (2 trials, 769 participants) among individuals with skin conditions;

- may make little or no difference to healthcare provider (2 trials, 378 participants) or participant acceptability and satisfaction (4 trials, 972 participants) when primary care providers consult with dermatologists;

- may make little or no difference for total or expected costs per participant for adults with some skin conditions or CKD (6 trials, 5423 participants).

Mobile technologies used by emergency physicians to consult with hospital specialists about people attending the emergency department

We assessed the certainty of evidence for this group of trials as moderate.

Mobile technologies:

- probably slightly reduce the consultation time between emergency physicians and hospital specialists (median difference -12 minutes, $95 \% \mathrm{Cl}-19$ to $-7 ; 1$ trial, 345 participants);

- probably reduce participants' length of stay in the emergency department by a few minutes (median difference -30 minutes, $95 \% \mathrm{Cl}-37$ to $-25 ; 1$ trial, 345 participants).

We did not identify trials that reported on providers' adherence, participants' health status and well-being, healthcare provider and participant acceptability and satisfaction, or costs.

\section{Mobile technologies used by community health workers or home-care workers to consult with clinic staff}

We assessed the certainty of evidence for this group of trials as moderate to low.

Mobile technologies:

- probably make little or no difference in the number of outpatient clinic and community nurse consultations for participants with diabetes or older individuals treated with home enteral nutrition ( 2 trials, 370 participants) or hospitalisation of older individuals treated with home enteral nutrition (1 trial, 188 participants);

- may lead to little or no difference in mortality among people living with HIV (RR 0.82, 95\% CI 0.55 to 1.22 ) or diabetes (RR $0.94,95 \% \mathrm{Cl}$ 0.28 to 3.12 ) (2 trials, 1152 participants);

- may make little or no difference to participants' disease activity or health-related quality of life in participants with rheumatoid arthritis (1 trial, 85 participants);

- probably make little or no difference for participant acceptability and satisfaction for participants with diabetes and participants with rheumatoid arthritis (2 trials, 178 participants). 
We did not identify any trials that reported on providers' adherence, time between presentation and management, healthcare provider acceptability and satisfaction, or costs.

\section{Authors' conclusions}

Our confidence in the effect estimates is limited. Interventions including a mobile technology component to support healthcare provider to healthcare provider communication and management of care may reduce the time between presentation and management of the health condition when primary care providers or emergency physicians use them to consult with specialists, and may increase the likelihood of receiving a clinical examination among participants with diabetes and those who required an ultrasound. They may decrease the number of people attending primary care who are referred to secondary or tertiary care in some conditions, such as some skin conditions and CKD. There was little evidence of effects on participants' health status and well-being, satisfaction, or costs.

\section{PLAIN LANGUAGE SUMMARY}

\section{Using mobile technologies to promote communication and management of care between healthcare professionals}

\section{What is the aim of this review?}

We aimed to find out if healthcare workers using mHealth services through their mobile phones or other mobile devices to communicate with other healthcare workers provide quicker access to healthcare, and improve patient health outcomes. We collected and analysed all relevant research and found 19 studies.

\section{Key messages}

Mobile technologies probably slightly decrease the time to deliver health care, as well as the number of face-to-face appointments, when compared with usual care, and probably increase the number of people receiving clinical examinations for some conditions, including an eye exam for people with diabetes. Mobile technologies may have little or no impact on healthcare workers' and participants' satisfaction, health status or well-being.

\section{What was studied in the review?}

Many healthcare workers work alone or have little access to colleagues and specialists. This is a common problem for healthcare workers in rural areas or low-income countries.

One possible solution to this problem is to offer healthcare workers advice and support through mobile technologies that allow healthcare workers to get help from colleagues who are not in the same place. For instance, healthcare workers can contact specialists or colleagues with more experience through a phone or the Internet. Healthcare workers can also use their mobile phones or other mobile devices such as tablets. As more healthcare workers use mobile phones and other devices as part of their work, this could make it particularly easy for them to use mHealth services.

\section{What are the main results of the review?}

We found 19 relevant studies, which included more than 5766 people who needed health care. Sixteen studies were from high-income countries. Two studies reported on technical problems, reporting few difficulties.

\section{When primary healthcare workers use mobile technologies to consult with hospital specialists, they:}

- probably make little or no difference to whether guidelines are followed for people with chronic kidney disease, or to health status or quality of life of people with psoriasis.

- may increase the likelihood of retinopathy screening for people with diabetes, or receiving an ultrasound if referred with symptoms, and may reduce referrals or a visit to the clinic for people with a skin condition or referred for clinic follow-up for different health problems.

- may make little or no difference to healthcare worker or patient satisfaction, or to how much it costs to deliver health care.

\section{When emergency doctors use mobile technologies to consult with hospital specialists:}

- patients are probably managed slightly more quickly.

We did not find any studies that looked at the effect of mobile technologies on emergency doctors following guidelines, patients' health and well-being, healthcare worker or patient satisfaction, or costs.

\section{When community health workers or home-care workers use mobile technologies to consult with clinic staff, they:}

- probably make little or no difference to the number of times people with a new diabetes-related foot ulcer have to see a nurse, or elderly people using tube feeding have to see a nurse or go into hospital. 
- may make no difference to the number of people living with HIV or diabetes who die; and may make little or no difference to the health status or quality of life of people with rheumatoid arthritis.

- probably make little or no difference to the satisfaction of people with diabetes or rheumatoid arthritis.

We did not find any studies that looked at the effect of mobile technologies on whether community health workers follow guidelines, how quickly people receive care, healthcare worker satisfaction, costs, or technical difficulties.

\section{How up-to-date is this review?}

We searched for studies up to 22 July 2019. 


\section{SUMMARY OF FINDINGS}

\section{Summary of findings 1 . Mobile technologies used by primary care providers to consult with a hospital-based specialist compared with usual care}

Mobile technologies used by primary care providers to consult with a hospital-based specialist compared with usual care

Population: Primary care providers consulting with dermatologists ( 6 studies), ophthalmologists ( 2 studies), radiologists ( 1 study), nephrologists ( 1 study), or different specialists (1 study)

Setting: Primary care settings in North America (5 studies), Europe (4 studies), the Dominican Republic (1 study) or Mongolia (1 study)

Intervention: Mobile technologies for retinal screening using a non-mydriatic camera ( 2 studies), portable ultrasound ( 1 study), teledermatology to send digital images (6 studies), eConsult through audio-conferencing or secure direct messaging between healthcare providers ( 2 studies)

Comparison: Usual care that included a reminder to book an appointment with participant's healthcare provider; direct booking of a face-to-face appointment; regular ex amination during the index face-to-face appointment with the participant's primary care provider

\begin{tabular}{|c|c|c|c|c|}
\hline Outcomes & Impact & $\begin{array}{l}\text { № of partici- } \\
\text { pants } \\
\text { (studies) }\end{array}$ & $\begin{array}{l}\text { Certainty of } \\
\text { the evidence } \\
\text { (GRADE) }\end{array}$ & Plain language statement \\
\hline $\begin{array}{l}\text { Providers' ad- } \\
\text { herence to } \\
\text { recommend- } \\
\text { ed practice, } \\
\text { guidelines or } \\
\text { protocols: Ad- } \\
\text { herence to } \\
\text { the advised } \\
\text { monitoring } \\
\text { criteria }\end{array}$ & $\begin{array}{l}1 \text { trial of telenephrology (Van Gelder 2017), using a web-based plat- } \\
\text { form with access to the electronic medical record reported OR of } 1.23 \\
\text { ( } 95 \% \mathrm{Cl} 0.89 \text { to } 1.70 \text { ) for monitoring of disease and } 0.61 \text { ( } 0.22 \text { to } 1.72 \text { ) } \\
\text { for monitoring of metabolic parameters }\end{array}$ & $\begin{array}{l}3004 \\
\text { (1 cluster-ran- } \\
\text { domised tri- } \\
\text { al, } 47 \text { general } \\
\text { practices) }\end{array}$ & $\begin{array}{l}\oplus \oplus \oplus \ominus \\
\text { Moderate } a\end{array}$ & $\begin{array}{l}\text { Mobile technologies used by primary care } \\
\text { providers to consult with a hospital-based } \\
\text { specialist probably } \\
\text { make little or no difference to primary care } \\
\text { providers' adherence to the advised monitor- } \\
\text { ing criteria for participants with chronic kid- } \\
\text { ney disease (CKD), when compared with usu- } \\
\text { al care }\end{array}$ \\
\hline \multicolumn{5}{|l|}{$\begin{array}{l}\text { Follow-up not } \\
\text { specified }\end{array}$} \\
\hline $\begin{array}{l}\text { Time between } \\
\text { presentation } \\
\text { and manage- } \\
\text { ment of the } \\
\text { health condi- }\end{array}$ & $\begin{array}{l}2 \text { trials of teledermatology (Piette 2017; Whited 2002) } \\
\text { reported that participants allocated to IG received the required treat- } \\
\text { ment in less time than those allocated to CG (median delay } 4 \text { days for } \\
\text { IG and } 40 \text { days for CG; MD }-40.5 \text { days, } 95 \% \mathrm{Cl}-23 \text { to }-58 \text { ) }\end{array}$ & $\begin{array}{l}656 \\
(4 \text { ran- } \\
\text { domised tri- } \\
\text { als) }\end{array}$ & $\begin{array}{l}\oplus \oplus \oplus \ominus \\
\text { Moderate }\end{array}$ & $\begin{array}{l}\text { The intervention probably reduces time be- } \\
\text { tween participants presenting and manage- } \\
\text { ment among individuals with some skin con- } \\
\text { ditions, symptoms requiring an ultrasound, } \\
\text { or requiring an appointment with a specialist } \\
\text { after attending primary care }\end{array}$ \\
\hline
\end{tabular}

for people presenting with symptoms that required an ultrasound refor people presenting with symptoms that requir
ported little or no difference between groups.

Follow-up: 3

to 6 months

1 trial of eConsult for people attending primary care (Azogil-López

2019) reported that participants allocated to IG had an appointment 
Healthcare $\quad 4$ trials of teledermatology (Byamba 2015; Piette 2017; Whited 2002;

Follow-up: 3

to 12 months

$(95 \% \mathrm{Cl} 0.75$ to 0.88$)$ ) reported that those participants allocated to the intervention group were less likely to be referred for clinic follow-up or

attend an appointment at a clinic

2 trials of eConsults for nephrology (Van Gelder 2017) and different specialties (Liddy 2019a) reported little or no difference between groups (OR $0.61,95 \% \mathrm{Cl} 0.31$ to 1.23 and $\mathrm{RR} 0.93,95 \% \mathrm{Cl} 0.85$ to 1.03 , respectively)

2 trials of telemedicine for retinopathy screening (Davis 2003; Mansberger 2015) and 1 trial for people presenting with symptoms that required an ultrasound (Sutherland 2009; RR 3.92, 95\% Cl 2.11 to 7.31 ) reported that those participants allocated to the intervention group were more likely to receive a clinical examination

\begin{tabular}{|c|c|c|}
\hline 4810 & $\oplus \oplus \oplus \odot$ & Mobile technologies used by primary care \\
\hline $\begin{array}{l}\text { (9 ran- } \\
\text { domised tri- } \\
\text { als) }\end{array}$ & Moderatec & $\begin{array}{l}\text { cialists may reduce referrals and clinic visits } \\
\text { among people with skin conditions, and in- } \\
\text { crease the likelihood of receiving retinopa- } \\
\text { thy screening among participants with dia- } \\
\text { betes, and an ultrasound in those referred } \\
\text { with symptoms, when compared with usual } \\
\text { care }\end{array}$ \\
\hline
\end{tabular}
care

1 trial did not specifically report the number of participants involved

Participants' Patient-reported quality of life and health-related quality of life (Follow-up: 9 to 12 months)

health

2 trials of teledermatology (Armstrong 2018; Whited 2013) found little

or no difference between groups

For health status (EQ-5D-5L): MD $0(95 \% \mathrm{Cl}-0.003$ to 0.003$)$
622

(2 ran-

domised trials)

\section{$\oplus \oplus \oplus \odot$}

Moderated

For quality of life (Skindex-16): IG: MD -12.0 (SD 24.5, 160 participants), CG: MD -13.2 (SD 21.6, 164 participants)

For health-related quality of life (SF-12), results reported as little or no difference between groups

Clinician-assessed clinical course (follow-up: 4 to 9 months)

2 trials of teledermatology (Pak 2007; Whited 2013) found little or no 769 difference between groups

(2 ran-

$\oplus \oplus \oplus \odot$

domised tri-

als)
Mobile technologies used by primary care providers to consult with hospital-based specialists probably make little or no difference to quality of life and health-related quality of life among individuals with skin conditions
Acceptability and satisfaction

Healthcare provider acceptability and satisfaction (follow-up immediately after the intervention)

1 trial of teledermatology (Piette 2017) reported little or no difference
between groups
(2 randomised trials)
Mobile technologies used by primary care providers to consult with hospital-based dermatologists probably make little or no difference to clinical improvement among individuals with skin conditions 
process than GPs allocated to the control group

Participant acceptability and satisfaction (follow-up: 1 to 9 months)

4 trials of teledermatology (Eminović 2009; Piette 2017; Whited 2002; Whited 2013) reported little or no difference between groups

1 trial reported MD $0.0(95 \% \mathrm{Cl}-0.12$ to 0.12 ; PSQ III), another trial reported that $87 \%$ of participants allocated to the intervention group

were overall satisfied with treatment received, compared with $92 \%$ of those allocated to the control group*

2 trials reported the results as little or no difference only (VSQ9; *)

\begin{tabular}{|c|c|c|c|c|}
\hline $\begin{array}{l}\text { Costs } \\
\text { Follow-up: } 1 \\
\text { to } 9 \text { months }\end{array}$ & $\begin{array}{l}2 \text { teledermatology trials (Eminović 2009; Whited 2013) and } 1 \text { te- } \\
\text { lenephrology trial (Van Gelder 2017) reported little or no difference } \\
\text { between groups } \\
2 \text { teledermatology trials (Pak 2007; Whited 2002) reported that when } \\
\text { loss of productivity was considered, the cost per participant was high- } \\
\text { er for those allocated to the intervention } \\
1 \text { trial of teledermatology (Byamba 2015) reported that total costs } \\
\text { were lower for those allocated to the intervention group. }\end{array}$ & $\begin{array}{l}5423 \\
\text { (6 ran- } \\
\text { domised tri- } \\
\text { als) }\end{array}$ & $\begin{array}{l}\oplus \oplus \ominus \ominus \\
\text { Lowh }\end{array}$ & $\begin{array}{l}\text { The intervention may make little or no dif- } \\
\text { ference to total or expected costs per partici- } \\
\text { pant for adults with skin conditions or chron- } \\
\text { ic kidney disease }\end{array}$ \\
\hline $\begin{array}{l}\text { Technical } \\
\text { problems }\end{array}$ & $\begin{array}{l}1 \text { trial recruiting GPs consulting with dermatologists about images } \\
\text { they took (Pak 2007) reported that there was little or no difference be- } \\
\text { tween groups for technical problems }\end{array}$ & $\begin{array}{l}698 \text { (1 ran- } \\
\text { domised trial) }\end{array}$ & Moderate ${ }^{\mathrm{i}}$ & $\begin{array}{l}\text { The intervention probably results in few or no } \\
\text { technical difficulties }\end{array}$ \\
\hline
\end{tabular}

CG: Control group; Cl: Confidence interval; EQ5D: EuroQol five dimensions questionnaire; GPs: General practitioners; IG: Intervention group; MD: Median difference; OR: Odds ratio; PSO III: Shortened version of the Patient Satisfaction Questionnaire; RR: Risk ratio; SD: Standard deviation; SF-12: Short-Form Health Survey 12; VSQ9: Visit-specific satisfaction questionnaire (VSQ9)

* Questions developed by the authors for the specific trial

\section{GRADE Working Group grades of evidence}

High certainty: We are very confident that the true effect lies close to that of the estimate of the effect

Moderate certainty: We are moderately confident in the effect estimate: The true effect is likely to be close to the estimate of the effect, but there is a possibility that it is substantially different

Low certainty: Our confidence in the effect estimate is limited: The true effect may be substantially different from the estimate of the effect

Very low certainty: We have very little confidence in the effect estimate: The true effect is likely to be substantially different from the estimate of effect 
aWe downgraded one point for risk of bias due to performance and detection bias, and lack of protection against contamination

bWe downgraded one point for risk of bias due to high risk of selection bias ( 2 trials), performance bias ( 3 trials), and reporting ( 2 trials) bias.

cWe downgraded one point for risk of bias due to high risk of selection ( 2 trials), performance ( 6 trials), detection ( 3 trials), attrition (1 trial) and reporting ( 2 trial) bias

dWe downgraded one point for risk of bias due to high risk of performance ( 2 trials), detection ( 2 trials), and reporting ( 2 trials) bias.

eWe downgraded one point for risk of bias due to high risk of performance, attrition and reporting bias.

fWe downgraded two points for risk of bias due to high risk of selection (1 trial), performance ( 2 trials), detection ( 2 trials), and reporting ( 1 trial) bias.

gWe downgraded two points for risk of bias due to high risk of selection ( 1 trial), performance ( 4 trials), detection ( 4 trials), attrition (1 trial) and reporting ( 3 trials) bias.

hWe downgraded two points for risk of bias due to high risk of detection (2 trials), performance ( 6 trials), selection (1 trial), attrition ( 2 trials), contamination (1 trial) and reporting bias (4 trials).

iWe downgraded one point for risk of bias due to high risk of performance, reporting and attrition bias.

\section{Summary of findings 2. Mobile technologies for use in the emergency department compared with usual care}

\section{Mobile technologies for use in the emergency department compared with usual care}

Patient or population: Emergency physicians consulting with hospital specialists about adults attending the emergency department

Setting: Turkey

Intervention: Smartphone application for secure messaging, including clinical images

Comparison: Usual care - consultation requests were done by telephone, with any clinical information sent verbally

\begin{tabular}{|c|c|c|c|c|}
\hline Outcomes & Impact & $\begin{array}{l}\text { № of partici- } \\
\text { pants } \\
\text { (studies) }\end{array}$ & $\begin{array}{l}\text { Certainty of } \\
\text { the evidence } \\
\text { (GRADE) }\end{array}$ & Plain language statement \\
\hline $\begin{array}{l}\text { Providers' adherence to recom- } \\
\text { mended practice, guidelines or } \\
\text { protocols }\end{array}$ & - & - & - & No studies were identified \\
\hline $\begin{array}{l}\text { Time between presentation and } \\
\text { management of the health condi- } \\
\text { tion } \\
\text { Follow-up not reported }\end{array}$ & $\begin{array}{l}1 \text { trial (Gulacti } 2017 \text { ) reported that } \\
\text { those allocated with the interven- } \\
\text { tion group were admitted to hospital } \\
\text { or discharged more quickly from the } \\
\text { emergency department (median dif- } \\
\text { ference }-12 \text { minutes, } 95 \% \mathrm{Cl}-19 \text { to }-7 \\
\text { minutes) }\end{array}$ & $\begin{array}{l}345 \\
\text { (1randomised } \\
\text { trial) }\end{array}$ & $\begin{array}{l}\oplus \oplus \oplus \ominus \\
\text { Moderate } a\end{array}$ & $\begin{array}{l}\text { The intervention probably reduces time } \\
\text { between participants presenting and } \\
\text { management by a few minutes among } \\
\text { individuals visiting the emergency de- } \\
\text { partment }\end{array}$ \\
\hline $\begin{array}{l}\text { Healthcare use: length of stay in } \\
\text { the emergency department } \\
\text { Follow-up not reported }\end{array}$ & $\begin{array}{l}1 \text { trial (Gulacti } 2017 \text { ) reported that par- } \\
\text { ticipant allocated to the intervention } \\
\text { group participants had a shorter stay } \\
\text { in the emergency department (median } \\
\text { difference }-30 \text { minutes, } 95 \% \mathrm{Cl}:-37 \text { to } \\
-25 \text { minutes) }\end{array}$ & $\begin{array}{l}345 \\
(1 \text { randomised } \\
\text { trial) }\end{array}$ & $\begin{array}{l}\oplus \oplus \oplus \ominus \\
\text { Moderate } a\end{array}$ & $\begin{array}{l}\text { The intervention probably slightly re- } \\
\text { duces length of stay among individuals } \\
\text { visiting the emergency department }\end{array}$ \\
\hline
\end{tabular}




\begin{tabular}{lllll}
$\begin{array}{l}\text { Participant and provider accept- } \\
\text { ability or satisfaction }\end{array}$ & - & - & No studies were identified \\
\hline Costs & - & - & - & No studies were identified
\end{tabular}

Technical problems

1 trial (Gulacti 2017) reported that

there were no technical problems dur-

ing the course of the trial
345 (1 randomised
trial)

The intervention probably results in few or no technical difficulties

Cl: Confidence interval

\section{GRADE Working Group grades of evidence}

High certainty: We are very confident that the true effect lies close to that of the estimate of the effect

Moderate certainty: We are moderately confident in the effect estimate: The true effect is likely to be close to the estimate of the effect, but there is a possibility that it is substantially different

Low certainty: Our confidence in the effect estimate is limited: The true effect may be substantially different from the estimate of the effect

Very low certainty: We have very little confidence in the effect estimate: The true effect is likely to be substantially different from the estimate of effect

\section{Rationale for downgrading the evidence}

aWe downgraded one point for risk of bias due to high risk of performance and reporting bias.

\section{Summary of findings 3. Mobile technologies used by community health or home-care workers compared with usual care}

\section{Mobile technologies used by community health or home-care workers compared with usual care}

Patient or population: Community-based peer health workers consulting with clinic staff about receiving antiretroviral therapy, community nurses consulting with diabetes specialist nurses or podiatrists about adults with Type 2 diabetes, home-care nurses consulting with hospital specialists about home enteral nutrition, rural-based physical therapists consulting with urban-based rheumatologists

Setting: Canada, Italy, Norway, Uganda

Intervention: Mobile technologies (teledermatology, mobile text messaging, interactive web-based records, video-consultations)

Comparison: Usual care - home visits or outpatient clinics

\begin{tabular}{l|lll}
\hline Outcomes & Impact & $\begin{array}{l}\text { № of partici- } \\
\text { pants } \\
\text { (studies) }\end{array}$ & $\begin{array}{l}\text { Certainty of } \\
\text { the evidence } \\
\text { (GRADE) }\end{array}$ \\
\hline
\end{tabular}

Providers' ad-

herence to

recommend- 


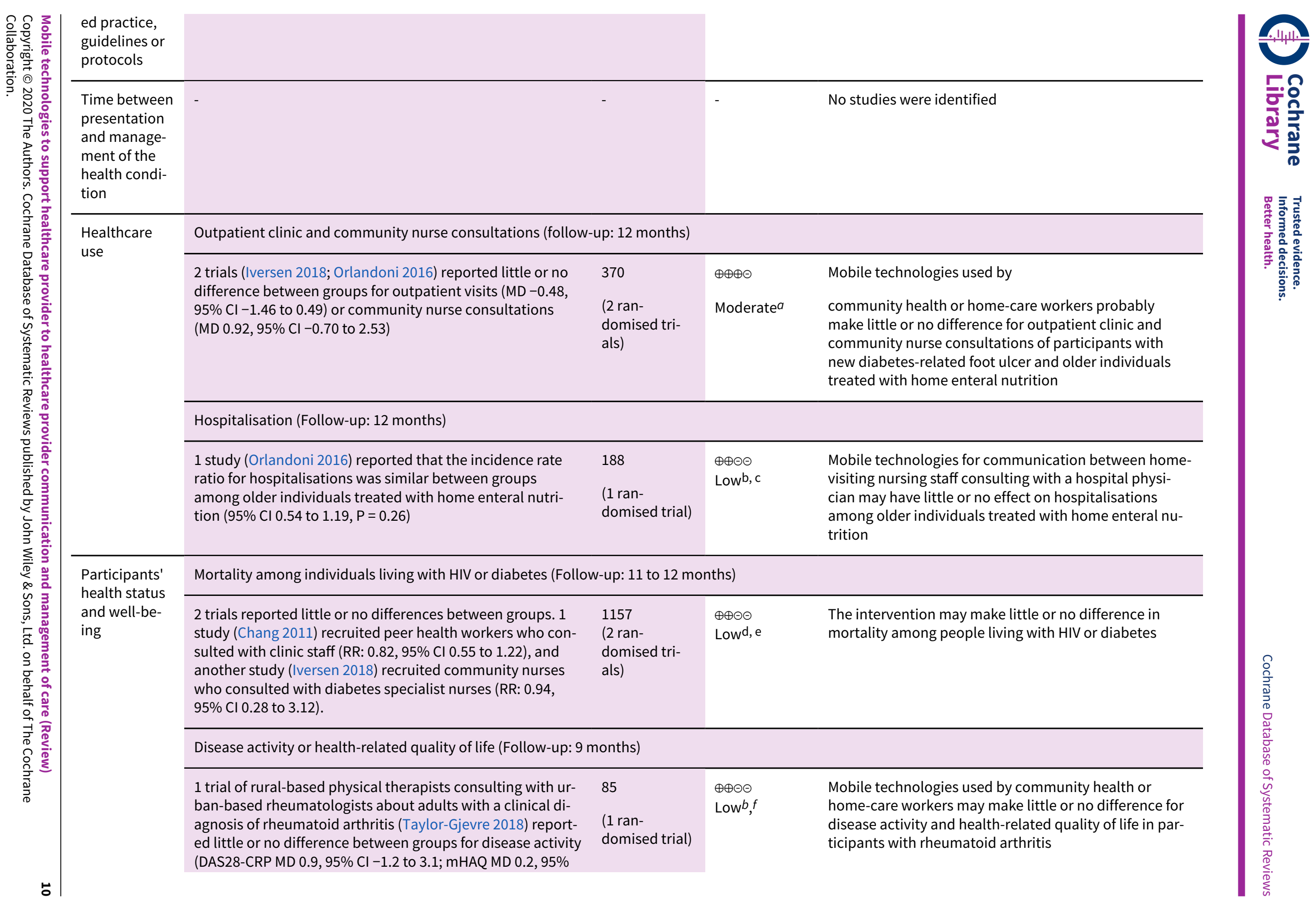


$\mathrm{Cl}-0.1$ to 0.5 ; RADAI MD $0.9,95 \% \mathrm{Cl}-0.5$ to 2.4 ) or health-re-

lated quality of life (EQ5D MD $-0.1,95 \% \mathrm{Cl}-0.4$ to 0.1 )

Participant and provider acceptability or satisfaction

Healthcare provider acceptability and satisfaction

(

Participant acceptability and satisfaction (Follow-up: 9 to 12 months)

2 trials on diabetes (Iversen 2018) and arthritis (Tay- 178

178

$\oplus \oplus \oplus \ominus$

lor-Gjevre 2018) reported little or no difference between

groups for participants' experience with healthcare (GS-

(2 ran-

Moderateg

sults reported narratively) with the intervention.

domised trials)
No studies were identified

Mobile technologies used by community health or home-care workers probably make little or no difference for participant acceptability and satisfaction for participants with new diabetes-related foot ulcer and participants with rheumatoid arthritis

\begin{tabular}{|c|c|c|c|c|}
\hline Costs & - & - & - & No studies were identified \\
\hline $\begin{array}{l}\text { Technical dif- } \\
\text { ficulties }\end{array}$ & - & - & - & No studies were identified \\
\hline
\end{tabular}

CI: Confidence interval; DAS28-CRP: Disease activity score for Rheumatoid Arthritis; EQ5D: EuroQol five dimensions questionnaire; GS-PEQ: Generic Short Patient Experiences Questionnaire; MD: Mean difference; mHAQ: Modified health assessment questionnaire; RADAl: Rheumatoid arthritis disease activity index; RR: Risk ratio; VSQ9: Visit-specific satisfaction questionnaire

\section{GRADE Working Group grades of evidence}

High certainty: We are very confident that the true effect lies close to that of the estimate of the effect

Moderate certainty: We are moderately confident in the effect estimate: The true effect is likely to be close to the estimate of the effect, but there is a possibility that it is substantially different

Low certainty: Our confidence in the effect estimate is limited: The true effect may be substantially different from the estimate of the effect

Very low certainty: We have very little confidence in the effect estimate: The true effect is likely to be substantially different from the estimate of effect

\section{Rationale for downgrading the evidence}

aWe downgraded one point for risk of bias due to high risk of performance ( 2 studies), detection ( 2 studies), attrition (1 study) and reporting ( 1 study) bias.

$b$ We downgraded one point for imprecision because the $95 \% \mathrm{Cl}$ shows potential effect on both sides of "no effect" line and that there were few events.

cWe downgraded one point for risk of bias due to high risk of performance, detection, and attrition bias.

$d$ We downgraded one point for imprecision because the $95 \% \mathrm{Cl}$ shows potential effect on both sides of "no effect" line

eWe downgraded one point for risk of bias due to high risk of performance ( 2 studies), detection (1 study), attrition (1 study) and reporting ( 2 studies) bias.

fWe downgraded one point for risk of bias due to high risk of performance, detection, attrition, and reporting bias.

gWe downgraded one point for risk of bias due to high risk of performance ( 2 studies), detection ( 2 studies), attrition ( 1 study), and reporting ( 2 studies) bias. 


\section{B A C K G R O U N D}

Effective communication with other healthcare providers and access to specialist expertise is essential for increasing health services capacity and providing optimal care, especially in areas where there is a shortage of healthcare providers (AAP 2015). The widespread use of information and communication technologies (ICT) can potentially increase the capacity of health services by supporting communication between different providers, and providing rapid access to specialist expertise.

\section{Description of the condition}

By 2035 there will be a worldwide shortage of approximately 12.9 million skilled healthcare providers (Campbell 2013). The biggest gaps will occur in Southeast Asia and sub-Saharan Africa, but elsewhere too this will be a problem due to larger ageing populations, the rising prevalence of non-communicable diseases, migration patterns and high turnover of healthcare providers. Remote and rural areas, where populations are likely to be poorer sicker and less educated, are particularly at risk (OPHI 2017; Wu 2016). Healthcare providers in those settings can be isolated and have limited interaction with colleagues and specialists, with few opportunities for mentoring, consultation with experts, or referrals to other healthcare providers.

\section{Description of the intervention}

Digital technologies are increasingly used to support health systems (WHO 2018) by providing flexible options for communication and the exchange of information. These technologies can be used for medical diagnostic, monitoring and therapeutic purposes, when participants are separated by distance or time or both, with the ultimate goal of improving the health of individuals and communities (Steinhubi 2013). Provision of health care at a distance is usually referred to as telemedicine (WHO 2018), and can be implemented through mobile or fixed devices.

The exchange of information can happen synchronously (when interactions happen in real time) or asynchronously (when there is a lag between the clinical information being transmitted and the response), and through different channels, including videoconferencing, mobile applications, and secure messaging (Kruse 2017; WHO 2016). The use of mobile technologies can improve access to specialty care (Liddy 2019b), particularly for underserved communities (Källander 2013). Widespread mobile broadband connectivity means that even healthcare providers in remote areas can access and communicate with their peers, improving cooperation (Aceto 2018). The World Health Organization (WHO) Global Observatory for eHealth conducted a survey of the WHO Member States on the use of eHealth (WHO 2016), and reported that of the 122 countries surveyed $70 \%$ reported on the use of mobile health devices for consultation between healthcare professionals. The most common areas were teleradiology, telepathology, and teledermatology (WHO 2016), with teleradiology programmes being widely used. Within this review our focus was on mobile technologies to support provider-to-provider communication and management of care.

In a bid to maximise the coverage of healthcare services and to decrease the cost of providing health care, governments and healthcare agencies in some countries have funded some type of telehealth programme for provision of care, including promoting communication and management of care between providers. Some examples include the Technology Enabled Care Services programme in England (NHS Commissioning Assembly 2015), the Scottish Centre for Telehealth and Telecare (SCTT 2017), the telehealth services provided within the Medicare programme in the USA (MedPAC 2016), the Asia eHealth Information Network (AeHIN 20017), the KwaZulu-Natal Experience in South Africa (Mars 2012), and the Aga Khan Development Network Digital Health Programme, which covers remote communities in South-Central Asia and East Africa (AKDN 2019).

\section{How the intervention might work}

The use of mobile technologies between healthcare providers for communication, consultations and patient management might contribute to developing professional skills and expertise, as well as optimising multidisciplinary communication (AAP 2015) and evidence-based clinical practice. This is particularly relevant for settings where there is a shortage of healthcare providers, for instance in low- and middle-income countries and in rural and remote areas (Källander 2013). By enabling healthcare providers who are geographically separated to exchange clinical information and knowledge, mobile technology can facilitate universal health coverage by increasing access to health care. In 2018 the WHO published a classification of digital health interventions to categorise the functionality of the different applications; using this classification as a guide we include interventions that are portable and facilitate remote healthcare provider communication or coordination of referrals, or both (WHO 2018).

Despite the possibilities, telehealth applications have been inconsistently implemented, with varying degrees of success due to technological challenges, legal considerations, human and cultural factors, and uncertainty around economic benefits and cost effectiveness (WHO 2016), although this is changing. Overcoming these barriers requires evidence-based implementation of guidelines, driven both by governmental and professional medical organisations; legislation on confidentiality, privacy and liability; and the involvement of stakeholders in designing, implementing and evaluating telemedicine applications, focusing on the safety and the effectiveness of applications (Agboola 2016).

\section{Why it is important to do this review}

The rapid progress of information and communication technologies is accelerating the evolution of remote communication between providers for the management of care. This review is one of a suite of 11 Cochrane Reviews that contributed to the WHO guideline on digital interventions for health systems strengthening (WHO 2019), and focuses on the effectiveness of mobile technologies for communication and management of care between healthcare providers who are in different locations. The effectiveness of mobile technologies to support patient-to-healthcare provider communication is being assessed in another review (Gonçalves-Bradley 2018a). The rationale for conducting this review is to assess the effectiveness of mobile health technologies as a method for healthcare providers to communicate, diagnose and manage patients; and to assess acceptability, satisfaction, resource use and technical difficulties. Research into the latter has been particularly neglected (Coiera 2016), and can provide crucial information for successful implementation. 


\section{O B JECTIVES}

To assess the effects of mobile technologies versus usual care for supporting communication and consultations between healthcare providers on healthcare providers' performance, acceptability and satisfaction, healthcare use, patient health outcomes, acceptability and satisfaction, costs, and technical difficulties.

\section{METHODS}

\section{Criteria for considering studies for this review}

\section{Types of studies}

We include randomised trials reported as full-text studies, conference abstracts and unpublished data, irrespective of their publication status and language of publication.

\section{Types of participants}

All types of healthcare providers (i.e. professionals, healthcare assistants, and lay health workers) providing patient care through mobile technologies. We included trials targeting people with any condition, regardless of their location, setting, diagnoses, or demographic factors such as age.

\section{Types of interventions}

We include trials comparing health care delivered through a mobile device versus usual care. We defined 'usual care' by the setting in which the trial took place, including face-to-face exchanges and communication through other non-digital channels. We include trials of healthcare providers who were geographically separated and used information and communication technologies. We have focused exclusively on the exchange of clinical information over wireless and mobile technologies, mobile phones of any kind (but not analogue land-line telephones), tablets, personal digital assistants and smartphones, and when the healthcare provider enquiry received a response in real-time or as immediate as clinically appropriate. Communication channels through a mobile device can include text messaging, video messaging, social media, voice calls, voice-over Internet protocol (VoIP), and videoconferencing, through software such as Skype, WhatsApp or Google Hangouts.

We include:

- trials in which the healthcare provider used mobile technologies, such as telemedicine applications, to seek clinical guidance and support from other qualified healthcare providers in order to deliver direct patient care. This included coordination of referrals and requests for expert opinion and diagnosis;

- trials in which the provider(s) seeking guidance was at a different location from the provider(s) offering guidance; and

- trials in which the provider(s) seeking guidance transmitted clinical information using a mobile device and the provider(s) offering guidance responded on any device, including stationary devices.

We include trials of telemedicine interventions if they were portable/mobile. We include trials assessing unspecified types of communication devices for transmitting clinical information, so long as they were mobile, since trials often failed to report this detail.
We include all health issues and did not restrict the content of clinical health information exchanged. We include trials where the digital component of the intervention was delivered as part of a wider package if we judged it to be the core component of the intervention.

\section{We excluded:}

- pilot and feasibility studies (pilot study defined as "a version of the main study that is run in miniature to test whether the components of the main study can all work together" and feasibility studies as "pieces of research done before a main study"; Arain 2010);

- trials that compared different technical specifications of telecommunication technologies (e.g. different communication channels, software, etc.);

- trials in which the use of telecommunications technology was not directly linked to patient care;

- trials in which the primary purpose of the intervention was education/training;

- trials assessing the accuracy of a portable medical device.

\section{Types of outcome measures}

\section{Main outcomes}

- Providers' adherence to recommended practice, guidelines or protocols.

- Time between presentation and management of the health condition.

\section{Other outcomes}

- Healthcare use, including referrals, clinical examinations and hospitalisations.

- Participants' health status and well-being, to include mortality and measures of health status such as the Nottingham Health Profile or the SF-36 (McDowell 2006).

- Healthcare provider acceptability and satisfaction; this includes self-reported acceptability and satisfaction, measured with a validated scale, such as the Physician Worklife Survey (Konrad 1999).

- Participant acceptability and satisfaction; this included selfreported acceptability and satisfaction, measured with a validated scale, such as the Patient Satisfaction Scale (La Monica 1986).

- Costs, including cost to the user and cost to the service (e.g. human resources/time, training, supplies and equipment).

- Unintended consequences; these could include errors in interpreting the data; transmission of inaccurate data, loss of verbal and non-verbal communication cues, issues of privacy and disclosure that might affect interpersonal relationships, negative impacts on equity, and technical difficulties, for example failure or delay in the message delivery.

\section{Search methods for identification of studies}

\section{Electronic searches}

An Information Specialist developed the search strategies in consultation with the review authors and WHO content experts. We used a minimum cut-off search date of 2000 , based on the increased availability and penetration of mobile devices from that 
date onwards (ITU 2019). Appendix 1 lists the search strategies and results.

We searched the following databases until 22 July 2019:

- Cochrane Central Register of Controlled Trials (CENTRAL; 2019, Issue 7), in the Cochrane Library;

- MEDLINE Ovid;

- Embase Ovid;

- POPLINE;

- WHO Global Health Library.

\section{Searching other resources}

\section{Trial registries}

We searched clinicaltrials.gov (clinicaltrials.gov) and the World Health Organization International Clinical Trials Registry Platform (who.int/ictrp).

\section{Grey literature}

We conducted a grey literature search in August 2017, to identify trials not indexed in the databases listed above. We searched for relevant systematic reviews and primary studies on similar topics using Epistemonikos (epistemonikos.org), a database of health evidence and health-related systematic reviews. We searched the content in mHealthEvidence (mhealthevidence.org), a database of global literature on mHealth. We contacted authors of relevant trials/reviews to clarify reported published information and to seek unpublished results/data, as well as researchers with expertise relevant to the review topic. Moreover, WHO issued a call for papers through popular digital health communities of practice such as the Global Digital Health Network and Implementing Best Practices, to identify additional primary trials as well as grey literature. We performed a backward and forward search of the primary reference identified for each eligible trial.

\section{Data collection and analysis}

\section{Selection of studies}

We downloaded all titles and abstracts retrieved by electronic searching to reference management databases (Distiller and Covidence) and removed duplicates. For title and abstract screening, we used a machine-learning classifier that is able to assign a probability score that a given record describes or does not describe a randomised trial (Wallace 2017). Two review authors (from AM, BB, DGB, GV, IRC, and NH) screened titles and abstracts of trials with at least a $10 \%$ probability of being a randomised trial, and one review author screened those with less than a $10 \%$ probability. We retrieved the full-text trial reports/publication of all potentially eligible reports, and two review authors (from AM, BB, DGB, GV, IRC, and NH) screened the full text to identify trials for inclusion and to identify and record reasons for excluding the ineligible trials. We resolved any disagreement through discussion, and if required consulted a third review author (DGB or SS).

We listed trials that initially appeared to meet the inclusion criteria but that we later excluded in the Characteristics of excluded studies table. We collated multiple reports of the same trial so that each trial rather than each report was the unit of interest in the review. We also provided any information we could obtain about ongoing studies. We recorded the selection process in sufficient detail to complete a PRISMA flow diagram (Liberati 2009).

\section{Data extraction and management}

We used the EPOC standard data collection form and adapted it for trial characteristics and outcome data (EPOC 2017a); we piloted the form on five trials. One review author extracted the following characteristics and a second review author cross-checked data (from AM, BB, DGB, GV, IRC, and NH).

- Methods: trial design, unit of allocation, location and trial setting, withdrawals.

- Participants: number, mean age, age range, sex, inclusion criteria, exclusion criteria, dates conducted, other relevant characteristics.

- Interventions: function of the intervention (monitoring, consultation, therapy), intervention components (including type of technology and mode of delivery, frequency of data transmission), comparison, fidelity assessment. For this review, we defined monitoring as the continuous evaluation of the progress of symptoms or a condition over a period of time; consultation as an exchange between the healthcare provider and the participant, where the provider discusses the participant's health status and provides guidance, support, or information; and therapy as the ongoing management and care of a participant, to counteract a disease or disorder.

- Outcomes: main outcomes specified and collected, time points reported.

- Notes: funding for trial, ethical approval.

We contacted authors of included trials to seek missing data. We noted in the Characteristics of included studies table if outcome data were reported in an unusable way. We resolved disagreements by consensus or by involving a third review author (DGB or SS). We used Review Manager 5 (RevMan 5.3) for data management.

\section{Assessment of risk of bias in included studies}

One review author assessed risks of bias for each trial using the criteria outlined in the Cochrane Handbook for Systematic Reviews of Interventions (Higgins 2017), plus the guidance from the EPOC group (EPOC 2017b), and a second review author cross-checked data (from AM, BB, DGB, GV, IRC, and $\mathrm{NH}$ ). We resolved any disagreement by discussion or by involving a third review author (DGB or SS). We assessed the risks of bias according to the following domains.

- Random sequence generation.

- Allocation concealment.

- Blinding of participants and personnel.

- Blinding of outcome assessment.

- Incomplete outcome data.

- Selective outcome reporting.

- Baseline outcomes measurement.

- Baseline characteristics.

- Other bias.

We judged the risk of each potential source of bias as being high, low or unclear, and provide a quotation from the trial report together with a justification for our judgement in the 'Risk of bias' table. We summarised the 'Risk of bias' judgements across different trials for each of the domains listed. We considered blinding separately for different key outcomes where necessary (e.g. for 
unblinded outcome assessment, risk of bias for all-cause mortality may be very different than for a participant-reported pain scale). We assessed incomplete outcome data separately for different outcomes. Where information on risk of bias relates to unpublished data or correspondence with a trialist, we noted this in the 'Risk of bias' table. We did not exclude trials on the grounds of their risk of bias but clearly reported the risk of bias when presenting the results of the trials.

When considering treatment effects, we took into account the risk of bias for the trials that contributed to that outcome.

We conducted the review according to the published protocol (Gonçalves-Bradley 2018b) and reported any deviations from it in 'Differences between protocol and review'.

\section{Measures of treatment effect}

We estimated the effect of the intervention using risk ratios (RRs) and associated 95\% confidence intervals (Cls) for dichotomous data. For continuous measures, we analysed the data based on the mean, standard deviation (SD) and number of people assessed to calculate the mean difference (MD) and 95\% Cl (Higgins 2019). We ensured that readers could interpret an increase in scores for continuous outcomes in the same way for each outcome, explained the direction of effect, and reported where the direction was reversed if this was necessary.

\section{Unit of analysis issues}

Six trials used a cluster design (Byamba 2015; Chang 2011; Eminović 2009; Iversen 2018; Piette 2017; Van Gelder 2017). Of those trials, all except one had controlled for unit-of-analysis errors by adjusting for clustering, and thus were not further re-analysed.

We had planned to control for unit of analysis errors by re-analysing the data after adjusting for clustering, using the intracluster correlation coefficient reported by the trials. When not reported, we calculated intracluster correlation coefficients estimates (Campbell $2000)$ and the formula $1+(M-1) x I C C$, where $M$ is the average cluster size (Higgins 2019). However, it was not possible to obtain average cluster size for Byamba 2015 and as such it is possible that there are potential unit of analysis errors associated with the effect estimates of that trial.

\section{Dealing with missing data}

We contacted investigators in order to verify key trial characteristics and obtain missing outcome data where possible (e.g. when a trial report was only available as an abstract). Whenever it was not possible to obtain data, we reported the level of missingness and considered how that might have impacted the certainty of the evidence.

\section{Assessment of heterogeneity}

We conducted meta-analyses and calculated the $1^{2}$ statistic to measure heterogeneity among the trials in each analysis. We considered an $\mathrm{I}^{2}$ value of $50 \%$ or more to represent substantial levels of heterogeneity, but this value was interpreted in light of the size and direction of effects and the strength of the evidence for heterogeneity, based on the P value from the Chi² test (Deeks 2017). We identified substantial heterogeneity for one of the outcomes (mortality), but were not able to explore it by prespecified subgroup analysis as there were not enough trials.

\section{Assessment of reporting biases}

We attempted to contact trial authors, asking them to provide missing outcome data. Where this was not possible, and we considered that the missing data might have introduced serious bias, we explored the impact of including such trials in the overall assessment of results. We were not able to explore possible publication bias through a funnel plot (Sterne 2011), as we did not combine a sufficient number of trials.

\section{Data synthesis}

We undertook meta-analyses for outcomes when the interventions, participants, and underlying clinical question were similar enough for pooling to make sense (Borenstein 2009). As there was considerable heterogeneity, we applied a random-effect model (Deeks 2017). A common way that trialists indicate the presence of skewed data is by reporting medians and interquartile ranges. When we encountered this we noted that the data were skewed and considered the implications.

\section{'Summary of findings' table}

Two review authors (DGB and MF) assessed the certainty of the evidence (high, moderate, low, and very low) using the five GRADE considerations: risk of bias, inconsistency, imprecision, indirectness, and publication bias) (Guyatt 2008). We used methods and recommendations described in the Cochrane Handbook for Systematic Reviews of Interventions (Schünemann 2017) and the EPOC worksheets (EPOC 2017c), using GRADEpro software (GRADEpro GDT). We resolved disagreements on certainty ratings by discussion and provided justification for decisions to down- or upgrade the ratings using footnotes in the table, making comments to aid readers' understanding of the review where necessary. We used plain language statements to report these findings in the review (EPOC 2017d).

We created 'Summary of findings' tables for the following outcomes in order to draw conclusions about the certainty of the evidence within the text of the review:

- Providers' adherence to recommended practice, guidelines or protocols;

- Time between presentation and management of the health condition;

- Healthcare use;

- Participants' health status and well-being;

- Participant and provider acceptability or satisfaction with the intervention;

- Costs;

- Technical problems.

We created three 'Summary of findings' tables, according to the setting where the intervention was delivered (primary, secondary and community care), as the populations in those settings, both healthcare providers and participants, are substantially different.

We considered whether there was any additional outcome information that we were not able to incorporate into metaanalyses, noted this in the tables and stated whether it supports or contradicts the information from the meta-analyses. When it was not possible to meta-analyse the data, we summarised the 
results in the text and in the 'Comments' section of the 'Summary of findings' tables.

\section{Subgroup analysis and investigation of heterogeneity}

We categorised trials by setting (community, primary and secondary care), according to healthcare provider type, e.g. primary care doctors' or nurses' communication with hospitalbased specialists, or community health workers consulting with clinic staff.

We planned to use the following outcomes in subgroup analysis.

- Time between presentation and management of the health condition.

- Participants' health status and well-being.

We planned to use the formal statistical techniques of MantelHaenszel and regression to test for subgroup interactions (Mantel 1959) but due to the limited number of studies we could not use this technique.

\section{Sensitivity analysis}

We planned to perform sensitivity analyses defined a priori to assess the robustness of our conclusions and explore the impact on effect sizes. This would have involved restricting the analysis to published trials and to trials at low risk of bias. We did not perform sensitivity analyses as there were no unpublished trials and within the pooled analyses all the trials had the same risk of bias for the relevant 'Risk of bias' criteria.

\section{RES U L T S}

\section{Description of studies}

We identified 19 published randomised trials of mobile technologies to support healthcare provider to healthcare provider communication and management of care (see Characteristics of included studies).

\section{Results of the search}

We retrieved 20,949 records for title and abstract screening, screened the full-text of 2041 citations and included 19 trials (35 citations) (Armstrong 2018; Azogil-López 2019; Byamba 2015; Chang 2011; Davis 2003; Eminović 2009; Gulacti 2017; Iversen 2018; Liddy 2019a; Mansberger 2015; Orlandoni 2016; Pak 2007; Piette 2017; Riordan 2015; Sutherland 2009; Taylor-Gjevre 2018; Van Gelder 2017; Whited 2002; Whited 2013). In addition, we identified 15 ongoing trials (ACTRN12617000389303; ACTRN12618001007224; Gervès-Pinquié 2017; Jeandidier 2018; Källander 2015; Koch 2018; Nakayama 2016; Stevanovic 2017; NCT02821143; NCT02986256; NCT03137511; Done 2018; NCT03559712; NCT03662256; Xu 2017). A total of 441 records were eligible for the associated review on mobile technologies to support patient to healthcare provider communication and management of care (Gonçalves-Bradley 2018a). Figure 1 presents the results of the search. 


\section{Figure 1. Flow diagram}

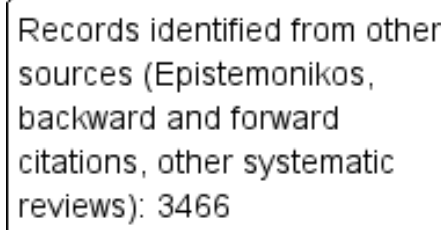

Records identified through database searching: 21,642

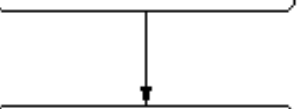

Records after duplicates removed: 17,483
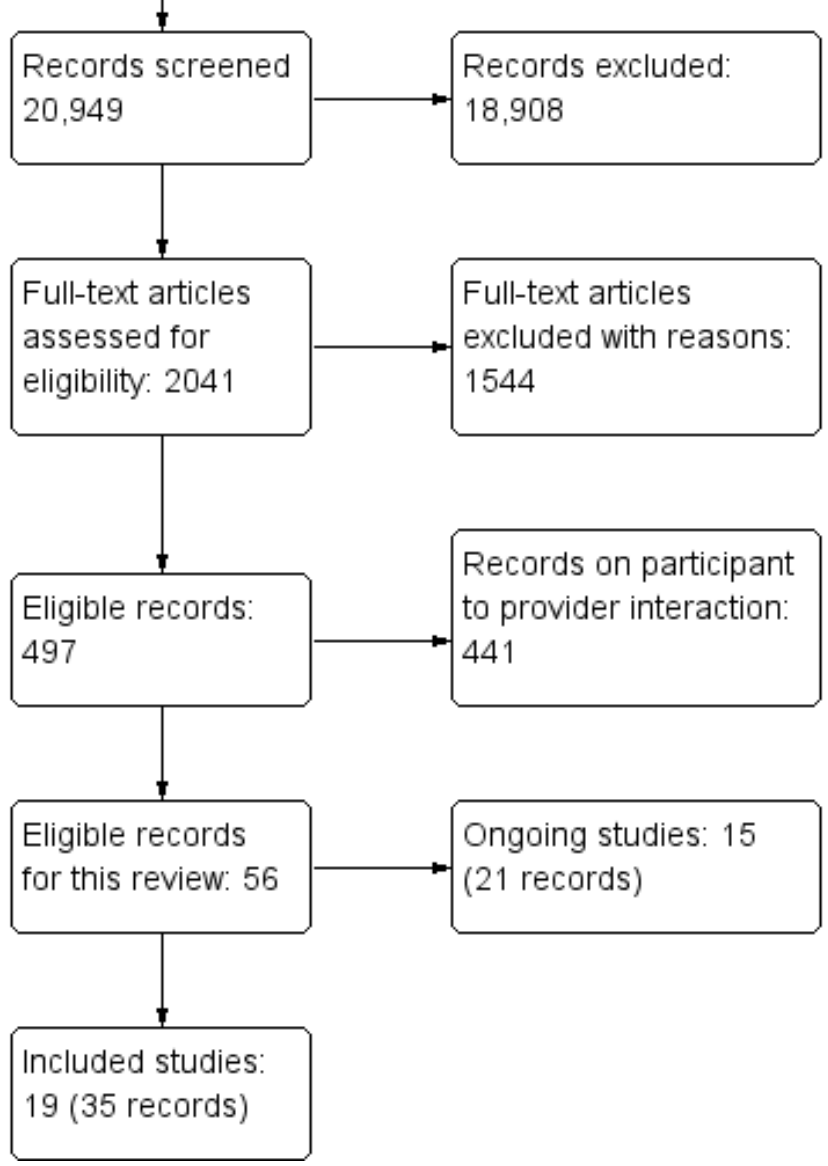

\section{Included studies}

\section{Trial populations}

Seventeen trials included 5766 participants, while two trials did not report the specific number of participants (Liddy 2019a; Riordan 2015). The number of healthcare professionals recruited ranged from one general practitioner (GP) consulting with one ophthalmologist (Davis 2003), to another trial that randomised 113 GPs consulting with several specialty physicians (Liddy 2019a). Most of the trials involved primary care professionals consulting with specialists, namely dermatologists (Armstrong 2018; Byamba 2015; Eminović 2009; Pak 2007; Piette 2017; Whited 2002; Whited 2013), ophthalmologists (Davis 2003; Mansberger 2015), nephrologists (Van Gelder 2017) or radiologists (Sutherland
2009). In two studies more than one type of specialist was involved (Azogil-López 2019; Liddy 2019a). The GPs mainly worked in urban settings and consulted with specialists also located in urban settings $(N=11)$. In four studies the GPs were located in rural settings, and consulted with providers in urban settings. There was one trial each for community-based peer health workers consulting with clinic staff (Chang 2011), home-visiting nursing staff consulting with a hospital physician (Orlandoni 2016), rural-based physical therapists consulting with rheumatologists (Taylor-Gjevre 2018), and community nurses consulting with specialist nurses or podiatrists (Iversen 2018). Two trials reported on emergency physicians consulting with hospital-based specialists (Gulacti 2017; Riordan 2015). 
All trials recruited adults, with Sutherland 2009 also recruiting adolescents and Azogil-López 2019 recruiting participants aged seven years and older, and Orlandoni 2016 specifically recruiting participants aged 65 years and older. Three trials recruited participants with diabetes (Davis 2003; Mansberger 2015; Iversen 2018), and one with rheumatoid arthritis (Taylor-Gjevre 2018). Seven trials recruited participants with a range of conditions seeking referral to a dermatologist (Armstrong 2018; Byamba 2015; Eminović 2009; Pak 2007; Piette 2017; Whited 2002; Whited 2013), two trials recruited participants attending the emergency department (Gulacti 2017; Riordan 2015) or requiring a hospital referral (Azogil-López 2019; Liddy 2019a), and one trial each recruited participants requiring a trans-abdominal or trans-vaginal ultrasound (Sutherland 2009) or with chronic kidney disease (Van Gelder 2017). The two remaining trials recruited participants receiving antiretroviral therapy (Chang 2011) and home enteral nutrition (Orlandoni 2016).

\section{Setting}

Trials were mainly conducted in North America (9 trials) and Europe (six trials), with one trial each conducted in the Dominican Republic, Turkey, and Uganda, and Mongolia.

\section{Interventions}

The trials included in the review evaluated interventions that varied in mode of delivery, number of sessions, and healthcare providers involved. All trials used a portable device, 10 of them using a portable device to obtain clinical images which were then transmitted for further assessment (Armstrong 2018; Byamba 2015; Davis 2003; Eminović 2009; Mansberger 2015; Pak 2007; Piette 2017; Sutherland 2009; Whited 2002; Whited 2013). Four trials used mobile phones for text messages and voice calls (Chang 2011), secure messaging (Gulacti 2017), audio-conferencing system (Azogil-López 2019), and for interactive web-based record and voice calls (Iversen 2018). Two trials used a tablet for secure messaging (Riordan 2015) or video consultation (Orlandoni 2016), whereas one trial employed a laptop for video consultation (Taylor-Gjevre 2018). The remaining trials used an electronic health record system for eConsults, which could also be implemented through mobile phones (Liddy 2019a; Van Gelder 2017).

The trials also varied in the frequency and duration of contacts between the healthcare providers, with most trials consisting of a single consultation (e.g. Eminović 2009).

Although the control group was always described as receiving usual care, the description of the specific care received varied. For trials conducted in primary care, 'usual care' generally consisted of a referral for a face-to-face appointment in secondary care (Byamba 2015; Eminović 2009; Liddy 2019a; Pak 2007; Whited 2002; Whited 2013) or a reminder to book an appointment (Davis 2003;
Mansberger 2015; Piette 2017; Sutherland 2009). For one trial that used a social media platform for emergency department physicians to communicate with specialists within the same hospital (Gulacti 2017), 'usual care' was to consult by phone, sending all clinical information verbally. For trials conducted in the community, 'usual care' was typically face-to-face appointments with specialists, either at the participant's home (Orlandoni 2016) or at outpatient clinics (Iversen 2018; Taylor-Gjevre 2018).

Several trials reported on additional components of the intervention (Table 1). Nine reported the delivery of training (Armstrong 2018; Byamba 2015; Chang 2011; Eminović 2009; Iversen 2018; Mansberger 2015; Piette 2017; Sutherland 2009; Taylor-Gjevre 2018), which usually focused on how to acquire digital images or use the web-based system. For one trial of eConsult, the specialists received financial incentives for each eConsult they undertook (Liddy 2019a), and two trials provided monetary incentives for participants to take part (Armstrong 2018) or to complete follow-up assessment (Mansberger 2015). Two trials reported that participants whose healthcare providers were allocated to the intervention group had increased access to health care, either directly (Armstrong 2018) or indirectly (Chang 2011).

\section{Funding, ethical approval, and conflict of interest}

Sixteen trials reported funding sources, all of which were provided by medical research institutes or university funding bodies. One of the trials also received funding from a biopharmaceutical company (Van Gelder 2017). Three trials did not report ethical or institutional review board approval (Byamba 2015, letter; Davis 2003, short report; Riordan 2015, conference abstract).

For three trials one or more members of the author team reported financial support from pharmaceutical companies (Armstrong 2018, 3/29 authors; Van Gelder 2017 1/10 authors; Whited 2013, $1 / 18$ authors). The lead author of Pak 2007 was the co-founder of a web-based consultation service identical to that used in the intervention. Six studies did not report conflicts of interest (Chang 2011; Davis 2003; Riordan 2015; Sutherland 2009; Taylor-Gjevre 2018; Whited 2002), and for the remaining nine studies the authors had no known conflict of interest.

\section{Excluded studies}

We excluded 1544 full texts, of which we report on 22 excluded trials (See Characteristics of excluded studies). The most frequent reason for excluding trials was the explicit use of non-mobile equipment (eight trials).

\section{Risk of bias in included studies}

Figure 2 presents a graph for risk of bias and Figure 3 summarises risk of bias. 
Figure 2. Risk of bias graph: review authors' judgements about each risk of bias item presented as percentages across all included studies.

Random sequence generation (selection bias)

Allocation concealment (selection bias)

Baseline outcome measurements similar (selection bias)

Baseline characteristics similar (selection bias)

Blinding of participants and personnel (performance bias): All outcomes

Blinding of objective outcome assessment (detection bias)

Blinding of subjective outcome assessment (detection bias)

Protection against contamination

Incomplete outcome data (attrition bias): All outcomes

Selective reporting (reporting bias)
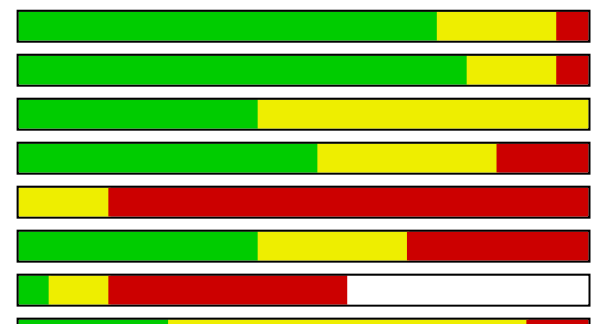

Other bias
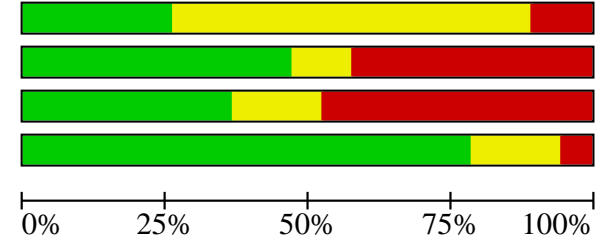

Low risk of bias

Unclear risk of bias

High risk of bias 
Figure 3. Risk of bias summary: review authors' judgements about each risk of bias item for each included study.

Azogil-López 2019

Byamba 2015

Chang 2011

Davis 2003

Eminovi\# 2009

Gulacti 2017

Iversen 2018

Liddy 2019a

Mansberger 2015

Orlandoni 2016

Pak 2007

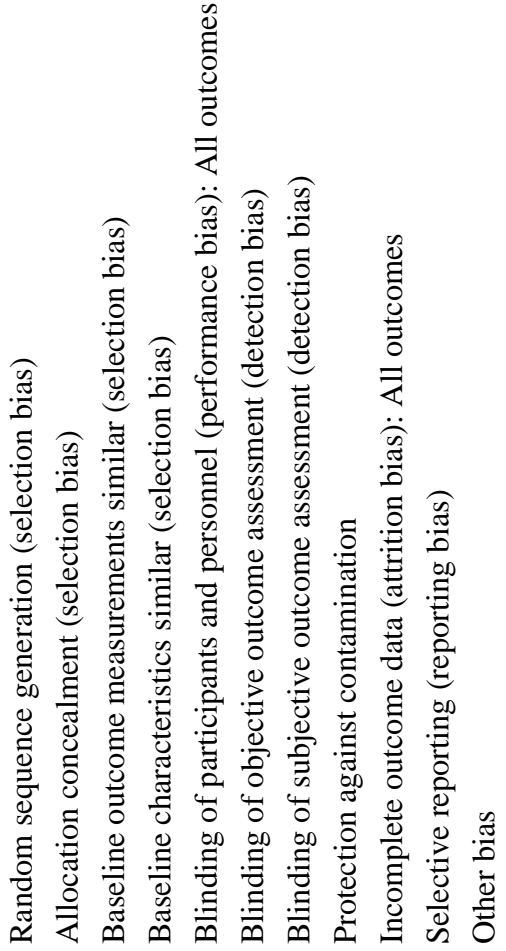

Piette 2017

Riordan 2015

Sutherland 2009

Taylor-Gjevre 2018

Van Gelder 2017

Whited 2002
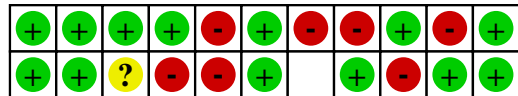

\begin{tabular}{ll|l|l|l|l}
\hline+ & + & $?$ & $?$ & $?$ & $?$
\end{tabular}

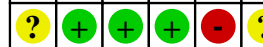

\begin{tabular}{lllllllllllll} 
& $?$ & $?$ & $?$ & $?$ & $?$ & $?$ & $?$ & $?$ & $?$ & $?$ \\
\hline
\end{tabular}

\begin{tabular}{llllllllllll}
\hline & + & + & + & - & $?$ & - & $?$ & - & - & ?
\end{tabular}

\begin{tabular}{lllllllllllll}
\hline & ? & ? & + & - & + & & ? & + & $\odot$ & + \\
\hline
\end{tabular}

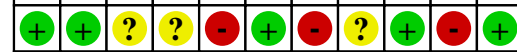

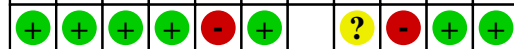
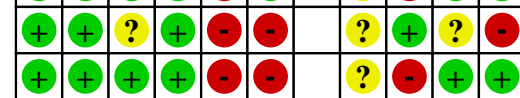

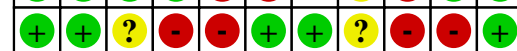

\begin{tabular}{rllllllllll}
\hline+ & + & - & - & - & - & + & + & + & + \\
\hline
\end{tabular}

\begin{tabular}{|l|l|l|l|l|l|l|l|l|l|l|}
\hline $\boldsymbol{?}$ & $?$ & $?$ & $?$ & $?$ & $?$ & $?$ & $?$ & $?$ & $?$ & ? \\
\hline
\end{tabular}

\begin{tabular}{llllllllllll}
\hline & - & $?$ & - & + & & + & + & + & + \\
\hline
\end{tabular}

$++\varphi+\odot \odot \odot ?$

Whited 2013

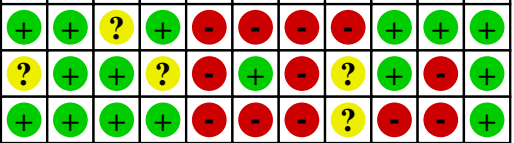

\section{Allocation}

Fourteen trials described the generation of the randomisation schedule, and were judged at low risk of bias (Armstrong 2018; Azogil-López 2019; Byamba 2015; Eminović 2009; Gulacti 2017;
Iversen 2018; Liddy 2019a; Mansberger 2015; Orlandoni 2016; Pak 2007; Piette 2017; Taylor-Gjevre 2018; Van Gelder 2017; Whited 2013), one trial that 'tossed a coin' was judged as high risk of bias (Sutherland 2009), and we rated the remaining trials at unclear risk 
of bias. Fifteen trials were judged at low risk of bias for allocation concealment (Armstrong 2018; Azogil-López 2019; Byamba 2015; Chang 2011; Eminović 2009; Iversen 2018; Liddy 2019a; Mansberger 2015; Orlandoni 2016; Pak 2007; Piette 2017; Taylor-Gjevre 2018; Van Gelder 2017; Whited 2002; Whited 2013), one at high risk (Sutherland 2009), and the remaining trials were unclear due to a lack of information.

Eight trials reported baseline outcome measurements that were similar between groups, thus being assessed at low risk of bias (Armstrong 2018; Chang 2011; Eminović 2009; Liddy 2019a; Orlandoni 2016; Taylor-Gjevre 2018; Whited 2002; Whited 2013), and the remaining 11 trials were assessed as being at unclear risk of bias. Ten trials reported similar baseline characteristics between groups and we judged them to be at low risk of bias (Armstrong 2018; Chang 2011; Eminović 2009; Gulacti 2017; Liddy 2019a; Mansberger 2015; Orlandoni 2016;Taylor-Gjevre 2018; Van Gelder 2017; Whited 2013), three trials reported differences between groups at baseline and we judged them to be at high risk of bias (Azogil-López 2019; Pak 2007; Piette 2017), and the remaining six trials were unclear.

\section{Blinding}

Due to the nature of the intervention it was often not possible to blind participants or healthcare professionals. We judged 16 trials to be at high risk of performance bias, and three at unclear (Byamba 2015; Davis 2003; Riordan 2015).

For objective outcomes we assessed six trials to be at high risk of detection bias (Mansberger 2015; Orlandoni 2016; Piette 2017; Taylor-Gjevre 2018; Van Gelder 2017; Whited 2013), eight trials to be at low risk of bias and five trials to have an unclear risk of bias (Byamba 2015; Chang 2011; Davis 2003; Eminović 2009; Riordan 2015). For subjective outcomes we assessed eight trials to be at high risk of detection bias (Armstrong 2018; Eminović 2009; Iversen 2018; Piette 2017; Taylor-Gjevre 2018; Van Gelder 2017; Whited 2002; Whited 2013), one trial to be at low risk of bias (Pak 2007), and two trials to have an unclear risk of bias (Davis 2003; Riordan 2015). Eight trials did not collect data on subjective outcomes.

\section{Incomplete outcome data}

Eight trials had high rates of incomplete outcome data and we judged them to be at high risk of attrition bias (Azogil-López 2019; Chang 2011; Eminović 2009; Liddy 2019a; Orlandoni 2016; Pak 2007; Taylor-Gjevre 2018; Whited 2013), and nine trials at low risk of attrition bias and were unclear about two trials (Davis 2003; Riordan 2015).

\section{Selective reporting}

We judged nine trials to be at high risk of reporting bias, as either outcomes were not reported per protocol (Armstrong 2018; Eminović 2009; Gulacti 2017; Iversen 2018; Taylor-Gjevre 2018; Whited 2013) or publications were found for the same trial without cross-reference (Chang 2011; Pak 2007; Whited 2002). For three trials it was not possible to make a judgement due to a lack of information (Davis 2003; Mansberger 2015; Riordan 2015), and seven trials had a low risk of reporting bias.

\section{Other potential sources of bias}

We judged other potential sources bias as unclear in three trials, two because there was not enough information (Davis 2003;
Riordan 2015), and the other due to several methods being reported to collect outcome data due to problems with follow-up (Eminovic 2009). We judged one trial to have a high risk of other potential sources of bias, as data collection methods differed for the two trial groups and were not clearly reported (Mansberger 2015). There was no other apparent source of bias for the remaining trials and we judged them to be at a low risk of bias.

\section{Effects of interventions}

See: Summary of findings 1 Mobile technologies used by primary care providers to consult with a hospital-based specialist compared with usual care; Summary of findings 2 Mobile technologies for use in the emergency department compared with usual care; Summary of findings 3 Mobile technologies used by community health or home-care workers compared with usual care

\section{Comparison 1: Mobile technologies used by primary care providers to consult with hospital based specialists}

Thirteen trials reported on mobile technologies used by primary care providers to consult with hospital-based specialists. The studies involved GPs consulting with dermatologists (Armstrong 2018; Byamba 2015; Eminović 2009; Pak 2007; Piette 2017; Whited 2002; Whited 2013), ophthalmologists (Davis 2003; Mansberger 2015), radiologists (Sutherland 2009), nephrologists (Van Gelder 2017), or different specialists (Azogil-López 2019; Liddy 2019a). The mobile component of the interventions consisted of a nonmydriatic camera for retinal screening (Davis 2003; Mansberger 2015), portable ultrasound (Sutherland 2009), teledermatology to send digital images (Armstrong 2018; Byamba 2015; Eminović 2009; Pak 2007; Piette 2017; Whited 2002; Whited 2013), and eConsult through audio-conferencing or secure direct messaging between healthcare providers, with a mobile component (Azogil-López 2019; Liddy 2019a; Van Gelder 2017). For an overview of the evidence please refer to Summary of findings 1 .

\section{Main outcomes}

\section{Providers' adherence to recommended practice, guidelines or protocols}

One trial reported on the use of telenephrology by nephrologists to communicate with primary care providers for people with chronic kidney disease (CKD) (Van Gelder 2017). The authors found little or no difference for providers' adherence to the advised monitoring criteria from national CKD guidelines, as measured by monitoring of disease progression and metabolic parameters (3004 participants; moderate-certainty evidence; Analysis 1.1). Follow-up was not reported.

\section{Time between presentation and management of the health condition}

Four trials reported on time between presentation and management of the health condition (656 participants; moderatecertainty evidence; Analysis 2.1). Two trials recruited GPs who collected digital images from people with a skin condition and consulted with hospital-based dermatologists on how to interpret them, reporting that people received the required treatment from their dermatologist in less time than those allocated to the control group: for Whited 2002 mean difference -40.5 days, $95 \% \mathrm{Cl}-23$ to -58 days (275 participants); Piette 2017 reported a median of 4 days for the intervention group (IG) and 40 days for the control group (CG), with an adjusted hazard ratio (HR) of 
2.55, $P=0.01$ (103 participants). A third trial recruited GPs who shared ultrasound images with radiologists, finding little or no difference between groups on median time to participant follow-up or diagnosis (Sutherland 2009; 105 participants). Azogil-López 2019 recruited GPs who either referred their participants to an in-person hospital appointment (control group) or to an audio-consultation (intervention group), finding that those allocated to the audioconsultation waited for less time (median -27 days, $99 \% \mathrm{Cl}-20$ to -33 days; 173 participants). Follow-up, when provided, ranged between three and six months.

\section{Other outcomes}

\section{Healthcare use}

Nine trials reported on various forms of healthcare use, including referrals, screening examinations, outpatient visits and hospitalisations (4810 participants; moderate-certainty evidence; Analysis 3.1).

Four trials recruited GPs who consulted with dermatologists through the use of digital images (Byamba 2015; Piette 2017; Whited 2002; Whited 2013; 4 trials, 1075 participants; follow-up between three and nine months, when reported), finding that those participants allocated to the intervention group were less likely to subsequently receive a referral for an appointment with a dermatologist, visit a dermatology clinic, or be referred to tertiary care: risk ratio (RR) ranged from $0.28(95 \% \mathrm{Cl} 0.21$ to 0.38$)$ to 0.82 ( 0.75 to 0.88 ). We did not retain the meta-analysis because of high statistical heterogeneity (Analysis 3.2; $1^{2}=91 \%$ ).

One trial of eConsults between PCPs and nephrologists reported that there was little or no difference between groups for referral rate (odds ratio (OR) $0.61,95 \% \mathrm{Cl} 0.31$ to 1.23 ; Van Gelder 2017; 3004 participants). Another trial of eConsults between PCPs and a range of specialists also found little or no difference between groups for face-to-face referral (RR 0.93, 95\% Cl 0.85 to 1.03; Liddy 2019a).

Two trials of retinopathy screening for participants with diabetes (Davis 2003; Mansberger 2015) reported that those allocated to the intervention group were more likely to receive a screening examination ( 2 trials, 626 participants; 12 months follow-up when reported). High statistical heterogeneity precluded retaining the meta-analysis (Analysis 3.3; $12=85 \%$ ). Another trial of GPs consulting with radiologists about participants requiring a transabdominal or trans-vaginal ultrasound found that participants allocated to the intervention group were more likely to receive an ultrasound (RR 3.92, 95\% Cl 2.11 to 7.31; Sutherland 2009; 105 participants).

\section{Participants' health status and well-being}

Two trials reported on a dermatologist providing feedback to GPs based on digital images, finding similar scores between those allocated to the intervention and the control group, for general health status at 12-month follow-up (Armstrong 2018), as well as quality of life and health-related quality of life as reported by the participants, at nine-month follow-up (Whited 2013) (2 trials, 622 participants; moderate-certainty evidence; Analysis 4.1). Two teledermatology trials reported on clinical course as assessed by dermatologists at four- (Pak 2007) and nine-month followup (Whited 2013), finding little or no difference between groups in clinical course ( 2 trials, 769 participants; moderate-certainty evidence; Analysis 4.2).

\section{Healthcare provider acceptability and satisfaction}

Two trials (378 participants) recruited GPs who consulted with dermatologists using digital images (low-certainty evidence); Piette 2017 reported little or no difference between groups for acceptability or satisfaction, and Whited 2002 reported that GPs allocated to the intervention were more likely to agree that participants received timely appointments and to be satisfied with the consult process than GPs allocated to the control group. One additional trial (Van Gelder 2017) reported on satisfaction for healthcare professionals allocated to the intervention group (Analysis 5.1).

\section{Participant acceptability and satisfaction}

Four trials (972 participants, low-certainty evidence; Analysis 5.2) recruiting GPs who consulted with dermatologists through the use of digital images reported little or no difference in participant satisfaction between those allocated to the intervention or to care as usual (Eminović 2009; Piette 2017; Whited 2002; Whited 2013).

\section{Costs}

Six trials reported costs (5423 participants; low-certainty evidence; Analysis 6.1). One teledermatology trial reported that the expected cost per participant per visit was higher for the intervention group (Whited 2002; 275 participants); a second teledermatology trial reported that the total direct costs were lower for the comparison group (Pak 2007; 698 participants; MD USD -4678 , 95\% Cl -4720 to -4635), and that this difference was offset by the lost productivity for participants allocated to the control group (MD USD 14,409, 95\% $\mathrm{Cl} 14,398$ to 14,419). Another teledermatology trial reported little or no difference between groups for total costs per participant from the healthcare perspective (MD USD $30,95 \%$ CI USD -79 to 20 ), and from the societal perspective that included the cost of loss of productivity (MD USD $-82,95 \% \mathrm{Cl}-12$ to -152 ) per participant allocated to the intervention (Whited 2013; 391 participants). Two trials (teledermatology and telenephrology, respectively) reported little or no difference between groups for costs (Eminović 2009, 605 participants; MD EUR 32.5, 95\% Cl -29.0 to 74.7; Van Gelder 2017; 3004 participants; IG: EUR 453.86, 95\% Cl 392.98 to 514.74; CG EUR $433.74,95 \% \mathrm{Cl} 387.64$ to $479.84, \mathrm{P}=0.60)$. One teledermatology trial set in rural areas in Mongolia reported lower costs associated with the intervention group, mainly explained by the long distances that those allocated to the control group had to travel, which was avoided with teledermatology (Byamba 2015; 450 participants, IG: USD 320, CG: 3174, difference USD 2854).

\section{Unintended consequences}

Four trials reported on the quality of the data transmitted (Analysis 7.1). However, only one trial recruiting GPs consulting with dermatologists about images they took from their participants reported data for both groups (Pak 2007), reporting that 10 images from each group were lost due to technical problems ( 1 trial, 698 participants; moderate-certainty evidence). The remaining trials reported results for the intervention group only (Piette 2017, Sutherland 2009, Whited 2002).

One trial where GPs could consult with dermatologists about people with psoriasis collected data about mortality as part of adverse events, reporting one death for each group (IG: 1/148; CG: 1/148; Armstrong 2018). 
Comparison 2: Mobile technologies for communication between specialists in the emergency department

Two trials reported on mobile technologies for communication between physicians and specialists in the emergency department (Gulacti 2017; Riordan 2015), using a smartphone application for secure messaging. For an overview of the evidence please refer to Summary of findings 2.

\section{Main outcomes}

\section{Providers' adherence to recommended practice, guidelines or} protocols

Neither of the trials of mobile technologies for communication between specialists in the emergency department reported data on providers' adherence.

\section{Time between presentation and management of the health condition}

One trial that recruited emergency physicians who consulted with specialist physicians using a smartphone application reported that participants allocated to the intervention group were probably either admitted to hospital or discharged in slightly less time from the emergency department (median difference -12 minutes, $95 \% \mathrm{Cl}$ -19 to $-7 ; 345$ participants; moderate-certainty evidence) (Gulacti 2017; Analysis 8.1)

\section{Other outcomes}

\section{Healthcare use}

One trial reported that participants seen by emergency physicians allocated to the intervention group probably had a shorter length of emergency department stay (median difference -30 minutes, $95 \% \mathrm{Cl}-37$ to -25 minutes; 345 participants; moderate-certainty evidence; Analysis 9.1, Gulacti 2017).

\section{Participants' health status and well-being}

Neither of the trials of mobile technologies for communication between specialists in the emergency department reported data on participants' health status and well-being.

\section{Healthcare provider acceptability and satisfaction}

Neither of the trials on mobile technologies for communication between specialists in the emergency department reported data on healthcare provider acceptability or satisfaction.

\section{Participant acceptability and satisfaction}

Neither of the trials on mobile technologies for communication between specialists in the emergency department reported on participant acceptability and satisfaction.

\section{Costs}

Neither of the trials on mobile technologies for communication between specialists in the emergency department reported data on costs.

\section{Unintended consequences}

Gulacti 2017 reported that there were no technical problems during the course of the trial (Analysis 10.1).
Comparison 3: Mobile technologies used by community health or home-care workers

Four trials reported on mobile technologies used by communitybased health workers or home-care workers. The professionals involved were community-based peer health workers consulting with clinic staff about receiving antiretroviral therapy (Chang 2011); community nurses consulting with diabetes specialist nurses or podiatrists about adults with Type 2 diabetes (Iversen 2018); home-care nurses consulting with hospital specialists about home enteral nutrition (Orlandoni 2016); and rural-based physical therapists consulting with urban-based rheumatologists (TaylorGjevre 2018). The mobile-based component of the interventions consisted of mobile phone, teledermatology, video-consultations, and interactive web-based records, respectively. For an overview of the evidence please refer to Summary of findings 3.

\section{Main outcomes}

\section{Providers' adherence to recommended practice, guidelines or} protocols

None of the trials of mobile technologies used by community-based health workers reported data on providers' adherence.

\section{Time between presentation and management of the health condition}

None of the trials of mobile technologies used by community health workers reported data on time between presentation and management of the health condition.

\section{Other outcomes}

\section{Healthcare use}

Two studies reported on outpatient clinic and community nurse consultations (370 participants, moderate-certainty evidence). Iversen 2018 recruited community nurses consulting with diabetes specialist nurses and podiatrists about adults with new diabetesrelated foot ulcers, reporting little or no difference between groups for outpatient consultations ( 0.48 fewer consultations in the intervention group, $95 \% \mathrm{Cl}-1.46$ to 0.49 ) or community nurse consultations ( 0.92 more consultations in the intervention group, $95 \% \mathrm{Cl}-0.70$ to 2.53 ). One trial (188 participants) that recruited home-visiting staff who consulted with hospital physicians through video-conferencing about older adults treated with home enteral nutrition reported little or no difference for healthcare use, as measured by outpatient visits (Incidence rate ratio $95 \% \mathrm{Cl} 0.65$ to $1.30, \mathrm{P}=0.62$ ) and hospitalisations (Incidence rate ratio $95 \% \mathrm{Cl} 0.54$ to $1.19, \mathrm{P}=0.26$ ) (Orlandoni 2016; low-certainty evidence; Analysis 11.1).

\section{Participants' health status and well-being}

Two trials, one recruiting community-based peer health workers consulting with clinic staff about adults who were receiving or started receiving antiretroviral therapy (Chang 2011) and another recruiting community nurses consulting with diabetes specialist nurses and podiatrists about adults with new diabetes-related foot ulcers (Iversen 2018), reported mortality at 11- to 12-month followup (RR $0.82,95 \% \mathrm{Cl} 0.55$ to 1.22 and RR $0.94,95 \% \mathrm{Cl} 0.28$ to 3.12 , respectively; 1157 participants; low-certainty evidence; Analysis 12.1).

One trial (85 participants) of rural-based physical therapists consulting with urban-based rheumatologists about adults with 
a clinical diagnosis of rheumatoid arthritis reported little or no difference between groups for health-related quality of life and disease activity (low-certainty evidence) (Taylor-Gjevre 2018; Analysis 12.1).

\section{Healthcare provider acceptability and satisfaction}

None of the trials of mobile technologies used by community health workers reported data on healthcare provider acceptability or satisfaction.

\section{Participant acceptability and satisfaction}

Two trials (178 participants) reported on participants' experience with healthcare (Iversen 2018) and satisfaction with the intervention (Taylor-Gjevre 2018), reporting little or no difference between those allocated to the intervention or the control groups (moderate-certainty evidence) (Analysis 13.1).

\section{Costs}

One trial reported the total cost of running the intervention and cost per participant for the intervention group only (Chang 2011, Analysis 14.1).

\section{Unintended consequences}

A trial that recruited community-based peer health workers consulting with clinic staff about adults who were receiving or started receiving antiretroviral therapy reported that healthcare professionals allocated to the intervention were not always able to charge the mobile phone, and that some mobile phones were stolen (Chang 2011; Analysis 15.1). Another trial where community nurses consulted with diabetes specialist nurses and podiatrists about adults with new diabetes-related foot ulcers through videoconference, reported that images were not always transmitted (Taylor-Gjevre 2018).

\section{Equity considerations}

Some of the included trials were designed and implemented to address geographical (Byamba 2015; Chang 2011; Davis 2003; Taylor-Gjevre 2018) or socio-economic limitations (Mansberger 2015; Sutherland 2009) on access to health care, and thus to promote equity for rural-based and other disadvantaged populations who would have less access to health care (Table 2).

Even when a trial was specifically designed to address inequities identified a priori, it might still exclude the most vulnerable elements of the targeted population. Chang 2011 recruited peer health workers in rural Uganda, giving them access to experienced clinical staff through text messages and mobile phone calls, in order to provide better health care to HIV-positive people. The peer health workers could interact with the participants using the mobile phone. The authors concluded that the relatively low penetration of mobile phones in Uganda, which at the time was 39\%, alongside the challenges posed with phone-charging in a setting where access to electricity is limited, might not only have limited the benefits of the intervention but also increased inequities. Furthermore, the authors also noted that the costs of the intervention could have been a limiting factor for the peer health workers, as the monthly stipend given for mobile phone credits was not always enough.

Whited 2013 excluded people who could not speak or read English, as well as those who failed a single-question literacy assessment.
Gulacti 2017 assessed the use of a messaging system for communication between emergency physicians in the emergency department and physicians working elsewhere in the hospital, excluding consultants who did not own a smartphone with a secure messaging service.

Armstrong 2018 excluded people without access to the Internet and either a digital camera or a mobile phone with camera features.

\section{DISCUSSION}

\section{Summary of main results}

We included 19 randomised trials of mobile technologies that recruited more than 5766 participants with varied conditions and health problems. Healthcare professionals included general practitioners, community-based peer health workers, nurses and physiotherapists, who consulted with specialist healthcare professionals in another healthcare facility, and emergency physicians who consulted colleagues within the same facility. Most trials reported on the use of mobile technologies by general practitioners to consult with specialists, and reported that mobile technologies reduced the time between presentation and management of the health problem (4 trials, 656 participants; moderate-certainty evidence). Accessing healthcare services through mobile technologies may reduce referrals and clinic visits among people with skin conditions and those with chronic kidney disease, and increase the likelihood of receiving an eye examination among people with diabetes and people referred for an ultrasound ( 9 trials, 4810 participants when reported, moderatecertainty evidence). There was little evidence of a difference to patient-reported quality of life outcomes ( 2 trials, 622 participants), clinician-reported outcomes of disease progression (2 trials, 769 participants); or to healthcare providers and participants' satisfaction and acceptability, or cost (6 trials, 5423 participants, low-certainty evidence). One trial reported on images being lost during transmission, when using mobile technologies and also in usual care; and one trial reported a few experiences of mobile phones not being charged or being lost. However, most trials did not measure or report technical problems.

Four studies reported on the use of mobile technologies by community health or home-care workers to consult with clinic staff, there was little evidence of an effect on consultations in the trials that recruited participants with new diabetes-related foot ulcer or older individuals treated with home enteral nutrition (2 trials, 370 participants; moderate-certainty evidence). There was little or no difference for hospitalisations among older individuals treated with home enteral nutrition (1 trial, 188 participants; low-certainty evidence), or mortality among people living with HIV or diabetes (2 trials, 1157 participants), for disease activity and health-related quality of life in participants with rheumatoid arthritis ( 1 trial, 85 participants) or participant acceptability and satisfaction in people with new diabetes-related foot ulcer or rheumatoid arthritis (178 participants).

\section{Overall completeness and applicability of evidence}

Most trials did not report data on providers' adherence, five trials reported on time between presentation and management of the health condition for the main comparison, and for the remaining comparisons and outcomes we identified very little evidence. A third of the trials recruited adults seeking care 
for dermatological conditions, reflecting current use of mobile technologies in healthcare settings.

The use of mobile technologies for communication between healthcare professionals and patient management might be particularly relevant for settings where there is a shortage of healthcare providers. However, most of the trials were conducted in high-income (eleven trials in North America and six trials in Europe) or upper-middle-income countries (two trials, one in North America and one in Asia), with one trial each conducted in a lower-middle rural country (Mongolia) and a low-income country (Uganda). A similar range of countries was reported in a review of mobile technologies for healthcare service delivery processes (Free 2013). Specific challenges might arise when implementing trials in those contexts, such as the lack of access to power sockets to charge the mobile phones, highlighted by the peer health workers interviewed by Chang 2011 in Uganda but not in the study conducted in Mongolia.

Similar contextual factors might contribute to the applicability of the evidence. One factor often mentioned was the variation in healthcare professionals' willingness to use mHealth (AzogilLópez 2019; Liddy 2019a), to attend training (Liddy 2019a), to invite people to participate (Eminović 2009), to select participants for electronic referrals (Van Gelder 2017), or to hold face-to-face appointments (Iversen 2018), or provide the required feedback (Sutherland 2009). Four trials reported that recruited participants might not have been representative of the general population, as the study population was more educated (Armstrong 2018), more likely to be male (Mansberger 2015; Whited 2002; Whited 2013), and more likely to be healthier (Armstrong 2018; Mansberger 2015). There was also variation associated with participants' location, as those allocated to the intervention who lived closer to the referral setting were less likely to accept a telephone appointment (Azogil-López 2019) and more likely to be referred to a face-to-face appointment from their healthcare provider (Iversen 2018). One trial reported that participants allocated to the control group had to travel on average $98 \mathrm{~km}$ to receive face-to-face care, thus indicating that the intervention might provide particular benefits in settings with a low-density population (Byamba 2015).

Some of the included trials were designed and implemented to address geographical limitations on access to health care and thus allowed for healthcare providers who were geographically separated to exchange clinical information, promoting equity for rural-based and other disadvantaged populations who would have less access to healthcare. Two trials were conducted in rural settings: South Carolina, USA (Davis 2003) and Saskatchewan, Canada (Taylor-Gjevre 2018). Two trials recruited participants from socio-economically disadvantaged areas (Mansberger 2015; Sutherland 2009).

\section{Certainty of the evidence}

The included randomised trials were mostly at low or unclear risk of selection bias. We downgraded the evidence for almost all of the outcomes due to a high risk of performance bias, and almost half of the trials were also at risk of detection, attrition, and reporting biases. We also downgraded some of the evidence for imprecision, due to the relatively small size of the trials. Our confidence in the effect estimates overall is moderate, although due to the relatively low number of trials, different uses of mHealth interventions and small numbers of participants recruited there is a possibility that the estimate of the effect is substantially different.

\section{Potential biases in the review process}

We limited the risk of publication bias by conducting a comprehensive literature search of different databases, including published articles, clinical trials registries and unpublished mHealth evidence. The WHO issued a call for papers through popular digital health communities of practice to identify additional primary trials as well as grey literature, all of which have contributed to limit publication bias. Two review authors screened records, extracted data and assessed the certainty of the evidence using GRADE, with discussion with the author team whenever there were any discrepancies.

\section{Agreements and disagreements with other studies or reviews}

Hasselberg 2014 conducted a review on image-based medical expert teleconsultation, with 24 studies, including non-randomised and feasibility studies. The overall results were similar to ours. A review on asynchronous electronic consultations that included 36 trials, seven of which were randomised trials, reported that healthcare providers were generally satisfied with the timely advice received and the health care provided to the participants (Liddy 2016). When updating the review, Liddy 2019b included non-randomised evidence and concluded that eConsults were expanding beyond teledermatology and that providers from other specialties were also satisfied. We found limited evidence from randomised trials about how satisfied healthcare providers are with mHealth to communicate with other providers. For both reviews the authors concluded that there was limited research on morbidity and mortality, which is consistent with our results (Liddy 2016; Liddy 2019b).

A Cochrane qualitative evidence synthesis (QES) on healthcare providers' perceptions and experiences of using mHealth technologies to deliver primary care healthcare services found that while providers thought that mobile technologies improved their work and relationships with other providers as well as participants, they also highlighted specific challenges such as access to electricity and network coverage (Odendaal 2020). Similarly, an unpublished overview of factors influencing the acceptability, feasibility and implementation of mobile health technologies also reported problems with installation and usability, as well as issues with electricity and connection (Glenton 2019). This is consistent with our results, especially for settings where constant access to electricity might be an issue (Chang 2011).

\section{AUTHORS' CONCLUSIONS}

\section{Implications for practice}

Mobile technologies are widespread, with the quality of transmission continuing to improve. Healthcare organisations in a number of settings have started to provide their healthcare providers with smartphones (Dala-Ali 2011) and healthcare professionals often use their mobile phones to share clinical information, including the transmission of images (Mobasheri 2015). This review found that mobile technologies may reduce the time between presentation and management of the health condition when primary care providers or emergency physicians use them to consult with specialists, may increase the likelihood of 
receiving a clinical examination among participants with diabetes and those who required an ultrasound and may reduce referrals to secondary or tertiary care.

One concern that has been raised is about data-sharing and privacy (Chang 2011; Gulacti 2017; WHO 2011). Most of the included trials reported using secure web connections, and mobile phone applications are being developed for secure communications between medical staff at work. A recent review reported that the main barriers to the adoption of mHealth by healthcare professionals concern the perceived usefulness and ease of use, concerns surrounding privacy, security, and technological issues, cost, time, and how it will impact the interaction with colleagues, patients, and management (Gagnon 2016), even in areas where the use of mobile technologies is more common. Training is usually required to support implementation, for instance teledermatology has been implemented in several settings and its optimal implementation includes training of primary healthcare providers on how to use the mobile equipment to obtain highquality images (Kukutsch 2017); this was highlighted by some of the included trials (e.g. Eminović 2009; Piette 2017).

There was little evidence about healthcare providers' satisfaction with the intervention in the trials we identified, and although healthcare providers reported that mobile technologies allowed for care to be delivered more quickly and facilitated triage, one study reported that they were less confident in their diagnosis and management plans when using teledermatology, compared with face-to-face care (Whited 2002). However, it is likely that this would improve with experience. A qualitative evidence synthesis reported that mobile technologies assisted contact with colleagues, and recommended that healthcare providers should be part of the planning, implementation, and evaluation of mobile health programmes. (Odendaal 2020). Similarly, it is important to establish whether mobile devices alleviate providers' workload, or instead add to it, including whether there is the capacity to provide the level of supervision and support required (Odendaal 2020).

\section{Implications for research}

- Funding is required to support the conduct of randomised trials of mobile technology interventions in settings where these types of intervention may have the potential to significantly strengthen health systems, such as remote locations and where there is a shortage of specialist services.

- Process evaluations, conducted alongside randomised trials, to identify factors that might modify the effect of mHealth interventions in different contexts would be a valuable addition to the evidence base (Craig 2008). Identifying core outcomes might be a useful step, for example, understanding the impact of mHealth on providers' adherence to guidelines, time from presentation to resolution, and participants' health status and well-being are outcomes for which more evidence is required. Research should also be conducted into consideration of factors to support implementation, such as the high attrition rates commonly found in studies that use mobile technologies.

- Detailed and standardised reporting of mobile health interventions, technical features and context will contribute to the quality of the evidence available (Agarwal 2016).

\section{ACKNOWLEDGEMENTS}

We acknowledge the help and support of Cochrane Effective Practice and Organisation of Care (EPOC), through the editorial input of the following editors and peer referees, who provided comments to improve the review: Julia Worswick (EPOC former Managing Editor); Paul Miller (EPOC information specialist); Joshua Vogel (EPOC contact editor); Michael Kent Ransom (EPOC internal editor); Craig Ramsay (EPOC stats editor); Andrew Farmer (external referee), and Elizabeth Shaw and Euphrasia Ebai-Atuh (consumer referees). The authors would also like to thank John Eyers for designing and running the search strategies; Hanna Bergman, Anna Georgeson, Jennifer Petkovic, Nicola Maayan, and Rachel Richardson, from Cochrane Response, for screening and extracting data; and Kate Cahill for copy-editing the review.

National Institute for Health Research (NIHR), via Cochrane Infrastructure funding to the Effective Practice and Organisation of Care (EPOC) Group. The views and opinions expressed therein are those of the authors and do not necessarily reflect those of the Systematic Reviews Programme, NIHR, National Health Service (NHS) or the Department of Health.

We are grateful to the Guideline Development Group of the Digital Health Guidelines (World Health Organization) for their constructive feedback in formulating the guiding questions for this systematic review, and for the funding they provided to complete the review.

Cochrane Response, an evidence services unit operated by the Cochrane Collaboration, provided screening and data extraction services for part of this review. 


\section{R E F E R E N C E S}

\section{References to studies included in this review}

Armstrong 2018 \{published data only\}

* Armstrong AW, Chambers CJ, Maverakis E, Cheng MY, Dunnick CA, Chren M-M, et al. Effectiveness of online vs inperson care for adults with psoriasis: a randomized controlled trial. JAMA Network Open 2018;1(6):e183062. [DOI: 10.1001/ jamanetworkopen.2018.3062]

Young PM, Chen AY, Ford AR, Cheng MY, Lane CJ, Armstrong AW. Effects of online care on functional and psychological outcomes in patients with psoriasis: a randomized controlled trial. Journal of the American Academy of Dermatology 2019 May 30 [Epub ahead of print]. [DOI: 10.1016/j.jaad.2019.05.089]

\section{Azogil-López 2019 \{published data only\}}

Azogil-López LM, Pérez-Lázaro JJ, Ávila-Pecci P, MedranoSanchéz EM, Coronado-Vázquez MV. Effectiveness of a new model of telephone derivation shared between primary care and hospital care [Efectividad de un nuevo modelo de derivación telefónica compartida entre atención primaria e atención hospitalaria]. Atención Primaria 2019;51(5):278-84. [DOI: 10.1016/j.aprim.2018.02.006]

* Azogil-López LM, Pérez-Lázaro JJ, Medrano-Sanchéz EM, Goméz-Salgado J, Coronado-Vázquez V. DETELPROG study: Effectiveness of a new model of scheduled telephone referral from primary care to internal medicine. A randomised controlled study. Journal of Clinical Medicine 2019;8(5):688. [DOI: $10.3390 / \mathrm{jcm} 8050688$ ]

\section{Byamba 2015 \{published data only\}}

Byamba K, Syed-Abdul S, García-Romero M, Huang C-W, Nergyi S, Nyamdorj A, et al. Mobile teledermatology for a prompter and more efficient dermatological care in rural Mongolia. British Journal of Dermatology 2015;173(1):265-7. [DOI: 10.1111/bjd.13607]

\section{Chang 2011 \{published data only\}}

* Chang LW, Kagaayi J, Arem H, Nakigozi G, Ssempijja V, Serwadda $D$, et al. Impact of a mHealth intervention for peer health workers on AIDS care in rural Uganda: a mixed methods evaluation of a cluster-randomized trial. AIDS Behavior 2011;15(8):1776-84. [DOI: 10.1007/s10461-011-9995-x]

Chang LW, Kagaayi J, Nakigozi G, Packer AH, Serwadda D, Quinn TC, et al. Responding to the human resource crisis: Peer health workers, mobile phones, and HIV care in Rakai, Uganda. AIDS Patient Care and STDs 2008;22(3):173-4. [DOI: 10.1089/ apc.2007.0234]

Chang LW1, Kagaayi J, Nakigozi G, Serwada D, Quinn TC, Gray $\mathrm{RH}$, et al. Cost analyses of peer health worker and mHealth support interventions for improving AIDS care in Rakai, Uganda. AIDS Care 2013;25(5):652-6. [DOI: 10.1080/09540121.2012.722600]

\section{Davis 2003 \{published data only\}}

* Davis RM, Fowler S, Bellis K, Pockl J, Al Pakalnis V, Woldorf A. Telemedicine improves eye examination rates in individuals with diabetes: a model for eye-care delivery in underserved communities. Diabetes Care 2003;26(8):2476.

Davis RM, Pockl J, Bellis K. Improved diabetic eye care utilizing telemedicine: a randomized controlled trial. Investigative Ophthalmology \& Visual Science 2003;44:166.

\section{Eminović 2009 \{published data only\}}

* Eminović N, De Keizer NF, Wyatt JC, Ter Riet G, Peek N, Van Weert HC, et al. Teledermatologic consultation and reduction in referrals to dermatologists: a cluster randomized controlled trial. Archives of Dermatology 2009;145(5):558-64. [DOI: 10.1001/ archdermatol.2009.44]

Eminović N, Dijkgraaf MG, Berghout RM, Prins AH, Bindels, PJ, De Keizer NF. A cost minimisation analysis in teledermatology: Model-based approach. BMC Health Services Research 2011;10:251. [DOI: 10.1186/1472-6963-10-251]

\section{Gulacti 2017 \{published data only\}}

Gulacti U, Lok U. Comparison of secure messaging application (WhatsApp) and standard telephone usage for consultations on length of stay in the ED. A prospective randomized controlled study. Applied Clinical Informatics 2017;8(3):742-53. [DOI: 10.4338/ACI-2017-04-RA-0064]

\section{Iversen 2018 \{published data only\}}

* Iversen MM, Espehaug B, Hausken MF, Graue M, Østbye T, Skeie $\mathrm{S}$, et al. Telemedicine versus standard follow-up care for diabetes-related foot ulcers: Protocol for a cluster randomized controlled noninferiority trial (DiaFOTo). JMIR Research protocols 2016;5(3):e148. [DOI: 10.2196/resprot.5646]

Kolltveit BH, Thorne S, Graue M, Gjengedal E, Iversen MM, Kirkevold M. Telemedicine follow-up facilitates more comprehensive diabetes foot ulcer care: a qualitative study in home-based and specialist health care. Journal of Clinical Nursing 2017;27(5-6):e1134-45. [DOI: 10.1111/jocn.14193]

Smith-Strøm H, Igland J, Østbye T, Tell GS, Hausken MF4, Graue M, et al. The effect of telemedicine follow-up care on diabetes-related foot ulcers: a cluster-randomized controlled noninferiority trial. Diabetes Care 2018;5(3):e148. [DOI: 10.2196/ resprot.5646]

Smith-Strøm H, Iversen MM, Graue M, Skeie S, Kirkevold M. An integrated wound-care pathway, supported by telemedicine, and competent wound management: Essential in followup care of adults with diabetic foot ulcers. International Journal of Medical informatics 2016;64:59-66. [DOI: 10.1016/ j.ijmedinf.2016.06.020]

\section{Liddy 2019a \{published data only\}}

Liddy C, Maranger J, Afkham A, Keely E. Ten steps to establishing an e-consultation service to improve access to specialist care. Telemedicine Journal and E-Health 2013;19(12):982-90. [DOI: 10.1089/tmj.2013.0056]

* Liddy C, Moroz I, Keely E, Taljaard M, Armstrong CD, Afkham A, et al. Understanding the impact of a multispecialty electronic consultation service on family physician referral 
rates to specialists: a randomized controlled trial using health administrative data. Trials 2019;20:348. [DOI: 10.1186/ s13063-019-3393-5]

\section{Mansberger 2015 \{published data only\}}

Mansberger SL, Gleitsmann K, Gardiner S, Sheppler C, Demirel S, Wooten K, et al. Comparing the effectiveness of telemedicine and traditional surveillance in providing diabetic retinopathy screening examinations: a randomized controlled trial. Telemedicine Journal and e-Health 2013;19(12):942-48. [DOI: 10.1089/tmj.2012.0313]

* Mansberger SL, Sheppler C, Barker G, Gardiner SK, Demirel S, Wooten $\mathrm{K}$, et al. Long-term comparative effectiveness of telemedicine in providing diabetic retinopathy screening examinations: a randomized clinical trial. JAMA Ophtalmology 2015;133(5):518-25. [DOI: 10.1001/jamaophthalmol.2015.1]

\section{Orlandoni 2016 \{published data only\}}

Orlandoni P, Jukic Peladic N, Spazzafumo L, Venturini C, Cola C, Sparvoli D, et al. Utility of video consultation to improve the outcomes of home enteral nutrition in a population of frail older patients. Geriatrics \& Gerontology International 2016;16(6):762-7. [DOI: 10.1111/ggi.12551]

\section{Pak 2007 \{published data only\}}

* Pak H, Triplett CA, Lindquist JH, Grambow SC, Whited JD. Store-and-forward teledermatology results in similar clinical outcomes to conventional clinic-based care. Journal of Telemedicine and Telecare 2007;13(1):26-30. [DOI: 10.1258/135763307779701185]

Pak HS, Datta SK, Triplett CA, Lindquist JH, Grambow SC, Whited JD. Cost minimization analysis of a store-and-forward teledermatology consult system. Telemedicine Journal and eHealth 2009;15(2):160-5. [DOI: 10.1089/tmj.2008.0083]

\section{Piette 2017 \{published data only\}}

Piette E, Nougairède M, Vuong V, Crickx B, Tran VT. Impact of a store-and-forward teledermatology intervention versus usual care on delay before beginning treatment: a pragmatic cluster-randomized trial in ambulatory care. Journal of Telemedicine and Telecare 2017;23(8):725-32. [DOI: $10.1177 / 1357633 \times 16663328]$

\section{Riordan 2015 \{published data only (unpublished sought but not} used)\}

Rordan J, Ottenritter C, Sullivan K, DaSilva K, O'Connor D, Dayal A. MedLibs: a mobile application for facilitating emergency department consultation requests. Annals of Emergency Medicine 2015;66(4S):S75.

\section{Sutherland 2009 \{published data only\}}

Sutherland JE, Sutphin HD, Rawlins F, Redican K, Burton J. A comparison of telesonography with standard ultrasound care in a rural Dominican clinic. Journal of Telemedicine and Telecare 2009;15(4):191-5. [DOI: 10.1258/jtt.2009.080909]

\section{Taylor-Gjevre 2018 \{published data only\}}

Taylor-Gjevre R, Nair B, Bath B, Okpalauwaekwe U, Sharma M, Penz E, et al. Addressing rural and remote access disparities for patients with inflammatory arthritis through video- conferencing and innovative inter-professional care models. Musculoskeletal Care 2018;16(1):90-5. [DOI: 10.1002/msc.1215]

Van Gelder 2017 \{published data only\}

Van Gelder VA, Scherpbier-de Haan ND, Van Berkel S, Akkermans RP, De Grauw IS, Adang EM, et al. Web-based consultation between general practitioners and nephrologists: a cluster randomized controlled trial. Family Practice 2017;34(4):430-6. [DOI: 10.1093/fampra/cmw131]

\section{Whited 2002 \{published data only\}}

Whited JD, Datta S, Hall RP, Foy ME, Marbrey LE, Grambow SC, et al. An economic analysis of a store and forward teledermatology consult system. Telemedicine Journal and eHealth 2003;9(4):351-60. [DOI: 10.1089/153056203772744671]

Whited JD, Hall RP, Foy ME, Marbrey LE, Grambow SC, Dudley TK, et al. Patient and clinician satisfaction with a storeand-forward teledermatology consult system. Telemedicine Journal and e-Health 2004;10(4):422-31. [DOI: 10.1089/ tmj.2004.10.422]

* Whited JD, Hall RP, Foy ME, Marbrey LE, Grambow SC, Dudley TK, et al. Teledermatology's impact on time to intervention among referrals to a dermatology consult service. Telemedicine Journal and e-Health 2002;8(3):313-21. [DOI: $10.1089 / 15305620260353207]$

\section{Whited 2013 \{published data only\}}

Datta SK, Warshaw EM, Edison KE, Kapur K, Thottapurathu L, Moritz TE, et al. Cost and utility analysis of a store-andforward teledermatology referral system: a randomized clinical trial. JAMA Dermatology 2015;151(12):1323-9. [DOI: 10.1001/ jamadermatol.2015.2362]

Whited JD, Warshaw EM, Edison KE, Kapur K, Thottapurathu L, Raju S, et al. Effect of store and forward teledermatology on quality of life: a randomized controlled trial. JAMA Dermatology 2013;149(5):584-91. [DOI: 10.1001/2013.jamadermatol.380]

* Whited JD, Warshaw EM, Kapur K, Edison KE, Thottapurathu L, Raju S, et al. Clinical course outcomes for store and forward teledermatology versus conventional consultation: a randomized trial. Journal of Telemedicine and Telecare 2013;19(4):197-204. [DOI: 10.1177/1357633X13487116]

\section{References to studies excluded from this review}

\section{Ateudjieu 2014 \{published data only\}}

Ateudjieu J, Stoll B, Nguefack-Tsague G, Tchangou C, Genton B. Vaccines safety: effect of supervision or SMS on reporting rates of adverse events following immunization (AEFI) with meningitis vaccine (MenAfriVac ${ }^{\mathrm{TM}}$ ): a randomized controlled trial. Vaccine 2014;32(43):5662-8.

\section{Atnafu 2017 \{published data only\}}

Atnafu $\mathrm{A}$, Otto $\mathrm{K}$, Herbst $\mathrm{CH}$. The role of mHealth intervention on maternal and child health service delivery: findings from a randomized controlled field trial in rural Ethiopia. mHealth 2017;3:39. 
Batista 2016 \{published data only\}

Batista JdA, Furtado MV, Katz N, Agostinho MR, Neto BS, Harzheim E, et al. Telemedicine-supported transition of stable coronary artery disease patients from tertiary to primary health care facilities: protocol for a randomized non-inferiority trial. BMC Health Services Research 2016;16:227.

\section{Bettinelli 2015 \{published data only\}}

Bettinelli M, Lei Y, Beane M, Mackey C, Liesching TN. Does robotic telerounding enhance nurse-physician collaboration satisfaction about care decisions? Telemedicine Journal and eHealth 2015;21(8):637-43. [DOI: 10.1089/tmj.2014.0162]

\section{Burns 2016 \{published data only\}}

Burns CL, Kularatna S, Ward EC, Hill AJ, Byrnes J, Kenny LM. Cost analysis of a speech pathology synchronous telepractice service for patients with head and neck cancer. Head \& Neck 2016;39(12):2470-80.

\section{Buvik 2016 \{published data only\}}

Buvik A, Bugge E, Knutsen G, Småbrekke A, Wilsgaard T. Quality of care for remote orthopaedic consultations using telemedicine: a randomised controlled trial. BMC Health Services Research 2016;16:483.

\section{Chiaravalloti 2017 \{published data only\}}

Chiaravalloti A, Schunck CH, Sørensen TF, Thestrup J, Rosengren P, Pellicano C, et al. PICASO: A personalised integrated care platform. Clinical and Translational Imaging 2017;5(1):S141.

\section{Conlin 2006 \{published data only\}}

Conlin PR, Fisch BM, Cavallerano AA, Cavallerano JD, Bursell SE, Aiello LM. Nonmydriatic teleretinal imaging improves adherence to annual eye examinations in patients with diabetes. Journal of Rehabilitation Research and Development 2006;43(6):733-40.

\section{Da Silva 2018 \{published data only\}}

Da Silva R, Rados D, Dos Santos E, Katz N, Harzheim E, Polanczyk C, et al. Teleconsultation support patients with benign prostatic hyperplasia being discharged from specialized care: a randomized noninferiority study. Journal of Urology 2018;199(4):e686-7.

\section{Ferrándiz 2017 \{published data only\}}

Ferrándiz L, Ojeda-Vila T, Corrales A, Martín-Gutiérrez FJ, Ruízde-Casas A, Galdeano R, et al. Impact of dermoscopy on an internet-based skin cancer triage system: interim results of a randomized study. Journal of the American Academy of Dermatology 2017;76(2):342-3.

* Ferrándiz L, Ojeda-Vila T, Corrales A, Martín-Gutiérrez FJ, Ruíz-de-Casas A, Galdeano R, et al. Internet-based skin cancer screening using clinical images alone or in conjunction with dermoscopic images: a randomized teledermoscopy trial. Journal of the American Academy of Dermatology 2017;76(4):676-82.

\section{Golberstein 2017 \{published data only\}}

Golberstein E, Kolvenbach S, Carruthers H, Druss B, Goering P. Effects of electronic psychiatric consultations on primary care provider perceptions of mental health care: Survey results from a randomized evaluation. Healthcare 2017;S2213-0764(16):30173-7. [DOI: 10.1016/ j.hjdsi.2017.01.002]

\section{Gong 2018 \{published data only\}}

Gong E, Gu W, Sun C, Turner EL, Zhou Y, Li z, et al. Systemintegrated technology-enabled model of care to improve the health of stroke patients in rural China: protocol for SINEMAa cluster-randomized controlled trial. American Heart Journal 2019;207:27-39.

\section{Haridy 2017 \{published data only\}}

Haridy J, lyngkaran G, Tse E. An eHealth model of care for community hepatitis $\mathrm{c}$ management: The healthelink project. Journal of Gastroenterology and Hepatology 2017;32:70-71.

\section{Loane 2001 \{published data only\}}

* Loane MA, Bloomer SE, Corbett R, Eedy DJ, Evans C, Hicks N, et al. A randomized controlled trial assessing telehealth economics of realtime teledermatology compared with conventional care: an urban versus rural perspective. Journal of Telemedicine and Telecare 2001;7(2):108-18. [DOI: 10.1258/1357633011936246]

Loane MA, Bloomer SE, Corbett R, Eedy DJ, Hicks N, Lotery HE, et al. A randomized controlled trial to assess the clinical effectiveness of both realtime and store-and-forward teledermatology compared with conventional care. Journal of Telemedicine and Telecare 2000;6(Suppl. 1):S1-3.

Wootton R, Bloomer SE, Corbett R, Eedy DJ, Hicks N, Lotery HE, et al. Multicentre randomised control trial comparing real time teledermatology with conventional outpatient dermatological care: societal cost-benefit analysis. BMJ 2000;320(7244):1252-6.

\section{NCT02710799 \{unpublished data only\}}

NCT02710799. Evaluation of the effects of teleconsultations on a endocrinology referral list. clinicaltrials.gov/ct2/show/ NCT02710799 (first received 17 March 2016).

\section{Nwando Olayiwola 2016 \{published data only\}}

Anderson D, Villagra V, Coman EN, Zlateva I, Hutchinson A, Villagra J, et al. A cost-effectiveness analysis of cardiology eConsults for Medicaid patients. American Journal of Managed Care 2018;24(1):e9-e16.

* Nwando Olayiwola J, Anderson D, Jepeal N, Aseltine R, Pickett C, Yan J, et al. Electronic consultations to improve the primary care-specialty care interface for cardiology in the medically underserved: a cluster-randomized controlled trial. Annals of Family Medicine 2016;14(2):133-40. [DOI: 10.1370/ afm.1869]

\section{Oakley 2000 \{published data only\}}

Loane MA, Oakley A, Rademaker M, Bradford N, Fleischl P, Kerr $P$, et al. A cost-minimization analysis of the societal costs of realtime teledermatology compared with conventional care: results from a randomized controlled trial in New Zealand. 
Journal of Telemedicine and Telecare 2001;7(4):233-8. [DOI: 10.1258/1357633011936453]

* Oakley AM, Kerr P, Duffill M, Rademaker M, Fleischl P, Bradford N, et al. Patient cost-benefits of realtime teledermatology: a comparison of data from Northern Ireland and New Zealand. Journal of Telemedicine and Telecare 2000;6(2):97-101. [DOI: 10.1258/1357633001935112]

\section{Owen 2019 \{published data only\}}

Owen RR, Woodward EN, Drummond KL, Deen TL, Oliver KA, Petersen NJ, et al. Using implementation facilitation to implement primary care mental health integration via clinical video telehealth in rural clinics: protocol for a hybrid type 2 cluster randomized stepped-wedge design. Implementation Science 2019;14(1):33.

\section{Phillips 2019 \{published data only\}}

Phillips JL, Heneka N, Lovell M, Lam L, Davidson P, Boyle F, et al. A phase III wait-listed randomised controlled trial of novel targeted inter-professional clinical education intervention to improve cancer patients' reported pain outcomes (The Cancer Pain Assessment (CPAS) Trial): study protocol. Trials 2019;20(1):62.

\section{Pryzbylo 2014 \{published data only\}}

Przybylo JA, Wang A, Loftus P, Evans KH, Chu I, Shieh L. Smarter hospital communication: Secure smartphone text messaging improves provider satisfaction and perception of efficacy, workflow. Journal of Hospital Medicine 2014;9(9):573-8. [DOI: 10.1002/jhm.2228]

\section{Romero 2009 \{published data only\}}

Romero G, Sánchez P, García M, Cortina P, Vera E, Garrido JA. Randomized controlled trial comparing store-and-forward teledermatology alone and in combination with web-camera videoconferencing. Clinical and Experimental Dermatology 2010;35(3):311-7. [DOI: 10.1111/j.1365-2230.2009.03503]

\section{Wesarg 2010 \{published data only\}}

Wesarg T, Wasowski A, Skarzynski H, Ramos A, Falcon Gonzalez JC, Kyriafinis G, et al. Remote fitting in Nucleus cochlear implant recipients. Acta Oto-Laryngologica 2010;130(12):1379-88. [DOI: 10.3109/00016489.2010.492480]

\section{References to ongoing studies}

\section{ACTRN12617000389303 \{published data only\}}

ACTRN12617000389303. Establishing the role of teleconsulting in the care of chronic conditions in rural areas of the Southern District Health Board (SDHB): a randomised controlled trial (RCT) in patients with inflammatory bowel disease. www.anzctr.org.au/Trial/Registration/TrialReview.aspx? id=372543 (first received 10 March 2017).

\section{ACTRN12618001007224 \{published data only\}}

ACTRN12618001007224. A prospective randomised controlled study of telehealth specialist palliative care consultations in rural and metropolitan settings and the impact on patient and carer clinical outcomes and quality-of-life. www.anzctr.org.au/
Trial/Registration/TrialReview.aspx?ACTRN=12618001007224 (first received 25 May 2018).

Done 2018 \{published data only\}

* Done N, Oh DH, Weinstock MA, Withed JD, Jackson GL, King HA, et al. VA Telederm study: protocol for a steppedwedge cluster randomised trial to compare access to care for a mobile app versus a workstation-based store-and-forward teledermatology process. BMJ Open 2018;8:e022218.

NCT03241589. Teledermatology mobile apps. clinicaltrials.gov/ ct2/show/NCT03241589 (first received 7 August 2017).

\section{Gervès-Pinquié 2017 \{published data only\}}

Ferrua M, Di Palma M, Lemare F, Fourcade A, Lalloué B, DaumasYatim F, et al. Impact of a cancer care coordination program based on health information technologies for patients treated by oral anticancer therapy: The CAPRI randomized trial. Annals of Oncology 2017;28(Suppl 5):mdx388.066.

* Gervès-Pinquié C, Daumas-Yatim F, Lalloué B, Girault A, Ferrua M, Fourcade A, et al. Impacts of a navigation program based on health information technology for patients receiving oral anticancer therapy: The CAPRI randomized controlled trial. BMC Health Services Research 2017;17(1):133.

NCT02828462. Impact of a monitoring device for patients with cancer treated using oral therapeutics (CAPRI). clinicaltrials.gov/ct2/show/NCT02828462 (first received 11 July 2016).

\section{Jeandidier 2018 \{published data only\}}

* Jeandidier N, Chaillous L, Franc S, Benhamou PY, Schaepelynck $\mathrm{P}$, Hanaire $\mathrm{H}$, et al. DIABEO app software and telemedicine versus usual follow-up in the treatment of diabetic patients: protocol for the TELESAGE randomized controlled trial. JMIR Research Protocols 2018;7(4):e66.

NCT02287532. Evaluation of the DIABEO system in poorly controlled DM1 or DM2 patients treated with a basal-bolus Insulin regimen (TELESAGE). clinicaltrials.gov/ct2/show/ NCT02287532 (first received 10 November 2014).

Källander 2015 \{published data only\}

Källander K, Strachan D, Soremekun S, Hill Z, Lingam R, Tibenderana J, et al. Evaluating the effect of innovative motivation and supervision approaches on community health worker performance and retention in Uganda and Mozambique: study protocol for a randomised controlled trial. Trials 2015;16:157. [DOI: 10.1186/s13063-015-0657-6]

\section{Koch 2018 \{published data only\}}

DRKS00012944. Implementation of teledermatologic referrals into general practice: A cluster-randomized controlled trial. www.drks.de/drks_web/setLocale_EN.do (first received 31 August 2017)

Koch R, Polanc A, Haumann H, Kirtschig G, Martus P, Thies C, et al. Improving cooperation between general practitioners and dermatologists via telemedicine: study protocol of the cluster-randomized controlled TeleDerm study. Trials 19;1(583):10.1186/s13063-018-2955-2. 
Nakayama 2016 \{published data only\}

Nakayama M, Inoue R. Prospective randomized trial of telemedicine-based collaborativecare using a prefectural medical information network system. European Journal of Epidemiology 2016;31(Suppl. 1):S141.

\section{NCT02821143 \{published data only\}}

NCT02821143. The impact of telemedicine to support palliative care resident in nursing home (TELESM). clinicaltrials.gov/ct2/ show/NCT02821143 (first received 1 July 2016).

\section{NCT02986256 \{published data only\}}

NCT02986256. Evaluation of the management of diabetic foot ulcers by telemedicine on the number of hospital days in diabetic patients (TELEPIED). clinicaltrials.gov/ct2/show/ NCT02986256 (first received 8 December 2016).

\section{NCT03137511 \{published data only\}}

NCT03137511. Optimizing Access to Care Through New Technologies: A randomized study evaluating the impact of telephone contact and the sending by the general practitioner of suspicious lesions melanoma photographs taken with a smartphone, on the time limit to the consultation with a dermatologist (OASE Melanome). clinicaltrials.gov/ct2/show/ NCT03137511 (first received 2 May 2017).

\section{NCT03559712 \{published data only\}}

NCT03559712. Effectiveness of collaborative tele-mental health services for ADHD in primary care: a randomized trial in Dubai (ECTSAP- Dubai Trial). clinicaltrials.gov/ct2/show/NCT03559712 (first received 18 June 2018).

\section{NCT03662256 \{published data only\}}

NCT03662256. Reducing childhood hearing loss in rural Alaska through a preschool screening and referral process using mobile health and telemedicine. clinicaltrials.gov/ct2/show/ NCT03662256 (first received 7 September 2018).

\section{Stevanovic 2017 \{published data only\}}

NCT02617875. Telemedical support for prehospital emergency medical service (TEMS). clinicaltrials.gov/ct2/show/ NCT02617875 (first received 1 December 2015).

* Stevanovic A, Beckers SK, Czaplik M, Bergrath S, Coburn M, Brokmann CB, et al. Telemedical support for prehospital Emergency Medical Service (TEMS trial): study protocol for a randomized controlled trial. Trials 2017;18(1):43. [DOI: 10.1186/ s13063-017-1781-2]

\section{Xu 2017 \{published data only\}}

Xu L, Fang WY, Zhu F, Zhang HG, Liu K. A coordinated PCPCardiologist Telemedicine Model (PCTM) in China's community hypertension care: study protocol for a randomized controlled trial. Trials 2017;18(1):236. [DOI: 10.1186/s13063-017-1970-z]

\section{Additional references}

\section{AAP 2015}

American Academy of Pediatrics Comittee on Pediatric Workforce. The use of telemedicine to address access and physician workforce shortages. Pediatrics 2015;136(1):202-9.

\section{Aceto 2018}

Aceto G, Persico V, Pescapé A. The role of Information and Communication Technologies in healthcare: taxonomies, perspectives, and challenges. Journal of Network and Computer Applications 2018;107:125-54. [DOI: 10.1016/j.jnca.2018.02.008]

\section{AeHIN 20017}

Asia eHealth Information Network. Getting to know the Network. www.aehin.org/AboutUs.aspx (accessed 24 April 2020).

\section{Agarwal 2016}

Agarwal S, LeFevre AE, Lee J, L'Engle K, Mehl G, Sinha C, et al, WHO mHealth Technical Evidence Review Group. Guidelines for reporting of health interventions using mobile phones: mobile health (mHealth) evidence reporting and assessment (mERA) checklist. BMJ 2016;352:i1174. [DOI: 10.1136/bmj.i1174]

\section{Agboola 2016}

Agboola SO, Bates DW, Kvedar JC. Digital health and patient safety. JAMA 2016;315(16):1697-8.

\section{AKDN 2019}

AKDN Digital Health Programme. akdnehrc.org/ ehealth_programme/ (accessed 31 July 2019).

\section{Arain 2010}

Arain M, Campbell MJ, Cooper CL, Lancaster GA. What is a pilot or feasibility study? A review of current practice and editorial policy. BMC Medical Research Methodology 2010;10:67.

\section{Borenstein 2009}

Borenstein M, Hedges LV, Higgins JP, Rothstein HR. When does it make sense to perform a meta-analysis? In: Introduction to Meta-Analysis. Chichester (UK): John Wiley \& Sons, Ltd, 2009.

\section{Campbell 2000}

Campbell M , Grimshaw J , Steen N, for the Changing Professional Practice Europe Group (EU BIOMED II Concerted Action). Sample size calculations for cluster randomized trials. Journal of Health Services Research \& Policy 2000;5(1):12-6.

\section{Campbell 2013}

Campbell J, Dussault G, Buchan J, Pozo-Martin F, Guerra Arias M, Leone C, et al. A Universal Truth: No Health Without a Workforce. Recife, Brazil: Third Global Forum on Human Resources for Health; 2013. Forum report. Geneva: Global Health Workforce \& World Health Organization, 2013.

\section{Coiera 2016}

Coeira E, Ash J, Berg M. The unintended consequences of Health Information Technology revisited. Yearbook of Medical Informatics 2016;2016:163-9. [DOI: 10.15265/IY-2016-014]

\section{Covidence [Computer program]}

Veritas Health Innovation Covidence. Melbourne, Australia: Veritas Health Innovation, Version accessed 11 February 2020. Available at covidence.org.

Mobile technologies to support healthcare provider to healthcare provider communication and management of care (Review) 


\section{Craig 2008}

Craig P, Dieppe P, Macintyre S, Michie S, Nazareth I, Petticrew M, Medical Research Council Guidance. Developing and evaluating complex interventions: the new Medical Research Council guidance. BMJ 2008;337:a1655. [DOI: <10.1136/bmj.a1655]

\section{Dala-Ali 2011}

Dala-Ali BM, Lloyd MA, Al-Abed Y. The uses of the iPhone for surgeons. Surgeon 2011;9(1):44-8. [DOI: 10.1016/ j.surge.2010.07.014]

\section{Deeks 2017}

Deeks JJ, Higgins JP, Altman DG, editor(s), on behalf of the Cochrane Statistical Methods Group. Chapter 9: Analysing data and undertaking meta-analyses. In: Higgins JP, Churchill R, Chandler J, Cumpston MS, editor(s). Cochrane Handbook for Systematic Reviews of Interventions version 5.2.0 (updated June 2017), The Cochrane Collaboration, 2017. Available from www.training.cochrane.org/handbook.

\section{Distiller [Computer program]}

DistillerSR. Ottawa, Canada: Evidence Partners, Version accessed prior to 1 January 2019. Available at www.evidencepartners.com/products/distillersr-systematicreview-software/.

\section{EPOC 2017a}

Cochrane Effective Practice and Organisation of Care (EPOC). Data collection form. EPOC resources for review authors, 2017. epoc.cochrane.org/resources/epoc-resources-review-authors (accessed 31 August 2017).

\section{EPOC 2017b}

Cochrane Effective Practice and Organisation of Care (EPOC). Suggested risk of bias criteria for EPOC reviews. EPOC resources for review authors, 2017. epoc.cochrane.org/resources/epocresources-review-authors (accessed 31 August 2017).

\section{EPOC 2017C}

Cochrane Effective Practice and Organisation of Care (EPOC). EPOC worksheets for preparing a 'Summary of findings' table using GRADE. EPOC resources for review authors, 2017. epoc.cochrane.org/resources/epoc-resources-review-authors (accessed 31 August 2017).

\section{EPOC 2017d}

Cochrane Effective Practice and Organisation of Care (EPOC). Reporting the effects of an intervention in EPOC reviews. EPOC Resources for review authors, 2017. epoc.cochrane.org/ resources/epoc-resources-review-authors (accessed 31 August 2017).

\section{Free 2013}

Free C, Phillips G, Watson L, Galli L, Felix L, Edwards P, et al. The effectiveness of mobile-health technologies to improve health care service delivery processes: a systematic review and metaanalysis. PLOS Medicine 2013;10(1):e1001363. [DOI: 10.1371/ journal.pmed.1001363]

\section{Gagnon 2016}

Gagnon MP, Ngangue P, Payne-Gagnon J, Desmartis M. mHealth adoption by healthcare professionals: a systematic review. JAMA 2016;23(1):212-20. [DOI: 10.1093/jamia/ocv052]

\section{Glenton 2019}

Glenton C, Akama E, Tamrat T. Factors influencing the acceptability, feasibility and implementation of interactive telemedicine: an overview of reviews. In: WHO Guideline: Recommendations on Digital Interventions for Health System Strengthening Web Supplement 2: Summary of Findings and GRADE Tables. Geneva: World Health Organization, 2019. [Licence: CC BY-NC-SA 3.0 IGO]

\section{Gonçalves-Bradley 2018a}

Gonçalves-Bradley DC, Buckley BS, Fønhus MS, Glenton C, Henschke N, Lewin S, et al. Mobile-based technologies to support client to healthcare provider communication and management of care. Cochrane Database of Systematic Reviews 2018, Issue 1. Art. No: CD012928. [DOI: 10.1002/14651858.CD012928]

\section{GRADEpro GDT [Computer program]}

McMaster University (developed by Evidence Prime) GRADEpro GDT. Version accessed prior to 20 December 2017. Hamilton (ON): McMaster University (developed by Evidence Prime), 2015.

\section{Guyatt 2008}

Guyatt GH, Oxman AD, Vist G, Kunz R, Falck-Ytter Y, AlonsoCoello P, et al, GRADE Working Group. GRADE: an emerging consensus on rating quality of evidence and strength of recommendations. BMJ 2008;336(7650):924-6.

\section{Hasselberg 2014}

Hasselberg M, Beer N, Blom L, Wallis LA, Laflamme L. Imagebased medical expert teleconsultation in acute care of injuries: a systematic review of effects on information accuracy, diagnostic validity, clinical outcome, and user satisfaction. PLOS One 2014;9(6):e98539. [DOI: 10.1371/journal.pone.0098539]

\section{Higgins 2017}

Higgins JP, Altman DG, Sterne JA, editor(s). Chapter 8: Assessing risk of bias in included studies. in: Higgins JP, Churchill R, Chandler J, Cumpston MS, editor(s). Cochrane Handbook for Systematic Reviews of Interventions version 5.2.0 (updated June 2017). The Cochrane Collaboration, 2017. Available from www.training.cochrane.org/handbook.

\section{Higgins 2019}

Higgins JP, Thomas J, Chandler J, Cumpston M, Li T, Page MJ, et al editor(s). Cochrane Handbook for Systematic Reviews of Interventions version 6.0 (updated July 2019). The Cochrane Collaboration, 2019. Available from www.training.cochrane.org/ handbook.

\section{ITU 2019}

International Telecomunications Union. Measuring digital development: Facts and figures 2019. https:// www.itu.int/en/ITU-D/Statistics/Documents/ statistics/2019/ITU_Key_2005-2019_ICT_data_with \%20LDCs_280ct2019_Final.xls (accessed 27 April 2020). 


\section{Konrad 1999}

Konrad TR, Williams ES, Linzer M, McMurray J, Pathman DE, Gerrity $\mathrm{M}$, et al. Measuring physician job satisfaction in a changing workplace and a challenging environment. Medical Care 1999;37(11):1174-82.

\section{Kruse 2017}

Kruse CS, Krowski N, Rodriguez B, Tran L, Vela J, Brooks M. Telehealth and patient satisfaction: a systematic review and narrative analysis. BMJ Open 2017;7(8):e016242.

\section{Kukutsch 2017}

Kukutsch NA, Argenziano G, Bergman W. The opinion of dermoscopy experts about teledermoscopy involving primary care physicians and dermatologists. JEADV 2017;31(10):e470-1.

\section{Källander 2013}

Källander K, Tibenderana JK, Akpogheneta OJ, Strachan DL, Hill Z, Ten Asbroek AH, et al. Mobile health (mHealth) approaches and lessons for increased performance and retention of community health workers in low- and middleincome countries: A review. Journal of Medical Internet Research 2013;15(1):e17. [DOI: 10.2196/jmir.2130]

\section{La Monica 1986}

La Monica E, Oberst MT, Madea AR, Wolf RM. Development of a patient satisfaction scale. Research in Nursing \& Health 1986;9(1):43-50.

\section{Liberati 2009}

Liberati A, Altman DG, Tetzlaff J, Mulrow C, Gøtzsche PC, loannidis JP, et al. The PRISMA statement for reporting systematic reviews and meta-analyses of studies that evaluate health care interventions: explanation and elaboration. PLOS Medicine 2009;6(7):e1000100.

\section{Liddy 2016}

Liddy C, Drosinis P, Keely E. Electronic consultation systems: worldwide prevalence and their impact on patient care - a systematic review. Family Practice 2016;33(3):274-85. [DOI: 10.1093/fampra/cmw024]

\section{Liddy 2019b}

Liddy C, Moroz I, Mihan A, Nawar N, Keely E. A systematic review of asynchronous, provider-to-provider, electronic consultation services to improve access to specialty care available worldwide. Telemedicine Journal and e-Health 2019;25(3):184-98. [DOI: 10.1089/tmj.2018.0005]

\section{Mantel 1959}

Mantel N, Haenszel W. Statistical aspects of the analysis of data from retrospective studies of disease. Journal of the National Cancer Institute 1959;22(4):719-48.

\section{Mars 2012}

Mars M. Building the capacity to build capacity in e-Health in Sub-Saharan Africa: the KwaZulu-Natal Experience. Telemedicine Journal and e-Health 2012;18(1):32-7.

\section{McDowell 2006}

McDowell I. Measuring Health: A Guide to Rating Scales and Questionnaires. 3rd edition. New York (NY): Oxford University Press, 2006.

\section{MedPAC 2016}

Medicare Payment Advisory Commission (USA). Telehealth Services and the Medicare Program. Report to the Congress: Medicare and the Health Care Delivery System. www.medpac.gov/docs/default-source/reports/chapter-8telehealth-services-and-the-medicare-program-june-2016report-.pdf?sfvrsn $=0$ (accessed prior to 20 December 2017) 2016:227-60.

\section{Mobasheri 2015}

Mobasheri MH, King D, Johnston M, Gautama S, Purkayastha S, Darzi A. The ownership and clinical use of smartphones by doctors and nurses in the UK: A multicentre survey study. BMJ Innovations 2015;1:174-81.

\section{Morris 2006}

Morris NS, MacLean CD, Chew LD, Littenberg B. The Single Item Literacy Screener: Evaluation of a brief instrument to identify limited reading ability. BMC Family Practice 2006;7:21. [DOI: 10.1186/1471-2296-7-21]

\section{NHS Commissioning Assembly 2015}

NHS Commissioning Assembly. Technology Enabled Care Services: Resource for Commissioners, 2015. www.england.nhs.uk/wp-content/uploads/2014/12/ TECS_FinalDraft_0901.pdf (accessed prior to 20 December 2017).

\section{Odendaal 2020}

Odendaal WA, Anstey Watkins J, Leon N, Goudge J, Griffiths F, Tomlinson M, et al. Health workers' perceptions and experiences of using mHealth technologies to deliver primary healthcare services: a qualitative evidence synthesis. Cochrane Database of Systematic Reviews 2020, Issue 3. Art. No: CD011942. [DOI: 10.1002/14651858.CD011942.pub2]

\section{OPHI 2017}

Alkire S, Robles G. Global Dimensional Povery Index 2017. Oxford Poverty \& Human Development Initiative, ODID, 2017. Available from www.ophi.org.uk/wp-content/uploads/ B47_Global_MPI_2017.pdf (accessed 13 October 2017).

\section{RevMan 5.3 [Computer program]}

Copenhagen: The Nordic Cochrane Centre, The Cochrane Collaboration Review Manager (RevMan) Version 5.3. Copenhagen: The Nordic Cochrane Centre, The Cochrane Collaboration, 2014.

\section{Schünemann 2017}

Schünemann HJ, Oxman AD, Higgins JP, Vist GE, Glasziou P, Akl $E$, et al, on behalf of the Cochrane GRADEing Methods Group and the Cochrane Statistical Methods Group. Chapter 11: Completing 'Summary of findings' tables and grading the confidence in or quality of the evidence. In: Higgins JP, Churchill R, Chandler J, Cumpston MS, editor(s). Cochrane Handbook for Systematic Reviews of Interventions version 5.2.0 (updated 
June 2017). The Cochrane Collaboration, 2017. Available from www.training.cochrane.org/handbook.

\section{SCTT 2017}

Scottish Centre for Telehealth \& Telecare. Programmes. sctt.org.uk/programmes (accessed 13 October 2017).

\section{Steinhubi 2013}

Steinhubi SR, Muse ED, Topol EJ. Can mobile health technologies transform health care? JAMA 2013;310(22):2395-6.

\section{Sterne 2011}

Sterne JA, Sutton AJ, loannidis JP, Terrin N, Jones DR, Lau J, et al. Recommendations for examining and interpreting funnel plot asymmetry in meta-analyses of randomised controlled trials. BMJ 2011;343:d4002. [DOI: 10.1136/bmj.d4002]

\section{Wallace 2017}

Wallace BC, Noel-Storr A, Marshall IJ, Cohen AM, Smalheiser NR, Thomas J. Identifying reports of randomized controlled trials (RCTs) via a hybrid machine learning and crowdsourcing approach. Journal of the American Medical Informatics Association 2017;24(6):1165-8.

\section{WHO 2011}

World Health Organization Global Observatory for eHealth. Global Observatory for eHealth series - Volume 2. Telemedicine: Opportunities and developments in Member States. January 2011. www.who.int/goe/publications/ehealth_series_vol2/en/ (accessed 31 August 2017).

\section{WHO 2016}

World Health Organization. Global Observatory for eHealth. Global diffusion of eHealth: Making universal health coverage achievable. Report of the third global survey on eHealth. 2016. www.who.int/goe/publications/global_diffusion/en/ (accessed 31 August 2017).

\section{WHO 2018}

World Health Organization. Classification of Digital Health Interventions v1.0. WHO/RHR/19.06. www.who.int/ reproductivehealth/publications/mhealth/classification-digitalhealth-interventions/en/ (accessed 24 April 2020).

\section{WHO 2019}

World Health Organization. WHO Guideline: Recommendations on Digital interventions for Health System Strengthening. www.ncbi.nlm.nih.gov/books/NBK541902/pdf/ Bookshelf_NBK541902.pdf 2019 (accessed 24 April 2020).

\section{Wu 2016}

Wu Q, Zhao L, Ye X-C. Shortage of healthcare professionals in China. BMJ 2016;354:i4860.

\section{References to other published versions of this review Gonçalves-Bradley 2018b \\ Gonçalves-Bradley DC, Buckley BS, Fønhus MS, Glenton C, Henschke N, Lewin S, et al. Mobile-based technologies to support healthcare provider to healthcare provider communication and management of care. Cochrane Database of Systematic Reviews 2018, Issue 1. Art. No: CD012927. [DOI: 10.1002/14651858.CD012927]}

* Indicates the major publication for the study

\section{CHARACTERISTICS OF STUDIES}

Characteristics of included studies [ordered by study ID]

Armstrong 2018

\section{Study characteristics}

Methods Study design: Randomised trial (parallel assignment)

Unit of allocation: Participant (GP)

Participants Providers

Number: 296 participants randomised (same number ITT); number of professionals not described

Type: GPs consulting with dermatologists in secondary care

Other relevant characteristics: none reported

\section{Participants}

Number: Eligible: I: 148; C: 148 Analysed: same number (ITT)

Mean age (SD): 49 years (14)

Gender ( $\%$ female): $50 \%$ 
Inclusion criteria: Adults diagnosed with plaque psoriasis, access to Internet and digital camera or mobile phone with camera

Exclusion criteria: No diagnosis of plaque psoriasis, living outside the designated catchment area

Other relevant characteristics: Mainly white (63\%), with college education or more (88\%), and working full-time (47\%). Baseline scores for severity of the condition were lower than anticipated, as several participants were receiving other therapies

\section{Location and study setting: USA, 3 regions}

Recruitment method: Participants recruited from practice-based research networks, federally-qualified health centres, and university-based clinics, national groups and general public

Duration: Number of sessions varied by participant, 12-months follow-up. Study ran between 2 February 2015 and 18 August 2017

Withdrawals: $6 \%$ of randomised participants were lost to follow-up and $4 \%$ withdrew

Intervention components: Online, collaborative connected-health model between participant, PCP and dermatologist. PCP could communicate with the dermatologist using the consultation function, sending digital photographs and clinical history for discussion. The dermatologist would assess the data and reply to the PCP within 2 business days, recommending treatment as well as educational materials for the participant. With the PCP permission, the dermatologist could also contact the participant directly. The PCP could also request for the dermatologist to become the main HCP. All communication was done through a secure web-based platform. Participants were paid for participating in the study, through gift cards

Comparison: Usual care: in-person care as needed, frequency established by participants and their providers

Technical equipment used: Secure safety policy-compliant web-based connected-health platform; mobile phone or digital camera for collecting images

Fidelity assessment: Not reported; protocol states that protocol deviations will be noted, but not how they will be assessed

Outcomes

Main outcome: Self-reported psoriasis severity

Other outcomes: Quality of life, access to care; depression; disease severity

Time points reported: Baseline, 3-, 6-, 9-, 12-months

Conflicts of interest: "Dr Armstrong reported serving as an investigator, consultant, advisor, and/or speaker for AbbVie, Janssen, Lilly, Novartis, Sanofi, Regeneron, Leo, Science 37, Modmed, Pfizer, Ortho Dermatologics, and Modernizing Medicine. Dr Gelfand reported serving as a consultant for and receiving honoraria from BMS, Coherus (DSMB), Dermira, GSK, Janssen Biologics, Menlo Therapeutics, Novartis Corp, Regeneron, Dr Reddy's Laboratories, Sanofi, and Pfizer Inc; receiving research grants (to the Trustees of the University of Pennsylvania) from AbbVie, Janssen, Novartis Corp, Regeneron, Sanofi, Celgene, Ortho Dermatologics, and Pfizer Inc; receiving payment for continuing medical education work related to psoriasis that was supported indirectly by Lilly, Ortho Dermatologics, and AbbVie; and being a co-patent holder of resiquimod for treatment of cutaneous T-cell lymphoma. Dr Wong reported being an employee of DirectDerm. No other disclosures were reported."

\section{Risk of bias}


Armstrong 2018 (Continued)

Random sequence genera- Low risk Comment: Computer-generated random block sizes (p.3) tion (selection bias)

Allocation concealment $\quad$ Low risk $\quad$ Comment: Independent statistician (p.4)
(selection bias)

\begin{tabular}{|c|c|c|}
\hline $\begin{array}{l}\text { Baseline outcome mea- } \\
\text { surements similar (selec- } \\
\text { tion bias) }\end{array}$ & Low risk & $\begin{array}{l}\text { Comment: Baseline data provided for main outcome and similar between } \\
\text { groups (Table 1) }\end{array}$ \\
\hline
\end{tabular}

tion bias)

\begin{tabular}{lll}
\hline $\begin{array}{l}\text { Baseline characteristics } \\
\text { similar (selection bias) }\end{array}$ & Low risk & $\begin{array}{l}\text { Comment: Baseline characteristics provided and similar between groups (Ta- } \\
\text { ble 1) }\end{array}$ \\
\hline $\begin{array}{l}\text { Blinding of participants } \\
\text { and personnel (perfor- } \\
\text { mance bias) }\end{array}$ & High risk & Comment: Not possible to blind participants or personnel \\
All outcomes & & \\
\hline
\end{tabular}

Blinding of objective out- $\quad$ Low risk $\quad$ Comment: Data analyst blinded
come assessment (detec-

come assessment (detec-

tion bias)

\begin{tabular}{lll}
\hline $\begin{array}{l}\text { Blinding of subjective out- } \\
\begin{array}{l}\text { come assessment (detec- } \\
\text { tion bias) }\end{array}\end{array}$ & High risk & $\begin{array}{l}\text { Comment: Patient-reported outcome measures, unblinded participants and } \\
\text { personnel }\end{array}$ \\
\hline $\begin{array}{l}\text { Protection against conta- } \\
\text { mination }\end{array}$ & High risk & Comment: Patients were randomised to the groups \\
\hline $\begin{array}{l}\text { Incomplete outcome data } \\
\text { (attrition bias) }\end{array}$ & Low risk & Comment: Intention-to-treat analysis \\
\hline $\begin{array}{l}\text { Selective reporting (re- } \\
\text { porting bias) }\end{array}$ & High risk & $\begin{array}{l}\text { Comment: Not all outcomes specified in the protocol reported in publications } \\
\text { (distance travel, wait time) }\end{array}$ \\
\hline \begin{tabular}{l} 
Other bias \\
\hline
\end{tabular} & Low risk & Comment: No other apparent source of bias \\
\hline
\end{tabular}

\section{Azogil-López 2019}

\section{Study characteristics}

\begin{tabular}{ll}
\hline Methods & Study design: Randomised trial (parallel assignment) \\
& Unit of allocation: Participant (GP) \\
\hline Participants & Providers \\
& Number: 58 GPs randomised (31 analysed), number of hospital-based physicians not reported \\
& Type: GPs consulting with physicians in secondary care \\
& Other relevant characteristics: GPs' median age was approximately 57 years, on average $34 \mathrm{~km}$ away \\
from the hospital & Participants
\end{tabular}


Number: Eligible: I: 92; C: 164 Analysed: I: 72; C: 101

Median age: I: 56 years; $C$ : 55 years

Gender (\% female): I: 59\%; C: $60 \%$

Inclusion criteria: Adults who consulted with the GP and required a referral to secondary care

Exclusion criteria: People who required or preferred an in-person appointment

Other relevant characteristics: Not reported

Location and study setting: Spain, 6 primary care practices

Recruitment method: Not reported

Duration: Single session; 3-months follow-up. Study ran between March and December 2016

Withdrawals: $38 \%(\mathrm{~N}=19)$ of eligible GPs were excluded from analysis (IG: 6 GPs excluded as they did not request phone consultations with physicians; CG: 13 GPs excluded as they did not collect data for at least $50 \%$ of their eligible participants); of those receiving care by GPs allocated to the IG, $50 \%$ were excluded from analysis as they were given in-person appointments (either because they required or preferred it) ity appointment was needed, the GP would request an eConsult with the specialist, which would take place at the primary care practice. The GP would call the consultant at a convenient time, while the participant was still in the room. The 2 healthcare professionals would agree on the treatment, whether further investigations were required, and book follow-up appointments

Comparison: Usual care - participant was given a referral for an in-person appointment at secondary care

Technical equipment used: Hands-free telephone

Fidelity assessment: Not reported

Outcomes

Main outcomes: Waiting days between the GP referring the participant for an appointment and the appointment being provided; number of avoided/avoidable face-to-face referrals; waiting days for the resolution of the process

Time points reported: Post-intervention (3-months follow-up)

Notes Funding: Andalusian Society of Family and Community Medicine -SAMFyC- (Record ref. 157/18)

Ethical approval: Regional research ethics committee. Trial registry ACTRN12617001536358

Conflicts of interest: None known

\section{Risk of bias}

\begin{tabular}{lll}
\hline Bias & Authors' judgement & Support for judgement \\
\hline $\begin{array}{l}\text { Random sequence genera- } \\
\text { tion (selection bias) }\end{array}$ & Low risk & Comment: Random-number table (p. 3) \\
\hline $\begin{array}{l}\text { Allocation concealment } \\
\text { (selection bias) }\end{array}$ & Low risk & $\begin{array}{l}\text { Comment: Unit of allocation was by primary care practices, and allocation was } \\
\text { performed on all units at the start of the study (p.3) }\end{array}$ \\
\hline $\begin{array}{l}\text { Baseline outcome mea- } \\
\text { surements similar (selec- } \\
\text { tion bias) }\end{array}$ & Unclear risk & Comment: Not enough information provided \\
\hline
\end{tabular}


Azogil-López 2019 (Continued)

Baseline characteristics High risk Comment: Baseline differences between groups about participants distance to similar (selection bias) hospital and geographical living area (table 2)

Blinding of participants High risk

Comment: Not possible to blind participants or personnel and personnel (performance bias)

All outcomes

Blinding of objective out-
come assessment (detec- $\quad$ Low risk Comment: Automatically extracted from the EMR (p.4)

ssessment (detection bias)

Protection against conta- Low risk Comment: Allocation by healthcare providers
mination
mination

$\begin{array}{ll}\begin{array}{l}\text { Incomplete outcome data } \\ \text { (attrition bias) }\end{array} & \text { High risk } \\ \text { All outcomes } & \begin{array}{l}\text { Comment: High attrition rates (almost 40\% randomised GPs excluded from } \\ \text { analysis; } \text { p.4) }\end{array}\end{array}$

All outcomes

Selective reporting (re- Low risk Comment: All outcomes listed in Methods reported in Results
porting bias)
porting bias)

Other bias Low risk Comment: No other apparent source of bias

Byamba 2015

\section{Study characteristics}

\begin{tabular}{ll}
\hline Methods & Study design: Cluster-randomised trial (parallel assignment) \\
Unit of allocation: Cluster (clinics)
\end{tabular}

Participants

\section{Providers}

Number: 20 GPs, number of hospital-based physicians not reported

Type: GPs consulting with physicians in secondary care

Other relevant characteristics: Not reported

\section{Participants}

Number: Eligible: I: 221; C: 229 Analysed: same number

Median age: Not reported

Gender (\% female): Not reported

Inclusion criteria: Adults who consulted with the GP and required a referral to secondary care for skin lesions and problems

\section{Exclusion criteria: Not reported \\ Other relevant characteristics: Not reported}

Location and study setting: Mongolia, 20 rural health clinics in 1 of the least densely-population countries in the world.

Recruitment method: Not reported 
Byamba 2015 (Continued)

Duration: 5-month follow-up. Study ran between September 2013 and January 2014

Withdrawals: Not reported
Intervention components: A primary care provider in a rural health clinic used a smartphone camera to collect images and clinical history of participants with skin lesions and problems. The PCP attended a 2-day training session to learn how to take images and use the medical record system and software on mobile phones. The information was sent along with a teleconsultation request using the electronic medical record. The dermatologist reviewed the information and sent feedback within 24 hours.

Comparison: Usual care - GPs referred participants to district hospitals or the National Dermatology Centre

Technical equipment used: Android-based system

Fidelity assessment: GPs from clinics allocated to the intervention attended a 2-day training session on how to take pictures using the devices provided and how to operate the electronic medical record

\begin{tabular}{ll} 
Outcomes & Main outcomes: Tertiary care referrals; costs \\
& Time points reported: Post-intervention (5-months follow-up) \\
\hline Notes & $\begin{array}{l}\text { Funding: National science Council Project no. NSC 101-2923-E-038 -001 -MY2, Ministry of Health and } \\
\text { Welfare (MOHW), Taiwan, under grant MOHW103-TD-B-111-01 and Taipei Medical University under } \\
\text { grant 101TMUSHH-21 }\end{array}$
\end{tabular}

Ethical approval: Not reported

Conflicts of interest: None known

\section{Risk of bias}

\begin{tabular}{lll}
\hline Bias & Authors' judgement & Support for judgement \\
\hline $\begin{array}{l}\text { Random sequence genera- } \\
\text { tion (selection bias) }\end{array}$ & Low risk & Comment: Computer-generated sequence \\
\hline $\begin{array}{l}\text { Allocation concealment } \\
\text { (selection bias) }\end{array}$ & Low risk & Comment: Cluster randomisation, all done at the start of the study \\
\hline $\begin{array}{l}\text { Baseline outcome mea- } \\
\text { surements similar (selec- } \\
\text { tion bias) }\end{array}$ & Unclear risk & Comment: Not enough information provided \\
\hline $\begin{array}{l}\text { Baseline characteristics } \\
\text { similar (selection bias) }\end{array}$ & Unclear risk & Comment: Not reported \\
\hline $\begin{array}{l}\text { Blinding of participants } \\
\text { and personnel (perfor- } \\
\text { mance bias) }\end{array}$ & Unclear risk & Comment: Not reported \\
$\begin{array}{l}\text { All outcomes } \\
\end{array}$ & & \\
\hline
\end{tabular}

Blinding of objective out- Unclear risk Comment: Not reported how it was collected
come assessment (detec-
tion bias)

\begin{tabular}{lll}
\hline $\begin{array}{l}\text { Protection against conta- } \\
\text { mination }\end{array}$ & Low risk & $\begin{array}{l}\text { Comment: Allocation was by practice, unlikely that the control group received } \\
\text { the intervention }\end{array}$ \\
\hline $\begin{array}{l}\text { Incomplete outcome data } \\
\text { (attrition bias) }\end{array}$ & Low risk & Comment: There was no attrition \\
\hline
\end{tabular}

Mobile technologies to support healthcare provider to healthcare provider communication and management of care (Review) 
Byamba 2015 (Continued)

All outcomes

Selective reporting (re- Low risk Comment: All outcomes mentioned in Methods are presented in Results
porting bias)

Other bias Low risk Comment: No other apparent source of bias

Chang 2011

\section{Study characteristics}

Methods Study design: Cluster-randomised trial (parallel)

Unit of allocation: Cluster (10 clinics; I: 4, C: 6)

Participants

\section{Providers}

Number: I: 13, C: 16

Type: Community-based peer health workers consulting with clinic staff

Other relevant characteristics: None reported

\section{Participants}

Number: Randomised: 970 (I: 446, C: 524), Analysed: ITT analysis

Median age (range): 35 years (15-76)

Gender (\% female): $66 \%$

Inclusion criteria: Adults attending eligible clinics who were receiving or started receiving ART

Exclusion criteria: None reported

Other relevant characteristics: None reported

Location and study setting: Uganda, 10 clinic sites

Recruitment method: Not applicable; participants were not informed about the study as PHWs were performing routine care functions

Duration: Intervention lasted 26 weeks, median follow-up time was 103 weeks (97 - 111 weeks), study was conducted between May 2006 and July 2008

Withdrawals: $11 \%$ and $12 \%$ of participants allocated to Intervention and Control were lost to follow-up; main reason was death $(8.3 \%$ and $10.1 \%$ of all participants lost, respectively)

Intervention components: mHealth intervention: Periodic home visits, supported by mobile phone. PHWs participated in a 1-day residential training and were given a mobile phone and an hour-long field-based practicum. After each home visit the PHW would message data on adherence and other clinical information to a centralised database, which was staffed by clinic staff. Once a message had been received, clinic staff could provide care instructions, send a higher-level care provider, or arrange for the participant to be taken to a healthcare facility. PHWs could also call a hotline if they had questions

Comparison: No mobile phone, additional training or access to the hotline. All PHWs had previously been enrolled in a study of ART provision, where they received a 2-day residential training on HIV-related topics, as well as adherence counselling, patient confidentiality and filling out home visit forms. The main goal of the home visits was to evaluate and encourage adherence to ART therapy 
Technical equipment used: mobile phones (no further details provided)

Fidelity assessment: PHWs were supervised by a member of staff (part-time worker)

Main outcomes: Participants' cumulative risk of virologic failure
Other outcomes: Participant adherence; virologic failure at 24 and 48 weeks of ART; lost to follow-up;
mortality; qualitative evaluation (interviews, themes included impact of the intervention, confidentiali-
ty concerns and challenges with phones); cost analyses (intervention arm only)
Time points reported: Baseline, post-intervention (median follow-up was 103 weeks post-baseline)

Notes $\quad$ Funding: Doris Duke Charitable Foundation, The Division of Intramural Research, The National Institute for Allergy and Infectious Diseases, National Institutes of Health, and a National Institutes of Health Training Grant and Career Development Grant

Ethical approval: Institutional review boards at the Uganda Virus Research Institute's Safety and Ethics Committee, the Uganda National Council for Science and Technology, and Johns Hopkins University

Conflicts of interest: Not reported

\section{Risk of bias}

\begin{tabular}{lll}
\hline Bias & Authors' judgement & Support for judgement \\
\hline $\begin{array}{l}\text { Random sequence genera- } \\
\text { tion (selection bias) }\end{array}$ & Unclear risk & $\begin{array}{l}\text { Comment: Inadequate information reported, no description of sequence gen- } \\
\text { eration - }\end{array}$ \\
& $\begin{array}{l}\text { Quote: "The } 10 \text { sites (...) randomised 2:3 to PHWs receiving a mHealth support } \\
\text { intervention or not" (p.3) }\end{array}$
\end{tabular}

\begin{tabular}{lll}
\hline $\begin{array}{l}\text { Allocation concealment } \\
\text { (selection bias) }\end{array}$ & Low risk & Comment: Cluster randomisation, all clinics done at the start of the study \\
\hline $\begin{array}{l}\text { Baseline outcome mea- } \\
\text { surements similar (selec- } \\
\text { tion bias) }\end{array}$ & Low risk & $\begin{array}{l}\text { Quote: "[K]ey predictors of clinical outcomes appeared well balanced between } \\
\text { arms." (p.4) }\end{array}$ \\
\hline
\end{tabular}

\begin{tabular}{lll}
\hline $\begin{array}{l}\text { Baseline characteristics } \\
\text { similar (selection bias) }\end{array}$ & Low risk & Comment: Reported and similar between groups (Table 1) \\
\hline $\begin{array}{l}\text { Blinding of participants } \\
\text { and personnel (perfor- } \\
\text { mance bias) }\end{array}$ & High risk & Comment: Not possible to blind participants or personnel \\
All outcomes & & \\
\end{tabular}

$\begin{array}{lll}\text { Blinding of objective out- } & \text { Unclear risk } & \begin{array}{l}\text { Comment: No information provided on how objective outcomes were collect- } \\ \text { come assessment (detec- }\end{array} \\ \text { tion bias) } & \text { ed }\end{array}$

\begin{tabular}{|c|c|c|}
\hline $\begin{array}{l}\text { Protection against conta- } \\
\text { mination }\end{array}$ & Low risk & $\begin{array}{l}\text { Comment: Cluster-randomised trial with participants/peer health workers } \\
\text { with mobile phone intervention access in separate districts }\end{array}$ \\
\hline $\begin{array}{l}\text { Incomplete outcome data } \\
\text { (attrition bias) } \\
\text { All outcomes }\end{array}$ & High risk & Comment: High attrition rate \\
\hline $\begin{array}{l}\text { Selective reporting (re- } \\
\text { porting bias) }\end{array}$ & High risk & Comment: Outcomes reported in different publications \\
\hline
\end{tabular}


Chang 2011 (Continued)
Other bias
Low risk
Comment: No other apparent source of bias

Davis 2003

\section{Study characteristics}

\begin{tabular}{ll}
\hline Methods & Study design: Randomised trial (parallel) \\
Unit of allocation: Participant
\end{tabular}

Participants

Providers

Number: Two

Type: Primary care provider at the rural primary practice consulting with ophthalmologist in the university setting

Other relevant characteristics: None reported

\section{Participants}

Number: Randomised: 59 (I: 30, C: 29), Analysed: same number

Mean age (SD): Not reported

Gender (\% female): Not reported

Inclusion criteria: Adults with diabetes diagnosed by a physician

Exclusion criteria: Not reported

Other relevant characteristics: Mainly African-Americans

Location and study setting: USA, 1 rural primary practice and 1 urban university hospital

Recruitment method: Not reported

Duration: Not reported

Withdrawals: Not reported; all participants analysed

Intervention components: A primary care provider in a rural primary care practice used a nonmydriatic retinal camera and video-conferencing to send real-time images to an ophthalmologist located in an urban university setting. The ophthalmologist assessed the retinal photograph and communicated with the participant and the primary care professional

Comparison: Usual care - participants were reminded to schedule examinations with their usual eyecare provider

Technical equipment used: nonmydriatic retinal camera (Topcon with IMAGEnet software) and videoconferencing (no further details provided)

Fidelity assessment: Not reported

Outcomes Main outcomes: Frequency of eye examinations

Time points reported: Post-intervention

Notes Funding: Not reported

Ethical approval: Not reported 
Davis 2003 (Continued)

\section{Conflicts of interest: Not reported}

Notes: short reports (letter and abstract), limited information

\section{Risk of bias}

\begin{tabular}{lll}
\hline Bias & Authors' judgement & Support for judgement \\
\hline $\begin{array}{l}\text { Random sequence genera- } \\
\text { tion (selection bias) }\end{array}$ & Unclear risk & Comment: Not enough information provided \\
\hline
\end{tabular}

tion (selection bias)

Allocation concealment Unclear risk Comment: Not enough information provided
(selection bias)

Baseline outcome mea- Unclear risk $\quad$ Comment: Not enough information provided
surements similar (selec-
tion bias)

\begin{tabular}{|c|c|c|}
\hline $\begin{array}{l}\text { Baseline characteristics } \\
\text { similar (selection bias) }\end{array}$ & Unclear risk & Comment: Not enough information provided \\
\hline $\begin{array}{l}\text { Blinding of participants } \\
\text { and personnel (perfor- } \\
\text { mance bias) } \\
\text { All outcomes }\end{array}$ & Unclear risk & Comment: Not enough information provided \\
\hline $\begin{array}{l}\text { Blinding of objective out- } \\
\text { come assessment (detec- } \\
\text { tion bias) }\end{array}$ & Unclear risk & Comment: Not enough information provided \\
\hline $\begin{array}{l}\text { Blinding of subjective out- } \\
\text { come assessment (detec- } \\
\text { tion bias) }\end{array}$ & Unclear risk & Comment: Not enough information provided \\
\hline $\begin{array}{l}\text { Protection against conta- } \\
\text { mination }\end{array}$ & Unclear risk & Comment: Not enough information provided \\
\hline $\begin{array}{l}\text { Incomplete outcome data } \\
\text { (attrition bias) } \\
\text { All outcomes }\end{array}$ & Unclear risk & Comment: Not enough information provided \\
\hline $\begin{array}{l}\text { Selective reporting (re- } \\
\text { porting bias) }\end{array}$ & Unclear risk & Comment: Not enough information provided \\
\hline Other bias & Unclear risk & Comment: Not enough information provided \\
\hline
\end{tabular}

Eminović 2009

\section{Study characteristics}

\begin{tabular}{ll}
\hline Methods & Study design: Cluster-randomised trial (parallel) \\
& Unit of allocation: Cluster (36 GP practices; I: 19; C: 17) \\
\hline Participants & Providers \\
& Number: GPs: I: 59, C: 51 ; Dermatologists: 5
\end{tabular}


Type: GPs consulting with dermatologists

Other relevant characteristics: GPs: I: 29\% female, C: 35\% female

\section{Participants}

Number: Randomised: 631 (I: 327, C: 304), Analysed: 605 (I: 312, C: 293)

Mean age (SD): I: 42 years (23); C: 44 years (20)

Gender (\% female): I: $56 \%$; C: $64 \%$

Inclusion criteria: Practices were required to have facilities to send digital images over the Internet; participants were eligible if they were referred to a dermatologist by their GP

Exclusion criteria: GPs who already used teledermatology; patients were excluded if they required an urgent dermatology appointment

Other relevant characteristics: None reported

Location and study setting: The Netherlands, 36 primary care practices

Recruitment method: Dermatologists working in eligible areas were invited to participate; GPs working in practices that referred participants to those dermatologists were then invited to participate

Duration: Intervention was 1 teleconsultation, with 1 month follow-up; study conducted between February 2004 and January 2006

Withdrawals: $5 \%$ (I) and 7\% (C) of participants randomised were lost to follow-up, main reasons were problems with data entry and participants visiting another dermatologist; for $39 \%$ of participants, information on the main outcome was missing, mainly because GPs did not complete study forms

Interventions

Intervention components: GPs allocated to the intervention group received detailed instructions on how to take digital images and use the web-based form. GPs took 4 digital images of the skin problems and completed a structured form (which included questions about duration and location of the skin lesion) on a secure website; the form was sent to the dermatologist along with the main reason for referral (diagnosis, advice, reassurance). At this stage GPs could also refer the participant to another dermatologist. Within 48 hours the dermatologist assessed the images and replied to the GP using the same system, providing advice and whether further investigations or urgent referrals were required. After a month the dermatologist saw the participant in person, regardless of the outcome of the online consultation

Comparison: Usual care - participants saw a dermatologist according to the usual procedures, usually by being referred by the GP who would give the participant a letter to take to the clinic

Technical equipment used: digital cameras (Kodak EasyShare CX6230 2.0 megapixel) and a secure teledermatology website

Fidelity assessment: Not reported

Outcomes Main outcomes: Proportion of and reasons for preventable consultations

Other outcomes: Participant satisfaction in general and about interpersonal aspects of the consultation; costs

Time points reported: 1 month follow-up zation for Health Research and Development). KSYOS Health Management Research provided the digital cameras and teleconsultation software

Ethical approval: The ethics committee deemed this study to be exempt from review because the research did not interfere with usual care. Trial registration ISRCTN57478950 
Eminović 2009 (Continued)

Conflicts of interest: None known

\section{Risk of bias}

\begin{tabular}{lll}
\hline Bias & Authors' judgement & Support for judgement \\
\hline $\begin{array}{l}\text { Random sequence genera- } \\
\text { tion (selection bias) }\end{array}$ & Low risk & $\begin{array}{l}\text { Quote: "Using dedicated randomisation software, practices were assigned to } \\
\text { teledermatologic consultation or standard care." (p.559) }\end{array}$ \\
\hline $\begin{array}{l}\text { Allocation concealment } \\
\text { (selection bias) }\end{array}$ & Low risk & $\begin{array}{l}\text { Quote: "A special allocation concealment procedure (...) was followed to en- } \\
\text { sure that no allocation bias could occur." (p.559) }\end{array}$ \\
\hline $\begin{array}{l}\text { Baseline outcome mea- } \\
\text { surements similar (selec- } \\
\text { tion bias) }\end{array}$ & Low risk & Comment: Diagnostic categories well-balanced between groups (Table 4) \\
\hline $\begin{array}{l}\text { Baseline characteristics } \\
\text { similar (selection bias) }\end{array}$ & Low risk & $\begin{array}{l}\text { Comment: Baseline characteristics reported and similar between groups (Ta- } \\
\text { ble 2) }\end{array}$ \\
\hline $\begin{array}{l}\text { Blinding of participants } \\
\text { and personnel (perfor- } \\
\text { mance bias) }\end{array}$ & High risk & $\begin{array}{l}\text { Comment: Providers could not be blinded, no information on blinding of par- } \\
\text { ticipants }\end{array}$ \\
\hline
\end{tabular}

Blinding of objective out-

Unclear risk

Comment: Not enough information provided

come assessment (detec-

tion bias)

\begin{tabular}{|c|c|c|}
\hline $\begin{array}{l}\text { Blinding of subjective out- } \\
\text { come assessment (detec- } \\
\text { tion bias) }\end{array}$ & High risk & $\begin{array}{l}\text { Comment: Subjective assessment of whether in-person consultations could } \\
\text { have been prevented done by consulting dermatologist, who knew which par- } \\
\text { ticipants they had seen }\end{array}$ \\
\hline
\end{tabular}

\begin{tabular}{lll}
\hline $\begin{array}{l}\text { Protection against conta- } \\
\text { mination }\end{array}$ & Unclear risk & $\begin{array}{l}\text { Comment: Treatment and diagnosis of GPs in intervention clinics may have } \\
\text { been influenced cumulatively by consultations and contact with dermatolo- } \\
\text { gists }\end{array}$ \\
\hline $\begin{array}{l}\text { Incomplete outcome data } \\
\text { (attrition bias) } \\
\text { All outcomes }\end{array}$ & High risk & Comment: High rate of missing data for the primary outcome \\
\hline $\begin{array}{l}\text { Selective reporting (re- } \\
\text { porting bias) }\end{array}$ & High risk & $\begin{array}{l}\text { Comment: Trial registration states outcomes that were not reported (diagnos- } \\
\text { tic accuracy, delay in treatment, learning effect GPs) }\end{array}$ \\
\hline $\begin{array}{l}\text { Other bias } \\
\text { Unclear risk }\end{array}$ & $\begin{array}{l}\text { Comment: There were considerable problems following up participants and } \\
\text { several methods have been reported to gather outcome data and analyse in } \\
\text { different ways }\end{array}$ \\
\hline
\end{tabular}

Gulacti 2017

\section{Study characteristics}

\begin{tabular}{ll}
\hline Methods & Study design: Randomised trial (parallel) \\
Unit of allocation: Participants
\end{tabular}

Participants Providers

Mobile technologies to support healthcare provider to healthcare provider communication and management of care (Review) 
Number: Not provided

Type: Emergency physicians consulting with specialist physicians

Other relevant characteristics: Not provided

\section{Participants}

Number: Randomised: 345 (IG: 173, CG: 172), Analysed: same number

Mean age (SD): 48.5 years (22.1)

Gender ( $\%$ female): $33 \%$

Inclusion criteria: Participants: adults attending the emergency department; Physicians: owned a smartphone and were familiarised with secure messaging applications

Exclusion criteria: Not reported

Other relevant characteristics: Not reported

Location and study setting: Turkey, 1 hospital

Recruitment method: Not reported

Duration: Intervention was consultation request using 2 different methods; study was conducted between November 2015 and February 2016

Withdrawals: No withdrawals or losses to follow-up using a secure messaging service (Whatsapp). Any additional medical information (e.g. blood pressure, $x$-rays, ultrasounds, photographs) was sent through the same service

Comparison: Usual care; consultations were requested by telephone, with any additional medical information (e.g. blood pressure, sensory-motor findings, Glasgow Coma Score) sent verbally

Technical equipment used: Smartphone with Whatsapp (owned by the healthcare professionals)

Fidelity assessment: Not reported

\begin{tabular}{ll}
\hline Outcomes & Main outcomes: Difference between groups for emergency department length of stay \\
Other outcomes: Difference between groups in consult time (time when consultation was requested \\
minus time when a bed was requested or discharge time); termination of consultation between groups \\
Time points reported: Baseline, post-intervention \\
\hline Notes & Funding: Not reported \\
Ethical approval: Medical Ethics Committee. Trial registry NCT02586779 \\
Conflicts of interest: None known
\end{tabular}

\section{Risk of bias}

\begin{tabular}{lll}
\hline Bias & Authors' judgement & Support for judgement \\
\hline $\begin{array}{l}\text { Random sequence genera- } \\
\text { tion (selection bias) }\end{array}$ & Low risk & Comment: Computer programme (p.744) \\
\hline $\begin{array}{l}\text { Allocation concealment } \\
\text { (selection bias) }\end{array}$ & Unclear risk & Comment: Not enough information \\
\hline
\end{tabular}


Gulacti 2017 (Continued)

Baseline outcome mea- Unclear risk $\quad$ Comment: Not enough information provided
surements similar (selec-
tion bias)

\begin{tabular}{ll}
\hline $\begin{array}{l}\text { Baseline characteristics } \\
\text { similar (selection bias) }\end{array} \quad$ Low risk & $\begin{array}{l}\text { Comment: Baseline characteristics provided and similar between groups (Ta- } \\
\text { ble } 1)\end{array}$
\end{tabular}

\begin{tabular}{|c|c|c|}
\hline $\begin{array}{l}\text { Blinding of participants } \\
\text { and personnel (perfor- } \\
\text { mance bias) } \\
\text { All outcomes }\end{array}$ & High risk & $\begin{array}{l}\text { Comment: Not possible to blind participants or healthcare professionals, even } \\
\text { though consulting physicians were blinded to the purpose of the study (p.744) }\end{array}$ \\
\hline $\begin{array}{l}\text { Blinding of objective out- } \\
\text { come assessment (detec- } \\
\text { tion bias) }\end{array}$ & Low risk & Comment: Data collector was blinded (p.744) \\
\hline $\begin{array}{l}\text { Protection against conta- } \\
\text { mination }\end{array}$ & Unclear risk & $\begin{array}{l}\text { Comment: Healthcare professionals within the same hospital randomised and } \\
\text { it is not clear whether communication occurred between them }\end{array}$ \\
\hline $\begin{array}{l}\text { Incomplete outcome data } \\
\text { (attrition bias) } \\
\text { All outcomes }\end{array}$ & Low risk & Comment: No attrition \\
\hline $\begin{array}{l}\text { Selective reporting (re- } \\
\text { porting bias) }\end{array}$ & High risk & Comment: Outcomes stated in protocol are different from outcomes reported \\
\hline Other bias & Low risk & Comment: No other apparent source of bias \\
\hline
\end{tabular}

Iversen 2018

\section{Study characteristics}

\begin{tabular}{ll}
\hline Methods & Study design: Cluster-randomised trial (parallel) \\
& Unit of allocation: Cluster (42 sites, 21 each arm) \\
\hline Participants & Pumber: Not reported \\
Type: Community nurses consulting with diabetes specialist nurses and podiatrists \\
Other relevant characteristics: Not reported \\
Participants \\
Number: Randomised: 182 (I: 94, C: 88 ), Analysed: same number \\
Mean age (SD): I: 67.2 years (16.7); C: 65.5 years (16.5) \\
Gender (\% female): I: $75 \%$; C: $74 \%$ \\
Inclusion criteria: Adults aged $\geq 20$ years with new diabetes-related foot ulcers \\
Exclusion criteria: Repeated ulcer treated in the past 6 months, mental illness, life expectancy< 1 year \\
Other relevant characteristics: Diagnosed with diabetes for on average 20 years \\
Location and study setting: Norway, 2 hospitals
\end{tabular}


Recruitment method: Eligible patients attending 1 of 2 hospitals were invited to participate

Duration: Intervention length could vary according the clinical needs, participants seen every 6 weeks, maximum follow-up time as 12 months; not study conducted between September 2012 and June 2016

Withdrawals: For objective measures, all participants were followed-up and included in the analysis; for subjective measures attrition rates were $29 \%$ for the IG and $35 \%$ for the CG

\begin{abstract}
Interventions
Intervention components: Telemedicine application composed by a mobile phone and an interactive web-based ulcer record. Consultations happened every 6 weeks and included a written assessment and images taken using the mobile phone, which were then sent through the web to the specialist nurse or the podiatrist, who provided feedback. Any doubts could be further discussed. All staff received training in the use of the web-based system, as well as in-person access to hospital clinics to improve their practical skills
\end{abstract}

Comparison: Usual care - provided by outpatient clinic, usually scheduled every second week

Technical equipment used: Smartphone (no further description)

Fidelity assessment: Functionality was assessed yearly and minor adjustments introduced (protocol); all personnel received training and were following standardised guidelines for treatment of diabetes-related foot ulcers

Outcomes Main outcomes: Ulcer healing time

Other outcomes: Amputation; mortality; consultations; participant satisfaction; participant and healthcare professionals' experiences (qualitative)

Time points reported: Baseline, post-intervention (12 months post-baseline)

Notes $\quad$ Funding: Norwegian Directorate of Health and Innovation Norway, Western Norway Regional Health Authority, Norwegian Diabetes Association, Western Norway University of Applied Sciences, Norwegian Research Council

Ethical approval: Western Norway Regional Committee for Medical and Health Research Ethics. Trial registry: NCT01710774

Conflicts of interest: None known

\title{
Risk of bias
}

\begin{tabular}{|c|c|c|}
\hline Bias & Authors' judgement & Support for judgement \\
\hline $\begin{array}{l}\text { Random sequence genera- } \\
\text { tion (selection bias) }\end{array}$ & Low risk & Comment: Randomisation using computer programme (p.97) \\
\hline $\begin{array}{l}\text { Allocation concealment } \\
\text { (selection bias) }\end{array}$ & Low risk & Comment: Done by a person independent of the study (p.97) \\
\hline $\begin{array}{l}\text { Baseline outcome mea- } \\
\text { surements similar (selec- } \\
\text { tion bias) }\end{array}$ & Unclear risk & $\begin{array}{l}\text { Comment: Higher proportion of participants in the intervention group had ul- } \\
\text { cers in the toe area }(60.6 \%) \text { compared with control }(38.6 \%)(p .99)\end{array}$ \\
\hline $\begin{array}{l}\text { Baseline characteristics } \\
\text { similar (selection bias) }\end{array}$ & Unclear risk & $\begin{array}{l}\text { Comment: Higher proportion of participants in the intervention group had } \\
\text { type II diabetes }(86.2 \%) \text { compared with control }(71.6 \%)(p .99)\end{array}$ \\
\hline $\begin{array}{l}\text { Blinding of participants } \\
\text { and personnel (perfor- } \\
\text { mance bias) } \\
\text { All outcomes }\end{array}$ & High risk & Comment: Not possible to blind participants or healthcare professionals \\
\hline
\end{tabular}


Iversen 2018 (Continued)

Blinding of objective out- Low risk Comment: Electronic records (protocol) come assessment (detection bias)

\begin{tabular}{lll}
\hline $\begin{array}{l}\text { Blinding of subjective out- } \\
\text { come assessment (detec- } \\
\text { tion bias) }\end{array}$ & High risk & $\begin{array}{l}\text { Comment: Participants and healthcare professionals not blinded, self-report- } \\
\text { ed }\end{array}$ \\
\hline $\begin{array}{l}\text { Protection against conta- } \\
\text { mination }\end{array}$ & Unclear risk & Comment: Not enough information provided \\
\hline $\begin{array}{l}\text { Incomplete outcome data } \\
\begin{array}{l}\text { (attrition bias) } \\
\text { All outcomes }\end{array}\end{array}$ & Low risk & $\begin{array}{l}\text { Comment: No attrition for objective outcomes; high attrition for the subjective } \\
\text { outcome, intention-to-treat analysis }\end{array}$ \\
\hline $\begin{array}{l}\text { Selective reporting (re- } \\
\text { porting bias) }\end{array}$ & High risk & $\begin{array}{l}\text { Comment: Several outcomes mentioned in protocol and not reported (e.g. } \\
\text { quality of life, depression, anxiety) }\end{array}$ \\
\hline \begin{tabular}{l} 
Other bias \\
\hline
\end{tabular} & Low risk & Comment: No other apparent source of bias \\
\hline
\end{tabular}

Liddy 2019a

\section{Study characteristics}

Methods Study design: Randomised trial (parallel)

Unit of allocation: Participants (HCP)

\section{Participants}

\section{Providers}

Number: Randomised: IG: 57; CG: 56

Type: Primary care practitioners consulting with specialist physicians

Other relevant characteristics: PCP practicing in Ontario and not currently using eConsult. Mostly male (65\%), 20 years since graduation

\section{Participants}

Number: Specific number of participants not reported; each PCP allocated to IG saw on average 724 participants during the pre-intervention period (range 11 to 1692), whereas those in CG saw 828 participants during the same period (range 93 to 1971)

Mean age (SD): Not reported

Gender (\% female): Not reported

Inclusion criteria: Not reported

Exclusion criteria: Not reported

Other relevant characteristics: Not reported

Location and study setting: Ontario, Canada

Recruitment method: Eligible PCPs were sent an information pack and invited to participate by a third party; those interested could get directly in touch with the research team

Duration: Trial conducted between 31 January 2014 and 26 September 2014, 12 months follow-up from baseline 
Withdrawals: Approximately $12 \%$ of PCPs were not analysed at baseline and follow-up due to lack of referral data

Interventions

Intervention components: Champlain BASE ${ }^{\mathrm{TM}}$ eConsult service, a web-based application that the PCP used to submit participant-specific clinical questions to specialists. The specialists responded within 7 days, with recommendations, further questions, or recommendation for a face-to-face referral. Specialists received financial incentives for each eConsult they undertook

Comparison: Usual care - standard referral practices

Technical equipment used: The application could be accessed through smartphone, laptop or desktop; most users accessed it through their smartphones

Fidelity assessment: Participant PCPs underwent an orientation session and brief training, without which they could not access the system

Outcomes Main outcomes: Specialist referral rate per 100 participants seen to all medical specialties available through eConsult service

Other outcomes: Referral rate to all medical specialties

Time points reported: Baseline, follow-up

Notes Funding: Ontario Ministry of Health and Long-Term Care (MOHLTC) and Health Services Research Fund, Ministry Grant \#06547, Province of Ontario, Primary Health Care Program (INSPRE-PHC).

Ethical approval: Hospital Research Ethics Board and the Institutional Review Board. Trial registry NCT02053467

Conflicts of interest: None known

\begin{tabular}{lll}
\hline Risk of bias & & \\
\hline Bias & Authors' judgement & Support for judgement \\
\hline $\begin{array}{l}\text { Random sequence genera- } \\
\text { tion (selection bias) }\end{array}$ & Low risk & Comment: Computer-generated random list of numbers ("Randomization") \\
\hline $\begin{array}{l}\text { Allocation concealment } \\
\text { (selection bias) }\end{array}$ & Low risk & $\begin{array}{l}\text { Comment: Done by an independent research staff member, using opaque } \\
\text { sealed envelopes ("Randomization") }\end{array}$ \\
\hline $\begin{array}{l}\text { Baseline outcome mea- } \\
\text { surements similar (selec- } \\
\text { tion bias) }\end{array}$ & Low risk & $\begin{array}{l}\text { Comment: Baseline outcome measurements provided and similar between } \\
\text { groups, although IG had slightly lower referral rates at baseline (Table 2, Table } \\
\text { 3) }\end{array}$ \\
\hline $\begin{array}{l}\text { Baseline characteristics } \\
\text { similar (selection bias) }\end{array}$ & Low risk & $\begin{array}{l}\text { Comment: Baseline characteristics provided (Table 1); differences between } \\
\text { groups for model of practice and practice size, practice model and location ad- } \\
\text { justed for in the analysis }\end{array}$
\end{tabular}

\begin{tabular}{|c|c|c|}
\hline $\begin{array}{l}\text { Blinding of participants } \\
\text { and personnel (perfor- } \\
\text { mance bias) } \\
\text { All outcomes }\end{array}$ & High risk & Comment: Not possible due to the nature of the intervention \\
\hline $\begin{array}{l}\text { Blinding of objective out- } \\
\text { come assessment (detec- } \\
\text { tion bias) }\end{array}$ & Low risk & $\begin{array}{l}\text { Comment: Automatically extracted from electronic medical records ("Data } \\
\text { sources") }\end{array}$ \\
\hline $\begin{array}{l}\text { Protection against conta- } \\
\text { mination }\end{array}$ & Unclear risk & $\begin{array}{l}\text { Comment: PCPs were randomised to intervention and control groups; unclear } \\
\text { whether they could be located in the same practice }\end{array}$ \\
\hline
\end{tabular}


Liddy 2019a (Continued)

$\begin{array}{ll}\begin{array}{l}\text { Incomplete outcome data } \\ \text { (attrition bias) }\end{array} & \text { Comment: Authors note that for missing outcomes, due to limitations relat- } \\ \text { All outcomes } & \text { ed to the use of administrative health databases, they did not end up with } 50 \\ \text { providers per arm, resulting in an underpowered trial }\end{array}$

(attrition bias)

providers per arm, resulting in an underpowered trial

Selective reporting (re- Low risk Comment: Outcomes reported as per protocol

porting bias)

Other bias Low risk Comment: No other apparent source of bias

Mansberger 2015

\section{Study characteristics}

\begin{tabular}{ll}
\hline Methods & Study design: Randomised trial (parallel) \\
Unit of allocation: Participant
\end{tabular}

Participants Providers

Number: Primary care professionals not reported, 2 experienced investigators

Type: Primary care professionals consulting with experienced investigators based at an eye institute

\section{Other relevant characteristics:}

\section{Participants}

Number: Randomised: 567 (I: 296, C: 271), Analysed (12 months follow-up): same number

Mean age (SD): I: 50.2 years (12.3); C: 51.7 years (11.3)

Gender (\% female): I: $52 \%$; C: $51 \%$

Inclusion criteria: Adults diagnosed with diabetes who were scheduled to visit the primary care provider

Exclusion criteria: Cognitive impairment

Other relevant characteristics: On average, diagnosed with diabetes for 10 years. The overall prevalence of diabetic retinopathy $(21.5 \%)$ was lower than the national average $(28.5 \%)$

Location and study setting: USA, 2 primary care clinics

Recruitment method: Research assistants called potentially eligible patients and invited them to participate

Duration: Follow-up lasted 48 months; not reported when study was conducted

Withdrawals: $100 \%$ response rate at 12 months follow-up, approximately $76 \%$ response rate at 48 months follow-up

Intervention components: Telemedicine - digital images were captured with a non-mydriatic camera by clinic technicians and sent to a specialist for review and report generation. Technicians performing imaging attended a 3-day training session to learn how to take images and ongoing feedback as needed. Communication was done through private encrypted software, which transferred images and participant data to a secure database. Experienced investigators would receive an alert once the images were available, and grade them based on international standardised criteria, completing online reports that were automatically sent to clinic staff. Participants were also encouraged to see an eye care provider early as the camera-based exam is not considered to be a replacement for a comprehensive eye exam. Participants received monetary incentive to complete follow-up questionnaire 
Comparison: Usual care - during their primary care visit, participants were encouraged to see an eye care provider yearly. If a participant did not have an eye care provider, the primary care professional would refer them. The study investigators contacted all the providers the participants could be referred to, asking them to complete the same assessment forms as done for those allocated to the intervention group. Participants in this group were also offered telemedicine screening after 48 months enrolment

Technical equipment used: Digital non-mydriatic fundus camera (model NM-1000); Internal software for data transmission; Screen-Vu stereoscope

Fidelity assessment: Not reported

Outcomes

Main outcomes: Percentage of participants receiving annual diabetic retinopathy screening examinations; percentage of eyes with worsening diabetic retinopathy; percentage of telemedicine participants who would require referral to an eye care professional for follow-up care

Time points reported: Baseline, follow-up (12, 24, 36, and 48 months post-baseline)

\section{Notes}

Funding: National Eye Institute(NEI 3 K23 EY0155501-01), the Centers for Disease Control and Prevention (CDCU48DP000024-01 and 1U48DP002673-01), and the Good Samaritan Foundation at Legacy Health

Ethical approval: Institutional Review Boards of Legacy Health (Portland, OR), Oregon Health and Science University (Portland), and the Northwest Portland Area Indian Health Board (Portland). Trial registry: NCT01364129

Conflicts of interest: None known

\section{Risk of bias}

\begin{tabular}{|c|c|c|}
\hline Bias & Authors' judgement & Support for judgement \\
\hline $\begin{array}{l}\text { Random sequence genera- } \\
\text { tion (selection bias) }\end{array}$ & Low risk & $\begin{array}{l}\text { Quote: "We used a random number generator to randomly assign participants } \\
\text { to the telemedicine group or the traditional surveillance group" (p.519) }\end{array}$ \\
\hline $\begin{array}{l}\text { Allocation concealment } \\
\text { (selection bias) }\end{array}$ & Low risk & $\begin{array}{l}\text { Quote: "We used a random number generator to randomly assign participants } \\
\text { to the telemedicine group or the traditional surveillance group" (p.519) }\end{array}$ \\
\hline $\begin{array}{l}\text { Baseline outcome mea- } \\
\text { surements similar (selec- } \\
\text { tion bias) }\end{array}$ & Unclear risk & $\begin{array}{l}\text { Comment: Baseline measurements relating to service use outcome (i.e. previ- } \\
\text { ous attendance for screening) not reported. Baseline measurements relating } \\
\text { to the clinical outcome (diabetic retinopathy) not reported }\end{array}$ \\
\hline $\begin{array}{l}\text { Baseline characteristics } \\
\text { similar (selection bias) }\end{array}$ & Low risk & $\begin{array}{l}\text { Comment: Baseline characteristics reported and similar between groups (Ta- } \\
\text { ble 2) }\end{array}$ \\
\hline $\begin{array}{l}\text { Blinding of participants } \\
\text { and personnel (perfor- } \\
\text { mance bias) } \\
\text { All outcomes }\end{array}$ & High risk & $\begin{array}{l}\text { Comment: No information on blinding of central study personnel; not possible } \\
\text { to blind primary care providers as they conducted the screening examinations; } \\
\text { not possible to blind participants who received examinations in different set- } \\
\text { tings }\end{array}$ \\
\hline $\begin{array}{l}\text { Blinding of objective out- } \\
\text { come assessment (detec- } \\
\text { tion bias) }\end{array}$ & High risk & $\begin{array}{l}\text { Comment: Due to the nature of the intervention it was not possible to blind } \\
\text { participants or personnel }\end{array}$ \\
\hline $\begin{array}{l}\text { Protection against conta- } \\
\text { mination }\end{array}$ & Unclear risk & Comment: No specific mention of measures to prevent contamination \\
\hline $\begin{array}{l}\text { Incomplete outcome data } \\
\text { (attrition bias) } \\
\text { All outcomes }\end{array}$ & Low risk & Comment: Low attrition rates for first 2 data points. \\
\hline
\end{tabular}


Mansberger 2015 (Continued)

Selective reporting (re- Unclear risk Comment: Telemedicine was offered exclusively to the telemedicine group porting bias) only to 2 years after recruitment. At 2 years standard-care group also offered telemedicine. Yet follow-up of exclusive telemedicine reported only to 18 months. Outcomes for worsening retinopathy reported for intervention and control groups combined

Other bias

High risk

Comment: Data collection methods differed for the 2 study groups. Whereas outcome data (screening attendance and clinical) in the telemedicine group were recorded by study staff (telemedical assessors, both report authors), the study relies upon eye-care professionals in the community to report these for the standard care group. The researchers telephoned the community eye-care professionals to introduce the project and request their participation in completing data collection forms for the study. It is uncertain how community eyecare professional would know who was recruited in the study. Researchers also reviewed medical charts to search for eye examination data

Orlandoni 2016

Study characteristics

Methods

Study design: Randomised trial (parallel)

Unit of allocation: Participant

Participants

Providers

Number: Not reported

Type: Home-visiting nursing staff consulting with a hospital physician

Other relevant characteristics: Not reported

Participants

Number: Randomised: 188 (I: 100, C: 88), Analysed: unclear

Mean age (SD): I. 86.5 (7.0), C: 84.4 (7.1)

Gender (\% female): I: $72 \%$; C: $76 \%$

Inclusion criteria: Adults aged $\geq 65$ years, attending the Department of Clinical Nutrition, treated with home enteral nutrition

Exclusion criteria: Not reported

Other relevant characteristics: Most had multiple morbidities

Location and study setting: Italy, 1 hospital

Recruitment method: Not reported

Duration: Intervention lasted 12 months; study conducted between January and December 2013

Withdrawals: $38 \%$ and $33 \%$ of participants were lost to follow-up (I and C, respectively), reasons not provided

Interventions

Intervention components: Usual care plus video consultation - during the monthly home visits, the home-visiting staff called the hospital physician using the tablet. The latter would visually examine the participant for different clinical signs (e.g. hydration, oedema). Video calls lasted on average 2 minutes. If necessary, nutrition and pharmacological therapy would be adjusted 
Comparison: Usual care - regular monthly home visits done by nurses to perform scheduled evaluations, which included an electrocardiogram, pulse oximetry, and blood glucose and pressure measurement. Data collected were logged online and reviewed by the hospital physician 2 to 3 days after the visit

Technical equipment used: Tablet (Samsung Galaxy)

Fidelity assessment: Video-consultation followed a specific protocol; no further details provided

$\begin{array}{ll}\text { Outcomes } & \text { Main outcomes: Frequency and type of complications; frequency and reason for outpatient visits and } \\ \text { hospitalisations; modification of nutrition therapy; frequency and duration of video-consultations (in- } \\ \text { tervention group only) }\end{array}$

Time points reported: Baseline, follow-up (12 months post-baseline)

\begin{tabular}{ll}
\hline Notes & Funding: Not reported \\
& Ethical approval: Hospital Ethics Committee
\end{tabular}

Conflicts of interest: None known

\section{Risk of bias}

\begin{tabular}{lll}
\hline Bias & Authors' judgement & Support for judgement \\
\hline $\begin{array}{l}\text { Random sequence genera- } \\
\text { tion (selection bias) }\end{array}$ & Low risk & $\begin{array}{l}\text { Quote: "Block randomisation (...) was carried out by the statistical service of } \\
\text { [the hospital] using computer-generated allocation" (p.763) }\end{array}$ \\
\hline $\begin{array}{l}\text { Allocation concealment } \\
\text { (selection bias) }\end{array}$ & Low risk & Comment: Block randomisation was used \\
\hline $\begin{array}{l}\text { Baseline outcome mea- } \\
\text { surements similar (selec- } \\
\text { tion bias) }\end{array}$ & Low risk & $\begin{array}{l}\text { Comment: Baseline medical measurements that could impact the clinical out- } \\
\text { come (main indicators of nutritional status, comorbidities, general health sta- } \\
\text { tus) reported and similar between groups (Table 1) }\end{array}$ \\
\hline $\begin{array}{l}\text { Baseline characteristics } \\
\text { similar (selection bias) }\end{array}$ & Low risk & $\begin{array}{l}\text { Comment: Baseline characteristics provided and overall similar between } \\
\text { groups; participants allocated to intervention were slightly older than those al- } \\
\text { located to control }\end{array}$
\end{tabular}

\begin{tabular}{lll}
\hline $\begin{array}{l}\text { Blinding of participants } \\
\text { and personnel (perfor- } \\
\text { mance bias) } \\
\text { All outcomes }\end{array}$ & High risk & Comment: Not possible to blind participants and personnel \\
\hline $\begin{array}{l}\text { Blinding of objective out- } \\
\text { come assessment (detec- } \\
\text { tion bias) }\end{array}$ & High risk & $\begin{array}{l}\text { Comment: Main outcome is overall complications. The home-visit staff, who } \\
\text { were not blinded, collected the outcome data }\end{array}$ \\
\hline $\begin{array}{l}\text { Protection against conta- } \\
\text { mination }\end{array}$ & Unclear risk & $\begin{array}{l}\text { Comment: Contamination between groups is possible as all home-visiting staff } \\
\text { and physicians had tablets which could be used with control participants }\end{array}$ \\
\hline $\begin{array}{l}\text { Incomplete outcome data } \\
\begin{array}{l}\text { (attrition bias) } \\
\text { All outcomes }\end{array}\end{array}$ & High risk & Comment: High rates of attrition, not explained \\
\hline $\begin{array}{l}\text { Selective reporting (re- } \\
\text { porting bias) }\end{array}$ & Low risk & Comment: All outcomes presented in the Methods are reported in the Results \\
\hline \begin{tabular}{l} 
Other bias \\
\hline
\end{tabular} & Low risk & Comment: No other apparent source of bias \\
\hline
\end{tabular}




\section{Study characteristics}

\begin{tabular}{ll}
\hline Methods & Study design: Randomised trial (parallel) \\
& Unit of allocation: Participant \\
\hline Participants & Providers
\end{tabular}

Participants

\section{Providers}

Number: Not reported

Type: Primary care professional consulting with dermatologist

Other relevant characteristics: Not reported

\section{Participants}

Number: Randomised: 698 (I: 351, C: 347), Analysed: 508: 236 in usual care and 272 in teledermatology

Mean age (SD): I: 43.6 years; C: 46.8 years

Gender (\% female): I: $71 \%$; : $66 \%$

Inclusion criteria: Adults referred from Department of Defence primary care clinics

Exclusion criteria: Urgent condition, multiple complaints

Other relevant characteristics: Mainly white

Location and study setting: USA, 4 primary care clinics (Department of Defence owned)

Recruitment method: Eligible participants were invited to participate

Duration: Single consultation with 4 months follow-up; not reported when study was conducted

Withdrawals: $33 \%$ of randomised participants did not complete follow-up: $15 \%$ were withdrawn, mainly due to deployment or loss of privileges; $6 \%$ withdrew, mainly due to resolution of skin problem; $4 \%$ could not be contacted and were lost to follow-up done. A dermatologist would then review the consultation and the images, and could either schedule a face-to-face appointment with the participant or send a diagnosis and management plan to the primary care professional

Comparison: Usual care - a dermatology appointment was scheduled at a clinic

Technical equipment used: Digital camera (Coolpix 990, 3.3 megapixel); images were transferred using a web-based secure server purposively developed

Fidelity assessment: Data

Outcomes

Main outcomes: Clinical improvement based on serial cutaneous examination; costs

Time points reported: Baseline, post-intervention (4 months post-baseline) 
Pak 2007 (Continued)

matology: A user's guide, published by Cambridge University Press, and is slated to receive royalties based on sales."

\section{Risk of bias}

\begin{tabular}{|c|c|c|}
\hline Bias & Authors' judgement & Support for judgement \\
\hline $\begin{array}{l}\text { Random sequence genera- } \\
\text { tion (selection bias) }\end{array}$ & Low risk & Comment: Authors report that block randomisation was used (p.27) \\
\hline $\begin{array}{l}\text { Allocation concealment } \\
\text { (selection bias) }\end{array}$ & Low risk & $\begin{array}{l}\text { Comment: Following informed consent the sealed envelope was opened to re- } \\
\text { veal the randomisation assignment }\end{array}$ \\
\hline $\begin{array}{l}\text { Baseline outcome mea- } \\
\text { surements similar (selec- } \\
\text { tion bias) }\end{array}$ & Unclear risk & Comment: Not enough information provided \\
\hline $\begin{array}{l}\text { Baseline characteristics } \\
\text { similar (selection bias) }\end{array}$ & High risk & $\begin{array}{l}\text { Comment: Partciipants allocated to the control group were older than those } \\
\text { allocated to intervention group (Table } 1 \text { ) }\end{array}$ \\
\hline $\begin{array}{l}\text { Blinding of participants } \\
\text { and personnel (perfor- } \\
\text { mance bias) } \\
\text { All outcomes }\end{array}$ & High risk & $\begin{array}{l}\text { Comment: Not possible to blind participants or personnel as care pathway was } \\
\text { different }\end{array}$ \\
\hline $\begin{array}{l}\text { Blinding of objective out- } \\
\text { come assessment (detec- } \\
\text { tion bias) }\end{array}$ & Low risk & Comment: Calculated using repayment rates \\
\hline $\begin{array}{l}\text { Blinding of subjective out- } \\
\text { come assessment (detec- } \\
\text { tion bias) }\end{array}$ & Low risk & $\begin{array}{l}\text { Quote: "A dermatologist blinded to randomisation assignment reviewed the } \\
\text { images." (p.27) }\end{array}$ \\
\hline $\begin{array}{l}\text { Protection against conta- } \\
\text { mination }\end{array}$ & Unclear risk & $\begin{array}{l}\text { Comment: No information on strategies to prevent contamination or evidence } \\
\text { suggesting contamination }\end{array}$ \\
\hline $\begin{array}{l}\text { Incomplete outcome data } \\
\text { (attrition bias) } \\
\text { All outcomes }\end{array}$ & High risk & Comment: High attrition rates \\
\hline $\begin{array}{l}\text { Selective reporting (re- } \\
\text { porting bias) }\end{array}$ & High risk & Comment: Outcomes reported in different papers \\
\hline Other bias & Low risk & Comment: No other apparent risk of bias \\
\hline
\end{tabular}

\section{Piette 2017}

\section{Study characteristics}

Study design: Cluster-randomised trial (parallel assignment)
Unit of allocation: Cluster (8 primary care practices, 4 allocated to the intervention group and 4 allo-
cated to the control group)

Participants Providers

Number: 39 GPs, 3 dermatologists 
Type: GPs consulting with dermatologists

Other relevant characteristics: Not reported

\section{Participants}

Number: Randomised: 109 (I:55, C:54), Analysed: 103 (I:53, C:50)

Mean age: I: 44 years; C: 43.5 years

Gender (\% female): I: $70 \%$; C: $50 \%$

Inclusion criteria: Adults with a skin condition for which the GP required a dermatologist's advice

Exclusion criteria: Urgent medical care

Other relevant characteristics: Not reported

Location and study setting: France, 8 urban primary care practices

Recruitment method: Participants identified by the GPs and invited to participate

Duration: Single session; 90 days follow-up

Withdrawals: $5.5 \%$ of participants were excluded after being assessed as eligible (reasons provided)

Interventions

Intervention components: GPs received training and a workbook on how to take photographs (p.2, top 2nd column). GPs took at least 3 photos of skin lesions and sent them with a standardised written message (date of symptoms, symptomatology, topography, description and extension of lesions, drug intake) through secure e-mail to dermatologists. Dermatologists provided a diagnosis or possible differential diagnoses, and if necessary a management plan, which was implemented by the GP. The dermatologists could also book an appointment to see the participant in person

Comparison: Usual care - participants were given a standardised printed referral letter, which they could use to book an appointment with a dermatologist

Technical equipment used: Photos were taken using either a mobile phone or digital camera (minimum 3 megapixels)

Fidelity assessment: GPs received 2 hours training on how to take photos and were given a workbook explaining the detailed procedures to take photos compliant with the American Telemedicine Association recommendations

Outcomes Main outcomes: Days lapsed between the GP's consultation and the dermatologist's reply that allowed for the GP to begin treatment; participant's satisfaction; physicians' and participants' satisfaction; number of non-usable photographs taken

Time points reported: Post-intervention (3 months post-baseline)

Notes $\quad$ Funding: Pole de Santé Universitaire Gennevilliers Villeneuve la Garenne

Ethical approval: Hospital Institutional Review Board. Trial registry: NCT02122432

Conflicts of interest: None known

\section{Risk of bias}

\begin{tabular}{lll}
\hline Bias & Authors' judgement & Support for judgement \\
\hline $\begin{array}{l}\text { Random sequence genera- } \\
\text { tion (selection bias) }\end{array}$ & Low risk & Comment: Computer-generated random list (p.2) \\
\hline
\end{tabular}


Piette 2017 (Continued)

Allocation concealment Low risk Comment: Investigator generated the list at the start of the study for all prima(selection bias) ry practices; investigator did not have contact with physicians or participants (p.2)

Baseline outcome measurements similar (selection bias)

\section{Baseline characteristics High risk \\ similar (selection bias)}

Unclear risk

Comment: Not enough information provided

Blinding of participants and personnel (perfor-

High risk

mance bias)

All outcomes

Blinding of objective outcome assessment (detection bias)

High risk Comment: Days between consultations reported by the participant, who was not blinded to group allocation

Comment: Baseline characteristics provided, groups different for sex distribution and dermatologist final diagnosis (Table 1 )

Comment: Participants, GPs, and study personnel were not blinded to group allocation (p.2)

\begin{tabular}{lll}
\hline $\begin{array}{l}\text { Blinding of subjective out- } \\
\text { come assessment (detec- }\end{array}$ & High risk & $\begin{array}{l}\text { Comment: Reported by GPs and participants who were not blinded to group } \\
\text { allocation, and dermatologists (intervention group only) }\end{array}$ \\
\hline
\end{tabular}
tion bias) allocation, and dermatologists (intervention group only)

Protection against conta- Low risk Comment: Allocation by GP practices
mination

mination

Incomplete outcome data Low risk Comment: Low attrition rates (Figure 1)
(attrition bias)
All outcomes

\begin{tabular}{lll}
\hline $\begin{array}{l}\text { Selective reporting (re- } \\
\text { porting bias) }\end{array}$ & Low risk & $\begin{array}{l}\text { Comment: All outcomes specified in the protocol were reported in the pub- } \\
\text { lished article }\end{array}$ \\
\hline Other bias & Low risk & Comment: No other apparent risk of bias \\
\hline
\end{tabular}

Riordan 2015

\section{Study characteristics}

\begin{tabular}{ll}
\hline Methods & Study design: Randomised trial (cross-over) \\
Unit of allocation: Participant
\end{tabular}

Participants

\section{Providers}

Number: 8 emergency department (ED) residents

Type: ED residents consulting with consultants

Other relevant characteristics: Not reported

\section{Participants}

Number: Not reported

Mean age (SD): Not reported 
Gender (\% female): Not reported

Inclusion criteria: Adults attending the ED

Exclusion criteria: Not reported

Other relevant characteristics: Not reported

Location and study setting: USA, 1 ED

Recruitment method: Not reported

Duration: Single consultation with 1 month follow-up; not reported when study was conducted

Withdrawals: Not reported

Interventions

Intervention components: Electronic consultation application, used by the ED resident to communicate with consultants

Comparison: Usual care

Technical equipment used: Tablets (iPad)

Fidelity assessment: Not reported

Outcomes

Main outcomes: Conciseness; pertinence of information presented; flow; effectiveness of communication skills; overall quality of physician to physician consultations

Time points reported: Post-intervention (1 month post-baseline)

\begin{tabular}{|c|c|c|}
\hline Notes & \multicolumn{2}{|c|}{$\begin{array}{l}\text { Funding: Not reported } \\
\text { Ethical approval: Not reported } \\
\text { Conflicts of interest: Not reported }\end{array}$} \\
\hline \multicolumn{3}{|l|}{ Risk of bias } \\
\hline Bias & Authors' judgement & Support for judgement \\
\hline $\begin{array}{l}\text { Random sequence genera- } \\
\text { tion (selection bias) }\end{array}$ & Unclear risk & Comment: Not enough information provided \\
\hline $\begin{array}{l}\text { Allocation concealment } \\
\text { (selection bias) }\end{array}$ & Unclear risk & Comment: Not enough information provided \\
\hline $\begin{array}{l}\text { Baseline outcome mea- } \\
\text { surements similar (selec- } \\
\text { tion bias) }\end{array}$ & Unclear risk & Comment: Not enough information provided \\
\hline $\begin{array}{l}\text { Baseline characteristics } \\
\text { similar (selection bias) }\end{array}$ & Unclear risk & Comment: Not enough information provided \\
\hline $\begin{array}{l}\text { Blinding of participants } \\
\text { and personnel (perfor- } \\
\text { mance bias) } \\
\text { All outcomes }\end{array}$ & Unclear risk & Comment: Not enough information provided \\
\hline $\begin{array}{l}\text { Blinding of objective out- } \\
\text { come assessment (detec- } \\
\text { tion bias) }\end{array}$ & Unclear risk & Comment: Not enough information provided \\
\hline
\end{tabular}


Riordan 2015 (Continued)

Blinding of subjective out- Unclear risk Comment: Not enough information provided come assessment (detection bias)

Protection against conta- Unclear risk Comment: Not enough information provided
mination

Incomplete outcome data Unclear risk Comment: Not enough information provided

(attrition bias)

All outcomes

Selective reporting (re- Unclear risk Comment: Not enough information provided
porting bias)

Other bias Unclear risk Comment: Not enough information provided

Sutherland 2009

\section{Study characteristics}

\begin{tabular}{ll}
\hline Methods & Study design: Randomised trial (parallel) \\
& Unit of allocation: Participant \\
\hline
\end{tabular}

Participants

\section{Providers}

Number: 1 primary care physician, 6 radiologists

Type: Primary care physician consulting with radiologists

Other relevant characteristics: Primary care physician received sonographic training at 3 US medical centres

\section{Participants}

Number: Randomised: 105 (I: 53, C: 52), Analysed: same number

Mean age (SD): I: 27 years; C: 29 years

Gender (\% female): I: 90 ; C: $94 \%$

Inclusion criteria: Participants aged $\geq 13$ years attending a primary care clinic, with symptoms requiring a trans-abdominal or trans-vaginal ultrasound

Exclusion criteria: Not reported

Other relevant characteristics: Low-income setting

Location and study setting: Dominican Republic, 1 rural clinic

Recruitment method: All eligible patients were invited to participate

Duration: Intervention was 1 consultation; not reported when study was conducted

Withdrawals: No withdrawals guidelines, which were then emailed to US-based radiologists along with forms with any relevant clinical information. The on-site investigator received sonographic training over a 2-month period, as well as practice guidelines for trans-abdominal ultrasound scanning. The radiologists interpreted the scans 
Sutherland 2009 (Continued)

and returned the forms, along with an assessment of the scan's quality. Participants were instructed to return to the primary care clinic within 48 hours

Comparison: Usual care - received regular ultrasound referral and were instructed to return the diagnostic report in hand as soon as possible

Technical equipment used: Portable ultrasound scanner (SonoSite Titan with $5.2 \mathrm{MHz}$ curvilinear transducer), images sent by email as attachment

Fidelity assessment: Not reported

Outcomes Main outcomes: Time to final diagnosis; time to follow-up appointments; number of successful fol-
low-ups; number of delivered reports

Time points reported: Post-intervention

Notes $\quad$ Funding: Global Health Leadership Fellowship, sponsored by the Edward Via Virginia College of Osteo-
pathic Medicine

Ethical approval: Appropriate ethics committee

Conflicts of interest: Not reported

\section{Risk of bias}

\begin{tabular}{|c|c|c|}
\hline Bias & Authors' judgement & Support for judgement \\
\hline $\begin{array}{l}\text { Random sequence genera- } \\
\text { tion (selection bias) }\end{array}$ & High risk & Comment: Coin tossing (p.192) \\
\hline $\begin{array}{l}\text { Allocation concealment } \\
\text { (selection bias) }\end{array}$ & High risk & Comment: Coin tossing is at high risk of allocation being predictable. \\
\hline $\begin{array}{l}\text { Baseline outcome mea- } \\
\text { surements similar (selec- } \\
\text { tion bias) }\end{array}$ & Unclear risk & Comment: Not enough information provided \\
\hline $\begin{array}{l}\text { Baseline characteristics } \\
\text { similar (selection bias) }\end{array}$ & Unclear risk & Comment: Not enough information provided \\
\hline $\begin{array}{l}\text { Blinding of participants } \\
\text { and personnel (perfor- } \\
\text { mance bias) } \\
\text { All outcomes }\end{array}$ & High risk & $\begin{array}{l}\text { Comment: Only } 1 \text { primary care physician, not possible to blind; participants } \\
\text { were aware of group allocation as it implied different actions }\end{array}$ \\
\hline $\begin{array}{l}\text { Blinding of objective out- } \\
\text { come assessment (detec- } \\
\text { tion bias) }\end{array}$ & Low risk & $\begin{array}{l}\text { Comment: The radiologists were blinded from one another's interpretations } \\
\text { (p.194) }\end{array}$ \\
\hline $\begin{array}{l}\text { Protection against conta- } \\
\text { mination }\end{array}$ & Low risk & Comment: Not possible for contamination to occur \\
\hline $\begin{array}{l}\text { Incomplete outcome data } \\
\text { (attrition bias) } \\
\text { All outcomes }\end{array}$ & Low risk & Comment: No attrition \\
\hline $\begin{array}{l}\text { Selective reporting (re- } \\
\text { porting bias) }\end{array}$ & Low risk & $\begin{array}{l}\text { Comment: All outcomes mentioned in the Methods are reported in the Results } \\
\text { section }\end{array}$ \\
\hline Other bias & Low risk & Comment: No other apparent risk of bias \\
\hline
\end{tabular}




\section{Study characteristics}

\begin{tabular}{ll}
\hline Methods & Study design: Randomised trial (parallel) \\
& Unit of allocation: Participant \\
\hline
\end{tabular}

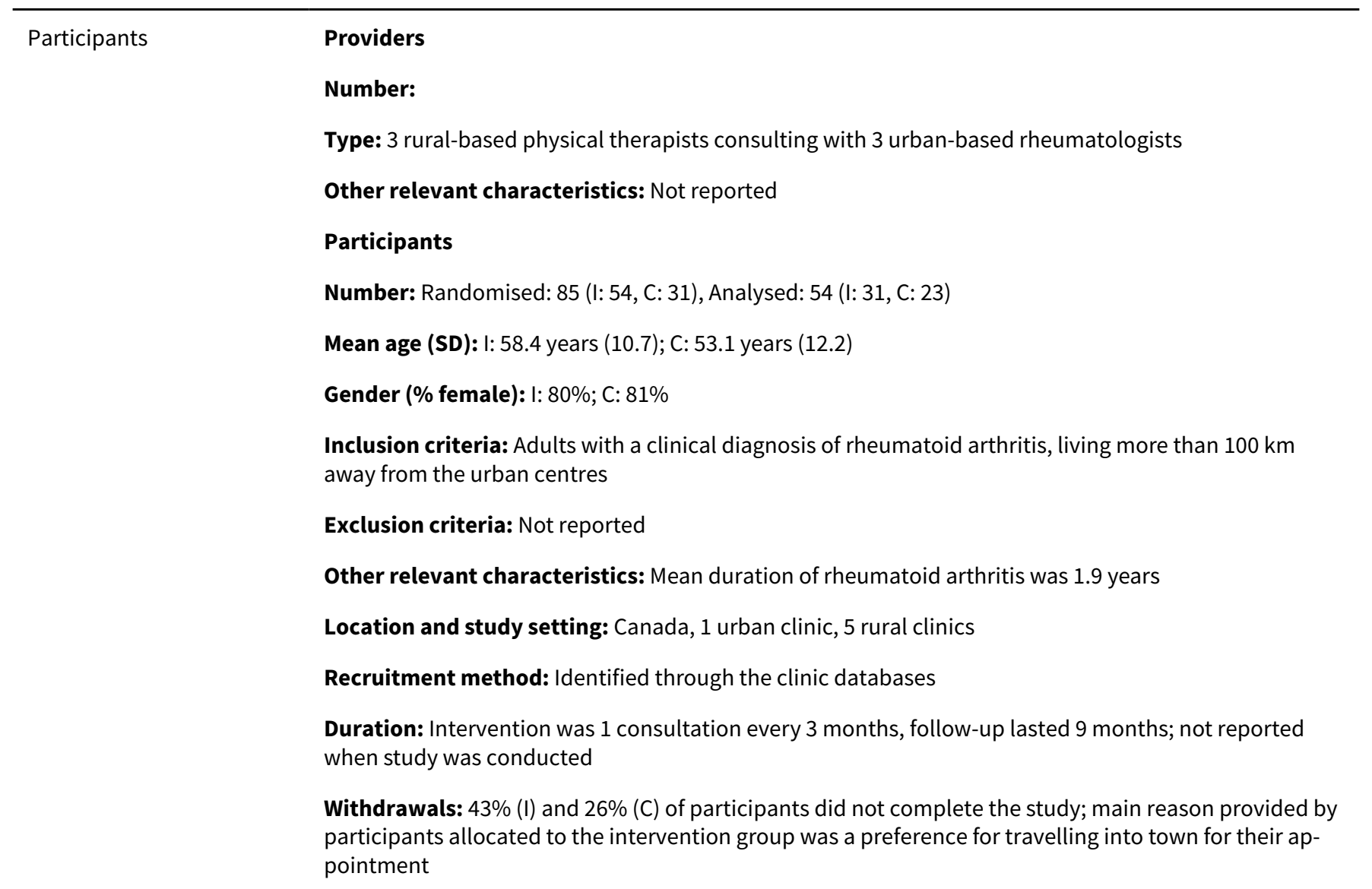

Intervention components: Video-consultations between physical therapist and rheumatologist; the participants were present for part of the consultation, during which they were examined by the rheumatologist. Physical therapists and rheumatologists received an orientation and education session about rheumatoid arthritis and the study protocol and methods

Comparison: Usual care - in-person rheumatology clinics

Technical equipment used: Laptops with video-conferencing software (VidyoDesktop software); detachable external web camera with remote pan, tilt and zoom functions

Fidelity assessment: All healthcare professionals attended an education session about the study protocol

\section{Outcomes}

Main outcomes: Disease activity metrics; health assessment; participant satisfaction

Time points reported: Baseline, post-intervention (9 months post-baseline)

\section{Notes}

Funding: Canadian Initiative for Outcomes in Rheumatology cAre (CIORA)

Ethical approval: University of Saskatchewan Biomedical Research Ethics Board; trial registry NCT02371915 
Taylor-Gjevre 2018 (Continued)

Conflicts of interest: Not reported

\section{Risk of bias}

\begin{tabular}{lll}
\hline Bias & Authors' judgement & Support for judgement \\
\hline $\begin{array}{l}\text { Random sequence genera- } \\
\text { tion (selection bias) }\end{array}$ & Low risk & Quote: "[S]tratified block randomisation algorithm" (p.2) \\
\hline $\begin{array}{l}\text { Allocation concealment } \\
\text { (selection bias) }\end{array}$ & Low risk & $\begin{array}{l}\text { Quote: "Clinicians were not involved in or aware of the outcome of the ran- } \\
\text { domisation allocation, which was overseen by the research coordinator" (p.2) }\end{array}$ \\
\hline $\begin{array}{l}\text { Baseline outcome mea- } \\
\text { surements similar (selec- } \\
\text { tion bias) }\end{array}$ & Low risk & $\begin{array}{l}\text { Comment: Baseline outcome measurements reported and similar between } \\
\text { groups (Fig. 2) }\end{array}$ \\
\hline
\end{tabular}

Baseline characteristics Low risk

similar (selection bias)

$\begin{array}{lll}\begin{array}{l}\text { Blinding of participants } \\ \text { and personnel (perfor- }\end{array} & \text { High risk } & \begin{array}{l}\text { Comment: Due to the nature of the intervention participants and personnel } \\ \text { could not have been blinded and no attempts at blinding were described }\end{array}\end{array}$

mance bias)

All outcomes

\section{Blinding of objective out- High risk come assessment (detec-} tion bias)

Blinding of subjective out- High risk come assessment (detection bias)

\begin{tabular}{|c|c|c|}
\hline $\begin{array}{l}\text { Protection against conta- } \\
\text { mination }\end{array}$ & Unclear risk & $\begin{array}{l}\text { Comment: Many of the dropouts were reportedly due to preference for stan- } \\
\text { dard treatment }\end{array}$ \\
\hline
\end{tabular}

Comment: Physical examination data were collected by on-site physical therapists and by urban rheumatologists, due to the nature of the intervention they could not have been blinded

Comment: Self-reported outcomes were quality of life and satisfaction with care, and participants were not blinded

\begin{tabular}{lll}
\hline $\begin{array}{l}\text { Incomplete outcome data } \\
\text { (attrition bias) } \\
\text { All outcomes }\end{array}$ & High risk & Comment: High attrition rates \\
\hline $\begin{array}{l}\text { Selective reporting (re- } \\
\text { porting bias) }\end{array}$ & High risk & $\begin{array}{l}\text { Comment: Reports all outcomes mentioned in Methods section of paper, but } \\
\text { not all outcomes stated in online trial record (NCT02371915), e.g. change in } \\
\text { healthcare use }\end{array}$ \\
\hline Other bias & Low risk & Comment: No other apparent risk of bias \\
\hline
\end{tabular}

Van Gelder 2017

\section{Study characteristics}

Study design: Cluster-randomised trial (parallel)
Unit of allocation: Cluster ( 47 primary care practices, 23 allocated to the intervention group and 24 to
the control group)

Participants $\quad$ Providers
Number: 128 GPs (number of nephrologists not provided)

Mobile technologies to support healthcare provider to healthcare provider communication and management of care (Review) 
Van Gelder 2017 (Continued)

Type: GPs consulting with nephrologists

Other relevant characteristics: Not reported

Participants

Number: I: 1277; C: 1727

Mean age (SD): I: 68.0 years (13.6); C: 66.4 years (13.2)

Gender ( $\%$ female): I: $67 \%$; C: $65 \%$

Inclusion criteria: Adults with a clinical diagnosis of chronic kidney disease who qualified for consultation or referral to nephrology specialist care

Exclusion criteria: Receiving secondary renal care

Other relevant characteristics: Most had at least 1 comorbid chronic condition

Location and study setting: The Netherlands, 47 primary care practices across the country

Recruitment method: GPs were invited to participate while attending a CKD management course; eligible patients were identified through EMR

Duration: Intervention was implemented between March 2011 and June 2012; follow-up duration unclear

Withdrawals: Approximately $3 \%$ of eligible patients did not start the trial (reasons provided); $7.7 \%$ of participants did not complete follow-up (deceased: $n=181$; moved: $n=50$; unknown: $n=1$ )

Intervention components: Telenephrology was added to the EMR as an add-on application, which was activated by the GP for each specific participant. The nephrologist was then notified about the consultation by e-mail or text message and advised the GP about further treatment required, including referrals if needed

Comparison: Usual care - conventional consultation methods

Technical equipment used: Encrypted EMR, accessed with a direct single sign-on

Fidelity assessment: Not reported

Outcomes Main outcomes: Difference in referral rate between intervention and control groups

Other outcomes: Difference in consultation rates by telephone or telenephrology; adherence to the advised monitoring criteria; GP's compliance with coding renal impairment as a separate entity; achievement of blood pressure targets; main related medical costs; incidence of CKD; GPs experience with using telenephrology

Time points reported: Unclear

Funding: Dutch Kidney Foundation and Amgen

Ethical approval: Not required according to the accredited Medical Research Ethics Committee Arnhem/Nijmegen. Clinicians and participants were informed electronic medical data were being used for research purposes and could opt-out. Netherlands Trial Registration 2242

Conflicts of interest: "The Department of Primary and Community Care received a non-conditional grant from Amgen. Jack Wetzels received research grants from Amgen, Genzyme and Pfizer for the Masterplan study. All other authors have no conflicting interests"

\section{Risk of bias}

\section{Bias}

\section{Authors' judgement Support for judgement}


Van Gelder 2017 (Continued)

Random sequence genera- $\quad$ Low risk $\quad$ Comment: Stratified block randomisation (p.432)
tion (selection bias)

\begin{tabular}{ll}
\hline $\begin{array}{l}\text { Allocation concealment } \\
\text { (selection bias) }\end{array}$ & Low risk
\end{tabular}

\begin{tabular}{|c|c|c|}
\hline $\begin{array}{l}\text { Baseline outcome mea- } \\
\text { surements similar (selec- } \\
\text { tion bias) }\end{array}$ & Unclear risk & Comment: Not enough information provided to make a decision \\
\hline $\begin{array}{l}\text { Baseline characteristics } \\
\text { similar (selection bias) }\end{array}$ & Low risk & $\begin{array}{l}\text { Comment: Baseline characteristics provided and similar between groups (ta- } \\
\text { ble 1) }\end{array}$ \\
\hline $\begin{array}{l}\text { Blinding of participants } \\
\text { and personnel (perfor- } \\
\text { mance bias) } \\
\text { All outcomes }\end{array}$ & High risk & $\begin{array}{l}\text { Comment: Due to the nature of the intervention participants and personnel } \\
\text { could not have been blinded and no attempts at blinding were described }\end{array}$ \\
\hline $\begin{array}{l}\text { Blinding of objective out- } \\
\text { come assessment (detec- } \\
\text { tion bias) }\end{array}$ & High risk & $\begin{array}{l}\text { Comment: All referrals were reported by both the GPs and the nephrologists in } \\
\text { an online survey system }\end{array}$ \\
\hline $\begin{array}{l}\text { Blinding of subjective out- } \\
\text { come assessment (detec- } \\
\text { tion bias) }\end{array}$ & High risk & $\begin{array}{l}\text { Comment: GPs in the intervention group answered a survey about their experi- } \\
\text { ence with the intervention ( } \mathrm{p.432)}\end{array}$ \\
\hline $\begin{array}{l}\text { Protection against conta- } \\
\text { mination }\end{array}$ & High risk & $\begin{array}{l}\text { Comment: GPs allocated to the CG participated in a training course about CKD } \\
\text { (p.435) }\end{array}$ \\
\hline $\begin{array}{l}\text { Incomplete outcome data } \\
\text { (attrition bias) } \\
\text { All outcomes }\end{array}$ & Low risk & Comment: Low attrition rates \\
\hline $\begin{array}{l}\text { Selective reporting (re- } \\
\text { porting bias) }\end{array}$ & Low risk & $\begin{array}{l}\text { Comment: All outcomes specified in the protocol were reported in the pub- } \\
\text { lished article }\end{array}$ \\
\hline Other bias & Low risk & Comment: No other apparent risk of bias \\
\hline
\end{tabular}

Whited 2002

\section{Study characteristics}

\begin{tabular}{ll}
\hline Methods & Study design: Randomised trial (parallel) \\
& Unit of allocation: Participant \\
\hline Participants & Providers \\
& Number: $60 \mathrm{GPs}, 8$ dermatologists \\
& Type: GPs consulting with dermatologists \\
& Other relevant characteristics: Dermatologists were mainly third-year residents \\
& Participants \\
& Number: Randomised: 274 (I: 134, C: 140), Analysed: ITT analysis
\end{tabular}


Whited 2002 (Continued)

Mean age (SD): I: 60.9 years (7.8); C: 66.9 years (8.5)

Gender (\% female): $5 \%$

Inclusion criteria: Adults referred to the Dermatology service from primary care clinics

Exclusion criteria: Urgent conditions that required immediate attention

Other relevant characteristics: Mainly white

Location and study setting: USA, 4 clinics at a Veteran Affairs Medical Centre

Recruitment method: Not reported

Duration: 1 consultation/referral; not reported when study was conducted

Withdrawals: Not reported

Interventions

Intervention components: GPs submitted digital images of skin lesions with a standardised medical history and any additional relevant information. The consultant dermatologist reviewed all the data and replied either by scheduling a clinic-based appointment or sending a diagnosis and management plan to the GP, without further need for a clinic-based appointment

Comparison: Usual care - GPs referred participants to the dermatology service as needed

Technical equipment used: Fujix DS-515 digital camera

Fidelity assessment: As a quality-control measure, images were assessed on a laptop computer while acquiring them

Outcomes

Main outcomes: Time to intervention; costs; participant and healthcare professional satisfaction

Time points reported: Baseline, resolution of the problem (variable)

Notes

Funding: VA Health Services Research and Development Service and VA Health Services Research and Development Service

Research Career Development Award

Ethical approval: Research and Development Committee and the Human Studies Subcommittee of the Department of Veterans Affairs Medical Center, Durham, North Carolina

Conflicts of interest: Not reported

\section{Risk of bias}

\begin{tabular}{lll}
\hline Bias & Authors' judgement & Support for judgement \\
\hline $\begin{array}{l}\text { Random sequence genera- } \\
\text { tion (selection bias) }\end{array}$ & Unclear risk & Comment: Not enough information provided \\
\hline $\begin{array}{l}\text { Allocation concealment } \\
\text { (selection bias) }\end{array}$ & Low risk & $\begin{array}{l}\text { Quote: "Referring primary care clinicians contacted the research assistants } \\
\text { during the course of clinic visits when a dermatology consult was consid- } \\
\text { ered appropriate. Research assistants were blinded to the study arm in which } \\
\text { prospective patients were randomised." (p.314) }\end{array}$ \\
\hline $\begin{array}{l}\text { Baseline outcome mea- } \\
\text { surements similar (selec- } \\
\text { tion bias) }\end{array}$ & Low risk & \begin{tabular}{l} 
Comment: Lesion characteristics were similar between groups (Table 2) \\
\hline $\begin{array}{l}\text { Baseline characteristics } \\
\text { similar (selection bias) }\end{array}$
\end{tabular} \\
\hline
\end{tabular}


Whited 2002 (Continued)
Blinding of participants
High risk
Comment: Not possible to blind participants and personnel and personnel (performance bias)

All outcomes

\begin{tabular}{lll}
\hline $\begin{array}{l}\text { Blinding of objective out- } \\
\text { come assessment (detec- } \\
\text { tion bias) }\end{array}$ & Low risk & $\begin{array}{l}\text { Quote: "Research assistants were blinded to the study arm in which prospec- } \\
\text { tive patients were randomised." (p.314) }\end{array}$ \\
\hline $\begin{array}{l}\text { Blinding of subjective out- } \\
\text { come assessment (detec- } \\
\text { tion bias) }\end{array}$ & High risk & Comment: Self-reported satisfaction \\
\hline $\begin{array}{l}\text { Protection against conta- } \\
\text { mination }\end{array}$ & Unclear risk & $\begin{array}{l}\text { Comment: Contamination unlikely to be a risk at participant level. Risks of or } \\
\text { strategies to prevent contamination at the level of responding dermatologists } \\
\text { unclear }\end{array}$ \\
\hline
\end{tabular}

Incomplete outcome data Low risk Comment: Data analysed for all participants

(attrition bias)

All outcomes

Selective reporting (re- High risk Comment: Different outcomes reported in different publications
porting bias)

\begin{tabular}{ll}
\hline Other bias $\quad$ Low risk $\quad$ Comment: No other apparent risk of bias \\
\hline
\end{tabular}

Whited 2013

\section{Study characteristics}

\begin{tabular}{ll}
\hline Methods & Study design: Randomised trial (parallel) \\
& Unit of allocation: Participant \\
\hline
\end{tabular}

\section{Participants}

\section{Providers}

Number: Not reported

Type: GPs consulting with dermatologists

Other relevant characteristics: Not reported

\section{Participants}

Number: Randomised: 392 (I: 196, C: 196), Analysed: 261 (I: 136; C: 125)

Mean age (SD): I: 62.9 years (13.9); C: 61.7 years (14.9)

Gender (\% female): $2 \%$ (Veteran Affairs clinics)

Inclusion criteria: Adults referred to the Dermatology service from primary care clinics

Exclusion criteria: More than 1 skin condition, required full-body examination, could not read or speak English, low health literacy

Other relevant characteristics: Mainly white

Location and study setting: USA, 2 outpatient community-based Veteran Affairs clinics 
Recruitment method: Eligible participants were identified whenever the GP generated a request for a consultation with the dermatology department

Duration: 1 consultation/referral (unless participant required further treatment), 9 months follow-up; study conducted between November 2008 and March 2011

Withdrawals: $33 \%$ of participants randomised did not complete follow-up (reasons provided, similar numbers for I and C)

Intervention components: Alongside the request for a referral, GPs submitted digital images of skin lesions with a standardised medical history and any additional relevant information. The consultant dermatologist reviewed all the data and replied either by scheduling a clinic-based appointment or sending a diagnosis and management plan to the GP, without further need for a clinic-based appointment

Comparison: Usual care - GPs referred participants to the dermatology service as needed using the electronic medical record

Technical equipment used: 8-megapixel digital camera with an integrated flash; if required, digital ring flash for short focal length or macro images

Fidelity assessment: Imaging protocol

Time points reported: Baseline, follow-up ( 3 and 9 months post-baseline assessment)

Ethical approval: Approved by institutional review boards. Trial registry: NCT00488293

Conflicts of interest: "Drs Whited and Edison are coeditors of the book Teledermatology: A User's Guide published by Cambridge University Press and receive royalties based on sales. Dr Chren is a consultant to Genetech Inc (on patient-reported outcomes)."

\section{Risk of bias}

\begin{tabular}{lll}
\hline Bias & Authors' judgement & Support for judgement \\
\hline $\begin{array}{l}\text { Random sequence genera- } \\
\text { tion (selection bias) }\end{array}$ & Low risk & Comment: Simple randomisation scheme stratified by site (p.586) \\
\hline $\begin{array}{l}\text { Allocation concealment } \\
\text { (selection bias) }\end{array}$ & Low risk & Comment: Off-site statistical co-ordinating centre (p.586) \\
\hline $\begin{array}{l}\text { Baseline outcome mea- } \\
\text { surements similar (selec- } \\
\text { tion bias) }\end{array}$ & Low risk & $\begin{array}{l}\text { Comment: Baseline outcome measurements provided and similar between } \\
\text { groups (table 1) }\end{array}$ \\
\hline $\begin{array}{l}\text { Baseline characteristics } \\
\text { similar (selection bias) }\end{array}$ & Low risk & $\begin{array}{l}\text { Comment: Baseline outcome characteristics provided and similar between } \\
\text { groups (table 1) }\end{array}$ \\
\hline $\begin{array}{l}\text { Blinding of participants } \\
\text { and personnel (perfor- } \\
\text { mance bias) } \\
\text { All outcomes }\end{array}$ & High risk & Comment: Not possible due to the nature of the intervention \\
\hline
\end{tabular}


Whited 2013 (Continued)

Blinding of objective out- High risk Comment: Costs partially calculated based on site reports, which are variable; come assessment (detecclinical staff not blinded to group allocation tion bias)

\begin{tabular}{|c|c|c|}
\hline $\begin{array}{l}\text { Blinding of subjective out- } \\
\text { come assessment (detec- } \\
\text { tion bias) }\end{array}$ & High risk & $\begin{array}{l}\text { Comment: Participants, clinical staff and research personnel not blinded to } \\
\text { group allocation }\end{array}$ \\
\hline
\end{tabular}

Protection against conta- Unclear risk
mination

Comment: Contamination unlikely to be a risk at participant level. Risks of or strategies to prevent contamination at the level of responding dermatologists unclear

\begin{tabular}{|c|c|c|}
\hline $\begin{array}{l}\text { Incomplete outcome data } \\
\text { (attrition bias) } \\
\text { All outcomes }\end{array}$ & High risk & $\begin{array}{l}\text { Comment: High attrition rates ( } 67 \% \text { participants randomised were included in } \\
\text { primary analysis) }\end{array}$ \\
\hline
\end{tabular}

\begin{tabular}{lll}
\hline $\begin{array}{l}\text { Selective reporting (re- } \\
\text { porting bias) }\end{array}$ & High risk & Comment: Outcomes differ between protocol and publications \\
\hline Other bias & Low risk & Comment: No other apparent risk of bias \\
\hline
\end{tabular}

Empty cells in the "Risk of bias" tables refer to instances where the specific risk of bias criterion did not apply, e.g. the type of outcome was not collected by the study.

ART: Antiretroviral Therapy; C: Control; CKD: Chronic kidney disease; EMR: Electronic medical record; GPs: General practitioners; HCP: Healthcare provider; HEW: Health extension workers; I: Intervention; PCP: Primary care provider; PHWs: Peer health workers; VA: Veteran Affairs

Characteristics of excluded studies [ordered by study ID]

\begin{tabular}{|c|c|}
\hline Study & Reason for exclusion \\
\hline Ateudjieu 2014 & Compares in-person supervision with automated text messages \\
\hline Atnafu 2017 & Mobile technologies used for emergency referrals, not seeking guidance or providing care \\
\hline Batista 2016 & Not mobile \\
\hline Bettinelli 2015 & Feasibility study \\
\hline Burns 2016 & Not mobile (desktop video-conferencing system) \\
\hline Buvik 2016 & Not mobile (desktop personal computers) \\
\hline Chiaravalloti 2017 & Pilot study \\
\hline Conlin 2006 & Not an intervention study (diagnostic accuracy) \\
\hline Da Silva 2018 & Not mobile \\
\hline Ferrándiz 2017 & Compares 2 Internet-based interventions (clinical images vs. dermoscopic images) \\
\hline Golberstein 2017 & Not mobile (desktop personal computers) \\
\hline Gong 2018 & Multifaceted study with several components \\
\hline
\end{tabular}




\begin{tabular}{|c|c|}
\hline Study & Reason for exclusion \\
\hline Haridy 2017 & Pilot study \\
\hline Loane 2001 & Not mobile (desktop video-conferencing telephone) \\
\hline NCT02710799 & Not mobile \\
\hline Nwando Olayiwola 2016 & Not mobile (desktop personal computers, as well as laptops) \\
\hline Oakley 2000 & Not mobile (desktop personal computers) \\
\hline Owen 2019 & Feasibility study \\
\hline Phillips 2019 & Mainly educational \\
\hline Pryzbylo 2014 & Compares 2 devices (smartphone and pager) for routine communication \\
\hline Romero 2009 & Diagnostic accuracy study \\
\hline Wesarg 2010 & $\begin{array}{l}\text { Compares } 2 \text { methods for fitting a Cochlear device, each participant has the device fitted remotely } \\
\text { or face-to-face (not randomised) }\end{array}$ \\
\hline
\end{tabular}

\section{Characteristics of ongoing studies [ordered by study ID]}

\section{ACTRN12617000389303}

\section{Study name}

Establishing the role of teleconsulting in the care of chronic conditions in rural areas of the Southern District Health Board (SDHB): A randomised controlled trial (RCT) in patients with Inflammatory Bowel Disease

\begin{tabular}{ll}
\hline Methods & Randomised trial, parallel assignment, open-label \\
\hline Participants & Adults aged $\geq 18$ years diagnosed with irritable bowel syndrome living in rural settings \\
\hline Interventions & Intervention: remote consultation through teleconference with nurse facilitation \\
& Comparison: usual care \\
\hline Outcomes & Main outcomes: disease control; disease-specific quality of life \\
\hline Otarting date & Other outcomes: cost effectiveness; acceptability \\
\hline Contact information & April 2017 (expected completion date June 2020) \\
\hline Notes & Ms Christine Ho (Christine.Ho@otago.ac.nz) \\
\hline
\end{tabular}

\section{ACTRN12618001007224}

$\begin{array}{ll}\text { Study name } & \begin{array}{l}\text { A prospective randomised controlled study of telehealth specialist palliative care consultations in } \\ \text { rural and metropolitan settings and the impact on patient and carer clinical outcomes and quali- } \\ \text { ty-of-life }\end{array}\end{array}$


ACTRN12618001007224 (Continued)

Methods Randomised trial, parallel assignment, open-label

Participants Adults aged $\geq 18$ years receiving community, inpatient or outpatient palliative care

Interventions Intervention: in-home consultation through teleconference with nurse facilitation

Comparison: usual care

Outcomes Main outcomes: clinical symptoms; quality of life; performance status

Other outcomes: emergency department attendances; time to set up teleconference equipment; user experience; home visit duration; other participant-reported symptoms

\begin{tabular}{ll}
\hline Starting date & June 2018 (expected completion date October 2020) \\
\hline Contact information & A/Prof Peter Poon (peter.poon@monashhealth.org) \\
\hline Notes & \\
\hline
\end{tabular}

\section{Done 2018}

\begin{tabular}{ll}
\hline Study name & Teledermatology mobile apps: implementation and impact on veterans' access to dermatology \\
\hline Methods & Randomised trial, cross-over assignment, open-label \\
\hline Participants & All people receiving dermatology care at eligible clinics \\
\hline Interventions & $\begin{array}{l}\text { Intervention: Tablet loaded with app, which allows to capture and immediately upload images in- } \\
\text { to the electronic records system, where it can be reviewed by referring providers and imagers }\end{array}$ \\
\hline Comparison: Usual care (for 3-month blocks, until they also start using the app)
\end{tabular}

Gervès-Pinquié 2017

\begin{tabular}{ll}
\hline Study name & CAPRI \\
\hline Methods & Randomised trial, parallel assignment, open-label \\
\hline Participants & $\begin{array}{l}\text { People with metastatic cancer or haematological malignancy being treated with oral therapy, aged } \\
\geq 18 \text { years }\end{array}$ \\
\hline Interventions & $\begin{array}{l}\text { Intervention: Participants will be given access to nurse navigators and a web portal, which will al- } \\
\text { so be used for nurses to communicate with other healthcare professionals }\end{array}$ \\
\hline
\end{tabular}


Gervès-Pinquié 2017 (Continued)

Comparison: Usual care

\begin{tabular}{ll}
\hline Outcomes & $\begin{array}{l}\text { Main outcomes: relative dose intensity } \\
\text { Other outcomes: compliance; toxicity }\end{array}$ \\
\hline Starting date & October 2016 (estimated completion date October 2020) \\
\hline Contact information & Marie Ferrua (marie.ferrua@gustaveroussy.fr) \\
\hline Notes & Registered trial (NCT02828462) \\
\hline
\end{tabular}

Jeandidier 2018

\begin{tabular}{ll}
\hline Study name & $\begin{array}{l}\text { Evaluation of the DIABEO system in poorly controlled DM1 or DM2 patients treated with a basal-bo- } \\
\text { lus insulin regimen }\end{array}$ \\
\hline Methods & Randomised trial, parallel assignment, open-label \\
\hline Participants & $\begin{array}{l}\text { People aged } \geq 18 \text { years with Type } 1 \text { or Type 2 diabetes } \\
\text { levels; results are uploaded to an online portal that can be accessed by HCP; clinical information } \\
\text { can be exchanged between different HCPs } \\
\text { Comparison: Usual care }\end{array}$ \\
\hline Interventions & $\begin{array}{l}\text { Main outcomes: change in HbAlc } \\
\text { Other outcomes: HbA1c levels; percent of responder participants; severe hypoglycaemia }\end{array}$ \\
\hline Outcomes & February 2013 (estimated completion date July 2018) \\
\hline Starting date & \begin{tabular}{l} 
Sylvia Franc \\
\hline Contact information
\end{tabular} \\
\hline Notes & Regublished results found, contact authors emailed twice for further information, no reply
\end{tabular}

Koch 2018

\begin{tabular}{ll}
\hline Study name & TeleDerm study \\
\hline Methods & Cluster-randomised trial, parallel assignment, open-label \\
\hline Participants & Adults with a dermatologic problem and insured by a specific health insurance company \\
\hline Interventions & $\begin{array}{l}\text { Intervention: When faced with a dermatologic case, the GP can trigger a teleconsultation process } \\
\text { with a dermatologist, based on high-resolution pictures and clinical history } \\
\text { Comparison: Usual care }\end{array}$ \\
\hline
\end{tabular}

\section{Outcomes}

Main outcomes: Number of physical referrals to dermatologists 
Koch 2018 (Continued)

Other outcomes: Referral time; process quality; health-related quality of life; costs

\begin{tabular}{ll}
\hline Starting date & July 2018 (expected completion date June 2019) \\
\hline Contact information & Roland Koch (roland.koch@med.uni-tuebingen.de) \\
\hline Notes & Registered trial (DRKS00012944) \\
\hline
\end{tabular}

Källander 2015

\begin{tabular}{ll}
\hline Study name & inSCALE \\
\hline Methods & Randomised trial (cluster parallel) \\
\hline Participants & $\begin{array}{l}\text { Community health workers (CHWs) working in districts with Integrated Community Case Manage- } \\
\text { ment (Uganda and Mozambique) }\end{array}$ \\
\hline Interventions & $\begin{array}{l}\text { CHWs are equipped with smartphones that can be used to facilitate decision-making, submit data, } \\
\text { receive personal performance feedback and communicate with their supervisor }\end{array}$ \\
\hline
\end{tabular}

Outcomes Main outcome: appropriate treatment of malaria, pneumonia and diarrhoea in children under 5 years of age at 12 months

Other outcomes: $\mathrm{CHWs}$ with medicine stock-out $<1$ week each quarter; $\mathrm{CHW}$ retention

\begin{tabular}{ll}
\hline Starting date & April 2013 \\
\hline Contact information & Karen Kalländer \\
\hline Notes & Registered trial (NCT01972321) \\
\hline
\end{tabular}

\section{Nakayama 2016}

\section{Study name}

Screening of cardiovascular, cerebrovascular, and renal disease for residents in rural areas using a medical IT network

\begin{tabular}{ll}
\hline Methods & Randomised trial, parallel assignment, open-label \\
\hline Participants & Adults aged $\geq 65$ years living in rural areas, with low-to-moderate risk of cardiovascular disease \\
\hline Interventions & $\begin{array}{l}\text { Intervention: Using clinical data from a medical information network, specialists in cardiology, } \\
\text { nephrology and cerebrovascular disease assess patient data and make treatment recommenda- } \\
\text { tions to GPs }\end{array}$
\end{tabular}

Comparison: Usual care, participants are treated in-person by physician

\begin{tabular}{ll}
\hline Outcomes & Main outcomes: Incidence of cardiovascular, cerebrovascular, or renal disease \\
& Other outcomes: Not reported \\
\hline Starting date & May 2015 (no information about study completion) \\
\hline Contact information & Masaharu Nakayama (nakayama@cardio.med.tohoku.ac.jp) \\
\hline
\end{tabular}


Nakayama 2016 (Continued)

Notes

No published results found, contact authors emailed twice for further information, no reply

Registered trial (UMIN000018552)

NCT02821143

\begin{tabular}{ll}
\hline Study name & The impact of Telemedicine to support palliative care resident in nursing home (TELESM) \\
\hline Methods & Randomised trial, parallel assignment, open-label \\
\hline Participants & Nursing home residents aged $\geq 65$ years, with palliative care needs \\
\hline Interventions & $\begin{array}{l}\text { Intervention: Telemedicine consultation - multi-professional consultation with healthcare profes- } \\
\text { sionals (participant and their families can also participate if desired) }\end{array}$
\end{tabular}

Comparison: Usual care

\begin{tabular}{ll}
\hline Outcomes & Main outcomes: hospitalisation rates \\
& $\begin{array}{l}\text { Other outcomes: emergency hospitalisation rates; proportion of hospitalised participants; quality } \\
\text { of life; caregiver satisfaction; costs }\end{array}$
\end{tabular}

of life; caregiver satisfaction; costs

\begin{tabular}{ll}
\hline Starting date & January 2018 \\
\hline Contact information & Sandrine Sourdet (sourdet.s@chu-toulouse.fr) \\
\hline Notes & \\
\hline
\end{tabular}

\section{NCT02986256}

\begin{tabular}{ll}
\hline Study name & Evaluation of the management of diabetic foot ulcers by telemedicine on the number of hospital \\
days in diabetic patients (TELEPIED)
\end{tabular}

\begin{tabular}{|c|c|}
\hline Methods & Randomised trial, parallel assignment, open-label \\
\hline Participants & Patiients with diabetes and foot ulcer aged $\geq 18$ years \\
\hline Interventions & $\begin{array}{l}\text { Intervention: During home visits the community nurse will photograph foot ulcers, which will be } \\
\text { sent to the specialist nurse for assessment and follow-up } \\
\text { Comparison: Usual care }\end{array}$ \\
\hline Outcomes & $\begin{array}{l}\text { Main outcomes: number of hospitalisation days due to diabetic foot ulcers } \\
\text { Other outcomes: total direct care costs; average duration of hospitalisation due to diabetic foot ul- } \\
\text { cers; ulcer recidivism rate; frequency of ulceration; duration of ulceration; healing rate; amputation } \\
\text { rate; participant satisfaction score }\end{array}$ \\
\hline Contact information & Sylvia Franc (sylvia.franc@free.fr) \\
\hline
\end{tabular}

Notes

Mobile technologies to support healthcare provider to healthcare provider communication and management of care (Review) 
NCT03137511

\begin{tabular}{ll}
\hline Study name & OASE Melanome \\
\hline Methods & Cluster-randomised trial, open-label \\
\hline Participants & $\begin{array}{l}\text { Adults aged } \geq 18 \text { years consulting a GP for a suspicious cutaneous lesion who require a referral to a } \\
\text { dermatologist }\end{array}$
\end{tabular}

Interventions

Intervention: The GP sends the dermatologist 2 photos of skin lesions, along with relevant clinical information, after which the dermatologist assesses the photos and follows up with the participant as required

Comparison: Usual care

\section{Outcomes}

Main outcomes: Time limit between consultation with GP and consultation with dermatologist

Other outcomes: Proportion of participants who did have a consultation with a dermatologist 12 months after consulting with GP

\begin{tabular}{ll}
\hline Starting date & May 2017 (estimated completion date May 2018) \\
\hline Contact information & Jean-Michel Nguyen (jeanmichel.nguyen@chu-nantes.fr) \\
\hline Notes & No published results found, contact authors emailed twice for further information, no reply \\
\hline
\end{tabular}

\section{NCT03559712}

\begin{tabular}{ll}
\hline Study name & $\begin{array}{l}\text { Effectiveness of collaborative tele-mental health services for ADHD in primary care: a randomised } \\
\text { trial in Dubai (ECTSAP- Dubai Trial) }\end{array}$ \\
\hline Methods & Randomised trial, parallel assignment, open-label \\
\hline Participants & Children aged 6 to 12 years diagnosed with attention deficit hyperactivity disorder (ADHD) \\
\hline Interventions & $\begin{array}{l}\text { Intervention: remote consultation through teleconference with specialist supervision } \\
\text { Comparison: usual care }\end{array}$ \\
\hline Outcomes & Change in clinical symptoms \\
\hline Starting date & $\begin{array}{l}\text { June 2018 (expected completion date December 2018, personal communication with principal in- } \\
\text { vestigator 22 October 2019 confirmed it is ongoing) }\end{array}$ \\
\hline Contact information & Ammar AlBanna (albanna@ajch.ae) \\
\hline
\end{tabular}

\section{Notes}

\section{NCT03662256}

\begin{tabular}{ll}
\hline Study name & Addressing early childhood hearing loss in rural Alaska: a community randomised trial \\
\hline Methods & Randomised trial, parallel assignment, single masking (outcomes assessor)
\end{tabular}


NCT03662256 (Continued)

\begin{tabular}{ll} 
Participants & Children aged 2 to 6 years, attending eligible schools \\
\hline Interventions & $\begin{array}{l}\text { Little information provided; intervention described as telemedicine referral and mHealth screening } \\
\text { tool }\end{array}$
\end{tabular}

Outcomes Main outcomes: time to diagnosis

Other outcomes: sensitivity and specificity of screening protocols; prevalence of hearing loss

\begin{tabular}{ll}
\hline Starting date & September 2018 (estimated completion date February 2020) \\
\hline Contact information & Samantha Robler (skleindienst@nshcorp.org) \\
\hline Notes & \\
\hline
\end{tabular}

Stevanovic 2017

\begin{tabular}{ll}
\hline Study name & Telemedical support for prehospital Emergency Medical Service (TEMS) \\
\hline Methods & Randomised trial, parallel assignment, open-label \\
\hline Participants & $\begin{array}{l}\text { All emergency calls that are assessed as non-life-threatening, which do not require an obligatory } \\
\text { emergency medical service physician on scene and which do not solely require an ambulance } \\
\text { staffed by paramedics }\end{array}$
\end{tabular}

Interventions
ported by the tele-EMS physicians based at a teleconsultation centre

Comparison: Usual care, participants are treated by physician on scene

\begin{tabular}{ll}
\hline Mutcomes & Main outcomes: adverse events \\
& Other outcomes: adherence to guidelines; quality of medical history; completeness and correct- \\
ness of data; tracer diagnoses; mortality; intensive care unit length of stay; hospital length of stay; & other outcomes
\end{tabular}

\begin{tabular}{ll}
\hline Starting date & July 2017 (estimated study completion date December 2019) \\
\hline Contact information & Ana Stevanovic (astevanovic@ukaachen.de) \\
\hline Notes & Published protocol \\
\hline
\end{tabular}

\section{Xu 2017}

\begin{tabular}{ll}
\hline Study name & $\begin{array}{l}\text { A coordinated PCP-cardiologist telemedicine model (PCTM) in China's community hypertension } \\
\text { care }\end{array}$ \\
\hline Methods & Randomised trial, parallel assignment, open-label \\
\hline Participants & $\begin{array}{l}\text { Adults aged } \geq 21 \text { years, with a clinical diagnosis of hypertension with uncontrolled blood pressure } \\
\text { in the past } 3 \text { months, currently taking or about to take anti-hypertensive medications }\end{array}$ \\
\hline
\end{tabular}


Xu 2017 (Continued)

Interventions
Intervention: Participants are given a blood pressure monitoring system for self-management, which feeds data back to the primary care and cardiology team. Primary care providers and cardiologists use a web-based system to communicate and manage care

Comparison: Usual care - based on national guidelines for hypertension management

\begin{tabular}{ll}
\hline Outcomes & $\begin{array}{l}\text { Main outcomes: Changes in mean systolic blood pressure } \\
\text { Other outcomes: Changes in mean diastolic blood pressure; hypertension control rate; medication } \\
\text { adherence }\end{array}$ \\
\hline Starting date & September 2016 (estimated completion date August 2018) \\
\hline Contact information & Lei Xu (waqyl@126.com) \\
\hline Notes & $\begin{array}{l}\text { No published results found, contact authors emailed twice for further information, no reply. Trial } \\
\text { registry NCT02919033 }\end{array}$ \\
\hline
\end{tabular}

DM1 or DM2: Type 1 or Type 2 Diabetes Mellitus; EMS: Emergency medical service; GP: General practitioner; HCP: Healthcare professionals

\section{DATA AND ANALYSES}

Comparison 1. Mobile technologies used by primary care providers to consult with a hospital-based specialist compared to usual care: Providers' adherence to recommended practice, guidelines or protocols

\begin{tabular}{lllll}
\hline Outcome or subgroup title & $\begin{array}{l}\text { No. of } \\
\text { studies }\end{array}$ & $\begin{array}{l}\text { No. of par- } \\
\text { ticipants }\end{array}$ & Statistical method & Effect size \\
\hline 1.1 Providers' adherence to recommended guidelines & 1 & Other data & No numeric data \\
\hline
\end{tabular}

Analysis 1.1. Comparison 1: Mobile technologies used by primary care providers to consult with a hospital-based specialist compared to usual care: Providers' adherence to recommended practice, guidelines or protocols, Outcome 1: Providers' adherence to recommended guidelines

\begin{tabular}{llll}
\hline Providers' adherence to recommended guidelines & & \\
\hline Study & Population & Outcome & Results \\
\hline Van Gelder $\mathbf{2 0 1 7}$ & $\begin{array}{l}\text { General practitioners consult- } \\
\text { ing with nephrologists about } \\
\text { adults with chronic kidney dis- } \\
\text { ease }\end{array}$ & $\begin{array}{l}\text { Complete monitoring of dis- } \\
\text { ease progression } \\
\text { Complete monitoring of meta- } \\
\text { bolic parameters }\end{array}$ & $\begin{array}{l}\text { OR 1.23 (0.89 to 1.70) } \\
\text { OR 0.61 (0.22 to 1.72) }\end{array}$ \\
& & $\begin{array}{l}\text { Follow-up not specified } \\
\text { OR: Odds ratio; IG: interven- } \\
\text { tion group; CG: control group } \\
\text { * Multilevel analysis for IG } \\
\text { compared to CG; model with a } \\
\text { random intercept keeping the } \\
\text { independent variable (General } \\
\text { Practice Information System) } \\
\text { fixed }\end{array}$ \\
& & & \\
\hline
\end{tabular}


Comparison 2. Mobile technologies used by primary care providers to consult with a hospital-based specialist compared to usual care: Time between presentation and management of the health condition

\begin{tabular}{lllll}
\hline Outcome or subgroup title & $\begin{array}{l}\text { No. of } \\
\text { studies }\end{array}$ & $\begin{array}{l}\text { No. of par- } \\
\text { ticipants }\end{array}$ & Statistical method & Effect size \\
\hline 2.1 Time between presentation and management & 4 & Other data & No numeric data \\
\hline
\end{tabular}

Analysis 2.1. Comparison 2: Mobile technologies used by primary care providers to consult with a hospital-based specialist compared to usual care: Time between presentation and management of the health condition, Outcome 1: Time between presentation and management

\begin{tabular}{|c|c|c|c|c|}
\hline \multicolumn{5}{|c|}{ Time between presentation and management } \\
\hline Study & Population & Outcome & Results & Notes \\
\hline Azogil-López 2019 & $\begin{array}{l}\text { General practitioner consult- } \\
\text { ing with hospital physicians } \\
\text { about participants (aged } \geq 7 \\
\text { years) }\end{array}$ & $\begin{array}{l}\text { Median time from referral re- } \\
\text { quest to appointment with } \\
\text { hospital physician } \\
\text { Median time from referral } \\
\text { request to resolution of the } \\
\text { process }\end{array}$ & $\begin{array}{l}\text { IG: } 17 \text { days (IQR } 8 \text { to } 32, \mathrm{~N}=72 \text { ) } \\
\text { CG: } 51 \text { days, (IQR } 35 \text { to } 57 \text { days, } \\
\mathrm{N}=101 \text { ) } \\
\text { Median difference: }-27 \text { days } \\
\text { (99\% } \mathrm{Cl}-20 \text { to }-33 \text { days) } \\
\text { IG: } 105 \text { days (IQR } 40 \text { to } 169 \text { ); } \\
\text { CG: } 147 \text { days (IQR } 74 \text { to } 228) \\
\text { Median difference: }-47 \text { days } \\
\left(95 \% \mathrm{Cl}-74 \text { to }-17 \text { days) }{ }^{\star}\right.\end{array}$ & $\begin{array}{l}\text { IG: Intervention group; CG: } \\
\text { Control group; IQR: Interquar- } \\
\text { tile range } \\
\text { 3-month follow-up } \\
{ }^{*} \text { As reported by the authors }\end{array}$ \\
\hline Piette 2017 & $\begin{array}{l}\text { General practitioner consult- } \\
\text { ing with dermatologists about } \\
\text { adults with skin lesions }\end{array}$ & $\begin{array}{l}\text { Median delay between } \\
\text { the initial GP's consultation } \\
\text { and the dermatologist's reply } \\
\text { allowing the participant or the } \\
\text { GP to begin treatment }\end{array}$ & $\begin{array}{l}\text { IG: } 4 \text { days }(N=53) \\
\text { CG: } 40 \text { days }(N=50) \\
\text { Adjusted HR } 2.55(P=0.01)^{\star}\end{array}$ & $\begin{array}{l}\text { 3-month follow-up } \\
\text { Reported in days } \\
\text { Data also provided for number } \\
\text { of participants not receiving } \\
\text { an appointment (15 days, 1-, 2- } \\
\text { and 3-month follow-up) } \\
\text { Adjusted hazard ratio (HR) as } \\
\text { provided by the authors (ad- } \\
\text { justing for clustering of GPs } \\
\text { and identities of dermatolo- } \\
\text { gists) }\end{array}$ \\
\hline Sutherland 2009 & $\begin{array}{l}\text { General practitioner consult- } \\
\text { ing with radiologists about } \\
\text { clients aged } \geq 13 \text { years requir- } \\
\text { ing a trans-abdominal or trans- } \\
\text { vaginal ultrasound }\end{array}$ & $\begin{array}{l}\text { Median time to participant fol- } \\
\text { low-up } \\
\text { Median time to final diagnosis }\end{array}$ & $\begin{array}{l}\text { IG: } 67.1 \text { hours (IQR: } 45.9 \text { to } \\
113.7, \mathrm{~N}=53 \text { ) } \\
\text { CG: } 76.7 \text { hours (IQR } 65.8 \text { to } \\
\text { 144.7, } \mathrm{N}=52 \text { ) } \\
\text { IG: } 17.8 \text { hours (IQR: } 12.2 \text { to } \\
27.1, \mathrm{~N}=53 \text { ) } \\
\text { CG: } 23.9 \text { (IQR } 21.4 \text { to } 48.1, \mathrm{~N}= \\
52 \text { ) }\end{array}$ & Duration not provided \\
\hline Whited 2002 & $\begin{array}{l}\text { General practitioner consult- } \\
\text { ing with dermatologists about } \\
\text { adults with skin condition }\end{array}$ & Mean time to intervention & $\begin{array}{l}\text { IG: } 73.8 \text { days }(\mathrm{SD} 71.6, \mathrm{~N}=135) \\
\text { CG: } 114.3 \text { days }(\mathrm{SD} 72.3, \mathrm{~N}= \\
\text { 140) } \\
\text { MD: }-40.5 \text { days }(95 \% \mathrm{Cl}-23.41 \\
\text { to }-57.89 \text { ) }\end{array}$ & $\begin{array}{l}\text { Duration not provided } \\
\text { SD: standard deviation; MD: } \\
\text { mean difference }\end{array}$ \\
\hline
\end{tabular}

Comparison 3. Mobile technologies used by primary care providers to consult with a hospital-based specialist compared to usual care: Healthcare use

\begin{tabular}{|c|c|c|c|c|}
\hline Outcome or subgroup title & $\begin{array}{l}\text { No. of } \\
\text { studies }\end{array}$ & $\begin{array}{l}\text { No. of } \\
\text { partici- } \\
\text { pants }\end{array}$ & Statistical method & Effect size \\
\hline 3.1 Healthcare use & 9 & & Other data & No numeric data \\
\hline 3.1.1 Healthcare use & 9 & & Other data & No numeric data \\
\hline
\end{tabular}




\begin{tabular}{|c|c|c|c|c|}
\hline Outcome or subgroup title & $\begin{array}{l}\text { No. of } \\
\text { studies }\end{array}$ & $\begin{array}{l}\text { No. of } \\
\text { partici- } \\
\text { pants }\end{array}$ & Statistical method & Effect size \\
\hline $\begin{array}{l}\text { 3.2 Referred for clinic follow-up or clinical exami- } \\
\text { nation, } 3 \text { to } 12 \text { months follow-up }\end{array}$ & 3 & & $\begin{array}{l}\text { Risk Ratio (M-H, Random, } \\
95 \% \mathrm{Cl})\end{array}$ & Totals not selected \\
\hline 3.2.1 Referred to a dermatology clinic & 3 & & $\begin{array}{l}\text { Risk Ratio (M-H, Random, } \\
95 \% \mathrm{Cl} \text { ) }\end{array}$ & Totals not selected \\
\hline $\begin{array}{l}\text { 3.3 Referred for clinic follow-up or clinical exami- } \\
\text { nation, } 3 \text { to } 12 \text { months follow-up }\end{array}$ & 2 & & $\begin{array}{l}\text { Risk Ratio (M-H, Random, } \\
95 \% \mathrm{Cl})\end{array}$ & Totals not selected \\
\hline
\end{tabular}

\section{Analysis 3.1. Comparison 3: Mobile technologies used by primary care providers to consult with a hospital-based specialist compared to usual care: Healthcare use, Outcome 1: Healthcare use}

\begin{tabular}{|c|c|c|c|c|}
\hline Healthcare use & & & & \\
\hline Study & Population & Outcome & Results & Notes \\
\hline \multicolumn{5}{|l|}{ Healthcare use } \\
\hline Byamba 2015 & $\begin{array}{l}\text { General practitioner consult- } \\
\text { ing with dermatologists about } \\
\text { adults with skin lesions }\end{array}$ & $\begin{array}{l}\text { Participant referred to ter- } \\
\text { tiary-care centres for consulta- } \\
\text { tion }\end{array}$ & $\begin{array}{l}\text { IG: } 7 / 221 \\
\text { CG: } 28 / 229 \\
\text { RR: } 0.28,95 \% \text { Cl } 0.13 \text { to } 0.63\end{array}$ & $\begin{array}{l}\text { IG: Intervention group; CG: } \\
\text { Control group } \\
\text { RR: risk ratio; CI: confidence } \\
\text { interval } \\
5 \text { months follow-up } \\
\text { Note: there was no evidence of } \\
\text { clustering taken into account } \\
\text { in the analysis, and we were } \\
\text { not able to re-analyse the data. } \\
\text { It is possible there are poten- } \\
\text { tial unit of analysis errors. }\end{array}$ \\
\hline Davis 2003 & $\begin{array}{l}\text { Primary care provider at the } \\
\text { rural primary practice consult- } \\
\text { ing with ophthalmologist at } \\
\text { the university setting about } \\
\text { adults with diabetes }\end{array}$ & $\begin{array}{l}\text { Participant received diabetic } \\
\text { retinopathy screening }\end{array}$ & $\begin{array}{l}\text { IG: } 23 / 30 \\
\text { CG: } 4 / 29 \\
\text { RR } 5.56 \text { ( } 95 \% \text { Cl } 2.19 \text { to } 14.10)\end{array}$ & $\begin{array}{l}\text { Follow-up not reported } \\
\text { RR: risk ratio; Cl: confidence } \\
\text { interval }\end{array}$ \\
\hline Liddy 2019a & $\begin{array}{l}\text { Primary care provider consult- } \\
\text { ing with specialists for a range } \\
\text { of different conditions }\end{array}$ & $\begin{array}{l}\text { Participants referred for face- } \\
\text { to-face visits to all medical } \\
\text { specialties available through } \\
\text { eConsult service during the } \\
\text { study period }\end{array}$ & $\begin{array}{l}\text { Mean number of participants } \\
\text { seen (SD, range) } \\
\text { IG: } 608(258,90 \text { to } 1134) \\
\text { CG: } 724(370,11 \text { to } 1692) \\
\text { RR } 0.93,95 \% \text { Cl } 0.85 \text { to } 1.03^{*}\end{array}$ & $\begin{array}{l}\text { 12-month follow-up } \\
\text { RR: risk ratio; } \mathrm{Cl} \text { : confidence } \\
\text { interval } \\
{ }^{\star} \text { Adjusted for covariates }\end{array}$ \\
\hline Mansberger 2015 & $\begin{array}{l}\text { Primary care providers con- } \\
\text { sulting with experienced in- } \\
\text { vestigators based at an eye in- } \\
\text { stitute about adults with dia- } \\
\text { betes }\end{array}$ & $\begin{array}{l}\text { Participant received diabetic } \\
\text { retinopathy screening }\end{array}$ & $\begin{array}{l}\text { IG: } 157 / 296 \\
\text { CG: } 90 / 271 \\
\text { RR } 1.60 \text { (95\% CI } 1.31 \text { to } 1.95)\end{array}$ & $\begin{array}{l}\text { 12-month follow-up }(24,36 \\
\text { and } 48 \text { months also reported; } \\
\text { during these periods telemed- } \\
\text { icine was offered to all partici- } \\
\text { pants) }\end{array}$ \\
\hline Piette 2017 & $\begin{array}{l}\text { General practitioner consult- } \\
\text { ing with dermatologists about } \\
\text { adults with skin lesions }\end{array}$ & $\begin{array}{l}\text { Participant referred for clinic } \\
\text { follow-up }\end{array}$ & $\begin{array}{l}\text { IG: } 14 / 39^{\star} ; \text { CG: } 50 / 50 \\
\text { RR: } 0.36 \text { ( } 95 \% \text { CI } 0.24 \text { to } 0.55)\end{array}$ & $\begin{array}{l}\text { 3-month follow-up } \\
{ }^{\star} \text { Only includes participants for } \\
\text { whom } \\
\text { dermatologists were able to } \\
\text { elaborate a treatment plan } \\
\text { based on transmitted pho- } \\
\text { tographs; for approx. } 1 / 5 \text { of } \\
\text { participants allocated to IG the } \\
\text { photographs were not usable }\end{array}$ \\
\hline Sutherland 2009 & $\begin{array}{l}\text { General practitioner consult- } \\
\text { ing with radiologists regarding } \\
\text { clients aged } \geq 13 \text { years requir- } \\
\text { ing a trans-abdominal or trans- } \\
\text { vaginal ultrasound }\end{array}$ & $\begin{array}{l}\text { Participant received ultra- } \\
\text { sound }\end{array}$ & $\begin{array}{l}\text { IG: } 36 / 53 \\
\text { CG: } 9 / 52 \\
\text { RR } 3.92 \text { (95\% CI } 2.11 \text { to } 7.31)\end{array}$ & $\begin{array}{l}\text { Follow-up not specified } \\
\text { RR: risk ratio; Cl: confidence } \\
\text { interval }\end{array}$ \\
\hline Van Gelder 2017 & $\begin{array}{l}\text { General practitioners consult- } \\
\text { ing with nephrologists about } \\
\text { adults with chronic kidney dis- } \\
\text { ease }\end{array}$ & $\begin{array}{l}\text { Participant referred for clinic } \\
\text { follow-up }\end{array}$ & $\begin{array}{l}\text { IG: } 29 / 1277 \\
\text { CG: } 52 / 1727 \\
\text { OR } 0.61(95 \% \text { Cl } 0.31 \text { to } 1.23)^{\star}\end{array}$ & $\begin{array}{l}\text { Follow-up not specified } \\
\text { OR: Odds ratio; Cl: confidence } \\
\text { interval } \\
{ }^{\star} \text { Multilevel analysis for IG } \\
\text { compared to CG; model with a } \\
\text { random intercept keeping the }\end{array}$ \\
\hline
\end{tabular}

Mobile technologies to support healthcare provider to healthcare provider communication and management of care (Review) 


\begin{tabular}{|c|c|c|c|c|}
\hline & & & & $\begin{array}{l}\text { independent variable (General } \\
\text { Practice Information System) } \\
\text { fixed }\end{array}$ \\
\hline Whited 2002 & $\begin{array}{l}\text { General practitioners consult- } \\
\text { ing with dermatologists about } \\
\text { adults with skin condition }\end{array}$ & $\begin{array}{l}\text { Participant referred for clinic } \\
\text { follow-up }\end{array}$ & $\begin{array}{l}\text { IG: } 110 / 135 ; \text { CG: } 140 / 140 \\
\text { RR: } 0.82 \text { (95\% CI } 0.75 \text { to } 0.88)\end{array}$ & $\begin{array}{l}\text { Follow-up not specified } \\
\text { RR: risk ratio; } \mathrm{Cl} \text { : confidence } \\
\text { interval }\end{array}$ \\
\hline Whited 2013 & $\begin{array}{l}\text { General practitioner consult- } \\
\text { ing with dermatologists about } \\
\text { adults with skin condition }\end{array}$ & $\begin{array}{l}\text { Client visited dermatology } \\
\text { clinic }\end{array}$ & $\begin{array}{l}\text { IG: } 78 / 125 \\
\text { CG: } 120 / 136 \\
\text { RR } 0.71(95 \% \mathrm{Cl} 0.61 \text { to } 0.82)\end{array}$ & $\begin{array}{l}\text { Proportion of participats who } \\
\text { had at least } 1 \text { visit to the der- } \\
\text { matology clinic during the 9- } \\
\text { month follow-up }\end{array}$ \\
\hline
\end{tabular}

Analysis 3.2. Comparison 3: Mobile technologies used by primary care providers to consult with a hospital-based specialist compared to usual care: Healthcare use, Outcome 2: Referred for clinic follow-up or clinical examination, 3 to 12 months follow-up

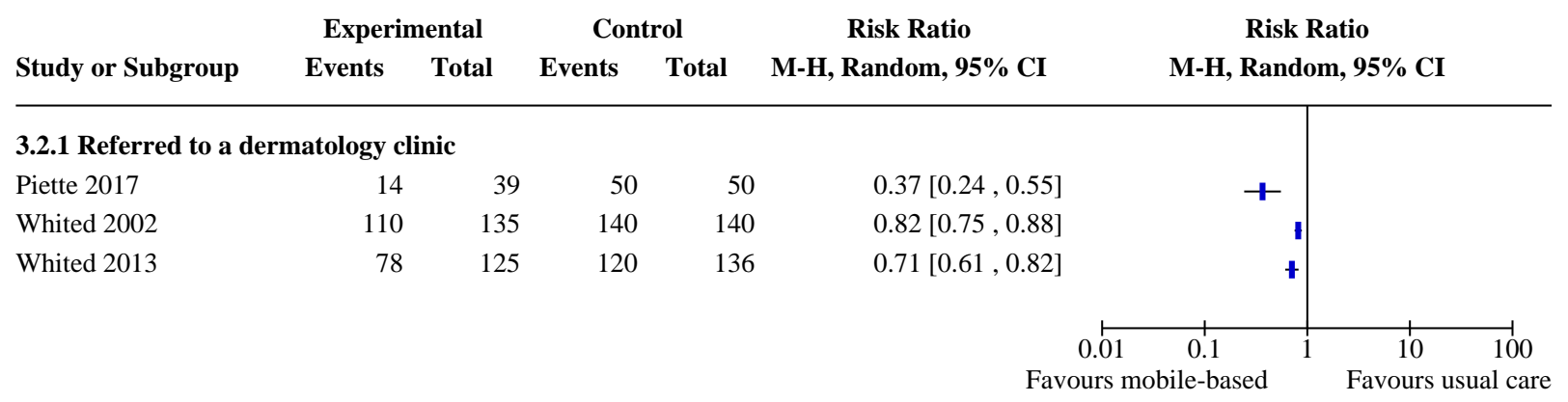

Analysis 3.3. Comparison 3: Mobile technologies used by primary care providers to consult with a hospital-based specialist compared to usual care: Healthcare use, Outcome 3: Referred for clinic follow-up or clinical examination, 3 to 12 months follow-up

\begin{tabular}{|c|c|c|c|c|c|c|}
\hline \multirow{2}{*}{ Study or Subgroup } & \multicolumn{2}{|c|}{ Mobile-based } & \multicolumn{2}{|c|}{ Usual care } & \multirow{2}{*}{$\begin{array}{c}\text { Risk Ratio } \\
\text { M-H, Random, 95\% CI }\end{array}$} & \multirow{2}{*}{\begin{tabular}{c}
\multicolumn{1}{c}{ Risk Ratio } \\
M-H, Random, 95\% CI
\end{tabular}} \\
\hline & Events & Total & Events & Total & & \\
\hline
\end{tabular}

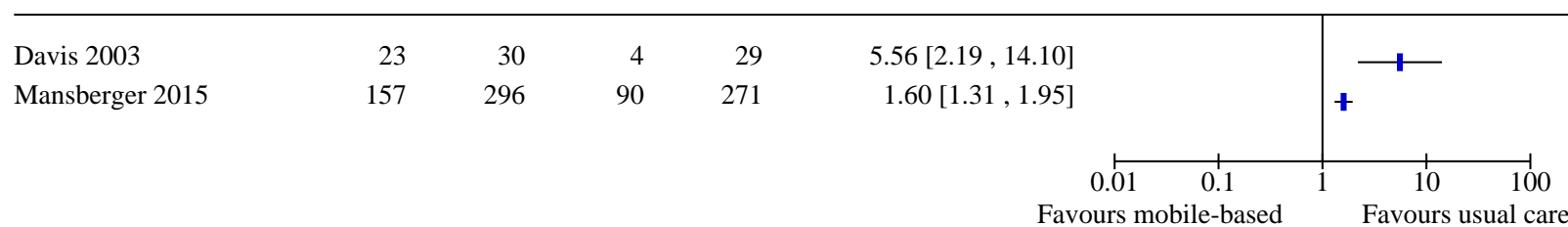

Comparison 4. Mobile technologies used by primary care providers to consult with a hospital-based specialist compared to usual care: Participant's healthcare status and well-being

\begin{tabular}{lllll}
\hline Outcome or subgroup title & $\begin{array}{l}\text { No. of } \\
\text { studies }\end{array}$ & $\begin{array}{l}\text { No. of } \\
\text { partici- } \\
\text { pants }\end{array}$ & Statistical method & Effect size \\
\hline 4.1 Health-related quality of life & 2 & Other data & No numeric data \\
\hline 4.2 Clinical course & 2 & Other data & No numeric data \\
\hline
\end{tabular}


Analysis 4.1. Comparison 4: Mobile technologies used by primary care providers

to consult with a hospital-based specialist compared to usual care: Participant's

healthcare status and well-being, Outcome 1: Health-related quality of life

\begin{tabular}{|c|c|c|c|c|}
\hline \multicolumn{5}{|c|}{ Health-related quality of life } \\
\hline Study & Population & Outcome & Results & Notes \\
\hline Armstrong 2018 & $\begin{array}{l}\text { General practitioner consult- } \\
\text { ing with dermatologists about } \\
\text { adults with psoriasis }\end{array}$ & $\begin{array}{l}\text { General health status: Descrip- } \\
\text { tion } \\
\text { General health status: Evalua- } \\
\text { tion }\end{array}$ & $\begin{array}{l}\mathrm{MD} 0(95 \% \mathrm{Cl}-0.003 \text { to } 0.003) \\
\mathrm{MD}-0.002(95 \% \mathrm{Cl}-2.75 \text { to } \\
2.75)\end{array}$ & $\begin{array}{l}\text { General health status - De- } \\
\text { scription assessed with Euro- } \\
\text { Qol-5D-5L. Scores converted } \\
\text { into an index number, with } \\
\text { values ranging from -0.109 } \\
\text { (worst) to } 1 \text { (best). } \\
\text { General health status - Evalua- } \\
\text { tion assessed with EuroQol-Vi- } \\
\text { sual Analogue Scale. Higher } \\
\text { scores represent better per- } \\
\text { ceived health status } \\
\text { Mean difference from baseline } \\
\text { to } 12 \text { months follow-up, } 296 \\
\text { participants. } \\
\text { MD: mean difference; Cl: confi- } \\
\text { dence interval }\end{array}$ \\
\hline
\end{tabular}

Analysis 4.2. Comparison 4: Mobile technologies used by primary care providers to consult with a hospital-based specialist compared to usual care: Participant's healthcare status and well-being, Outcome 2: Clinical course

\begin{tabular}{|c|c|c|c|c|}
\hline \multicolumn{5}{|l|}{ Clinical course } \\
\hline Study & Population & Outcome & Results & Notes \\
\hline Pak 2007 & $\begin{array}{l}\text { Primary care professional con- } \\
\text { sulting with dermatologist } \\
\text { about adults with skin condi- } \\
\text { tion }\end{array}$ & Clinical course ratings & $\begin{array}{l}\text { Improved } \\
\text { IG: } 173 / 272, \text { CG: } 154 / 236 \\
\text { No change } \\
\text { IG: } 89 / 272 ; \text { CG: } 76 / 236 \\
\text { Worse } \\
\text { IG: } 10 / 272 ; \text { CG: } 6 / 236\end{array}$ & $\begin{array}{l}\text { Based on dermatologist's as- } \\
\text { sessment, at four-month fol- } \\
\text { low-up } \\
\text { There was little or no differ- } \\
\text { ence between groups }\end{array}$ \\
\hline Whited 2013 & $\begin{array}{l}\text { General practitioner consult- } \\
\text { ing with dermatologists about } \\
\text { adults with skin condition }\end{array}$ & Clinical course ratings & $\begin{array}{l}\text { Resolved } \\
\text { IG: } 31 / 125 ; \text { CG: } 35 / 136 \\
\text { Improved } \\
\text { IG: } 59 / 125 ; \text { CG: } 63 / 136 \\
\text { Unchanged (not clinically rele- } \\
\text { vant) } \\
\text { IG: } 13 / 125 ; \text { CG: } 15 / 136 \\
\text { Unchanged (clinically relevant) } \\
\text { IG: } 13 / 125 ; \text { CG: } 17 / 136 \\
\text { Worse } \\
\text { IG: } 9 / 125 ; \text { CG: } 6 / 136\end{array}$ & $\begin{array}{l}\text { Based on dermatologist's as- } \\
\text { sessment, at nine-month fol- } \\
\text { low-up } \\
\text { There was little or no differ- } \\
\text { ence between groups }\end{array}$ \\
\hline
\end{tabular}


Comparison 5. Mobile technologies used by primary care providers to consult with a hospital-based specialist compared to usual care: Acceptability or satisfaction

\begin{tabular}{lllll}
\hline Outcome or subgroup title & $\begin{array}{l}\text { No. of } \\
\text { studies }\end{array}$ & $\begin{array}{l}\text { No. of } \\
\text { partici- } \\
\text { pants }\end{array}$ & $\begin{array}{l}\text { Statistical } \\
\text { method }\end{array}$ & Effect size \\
\hline 5.1 Healthcare provider satisfaction with the intervention & 3 & Other data & No numeric data \\
\hline 5.2 Participant satisfaction with care & 4 & Other data & No numeric data \\
\hline
\end{tabular}

\section{Analysis 5.1. Comparison 5: Mobile technologies used by primary care providers to consult with a hospital-based specialist compared to usual care: Acceptability or satisfaction, Outcome 1: Healthcare provider satisfaction with the intervention}

\begin{tabular}{|c|c|c|c|c|}
\hline \multicolumn{5}{|c|}{ Healthcare provider satisfaction with the intervention } \\
\hline Study & Population & Outcome & Results & Notes \\
\hline Piette 2017 & $\begin{array}{l}\text { General practitioners consult- } \\
\text { ing with dermatologists about } \\
\text { adults with a skin condition }\end{array}$ & Satisfaction & $\begin{array}{l}\text { Global satisfaction } \\
\text { Same proportion of GPs in } \\
\text { both groups were satisfied or } \\
\text { very satisfied (69\%) } \\
\text { Time to treatment satisfaction } \\
\text { Similar proportion of GPs in } \\
\text { both groups considered the } \\
\text { time for resolution to be short } \\
\text { or very short (IG: } 77 \% \text {; CG: } \\
54 \% \text { ) }\end{array}$ & $\begin{array}{l}\text { Response rate: } 65 \%(\mathrm{~N}=26) \\
2 \text { questions with a Likert scale } \\
\text { response ( } 1 \text { very satisfied to } 4 \\
\text { very unsatisfied) } \\
\text { Results provided narratively }\end{array}$ \\
\hline Van Gelder 2017 & $\begin{array}{l}\text { General practitioners consult- } \\
\text { ing with nephrologists about } \\
\text { adults with chronic kidney dis- } \\
\text { ease }\end{array}$ & $\begin{array}{l}\text { Exprience with the interven- } \\
\text { tion }\end{array}$ & $\begin{array}{l}\text { Content of information sent } \\
\text { was good } \\
\text { Yes: } 71 \% \text {; No: } 13 \% \text {; Did not use: } \\
\text { 16\% } \\
\text { Ease of use } \\
\text { Good: } 39 \% \text {; Reasonable: } 37 \% \text {; } \\
\text { Insufficient: } 8 \% \text {; Did not use: } \\
16 \% \\
\text { Added to knowledge of kidney } \\
\text { disease } \\
\text { Yes: } 68 \% \text {; No: } 16 \% \text {; Did not use: } \\
16 \% \\
\text { Pleased with feasibility of te- } \\
\text { lenephrology } \\
\text { Yes: } 79 \% \text {; No: } 5 \% \text {; Did not use: } \\
16 \%\end{array}$ & $\begin{array}{l}\text { Intervention group only (gen- } \\
\text { eral practitioners) } \\
\text { Response rate: } 66 \%(\mathrm{~N}=36)\end{array}$ \\
\hline Whited 2002 & $\begin{array}{l}\text { General practitioners consult- } \\
\text { ing with dermatologists about } \\
\text { adults with a skin condition }\end{array}$ & $\begin{array}{l}\text { Satisfaction with the interven- } \\
\text { tion }\end{array}$ & $\begin{array}{l}\mathrm{N}=275 \text { participants } \\
\text { Timely appointments (GPs) } \\
\text { IG: } 95 \% \text { agreed, } 5 \% \text { neutral } \\
\text { CG: } 7 \% \text { agreed, } 70 \% \text { disagreed } \\
\text { Consultant sent back informa- } \\
\text { tion (GPs) } \\
\text { IG: } 87 \% \text { agreed, } 13 \% \text { neutral } \\
\text { CG: } 68 \% \text { agreed, } 17 \% \text { neutral } \\
\text { Educational benefit from the } \\
\text { referral (GPs) } \\
\text { IG: } 55 \% \text { agreed, } 45 \% \text { neutral } \\
\text { CG: } 34 \% \text { agreed, } 41 \% \text { neutral } \\
\text { Satisfied with the consult } \\
\text { process (GPs) } \\
\text { IG: } 92 \% \text { agreed, } 3 \% \text { disagreed } \\
\text { CG: } 23 \% \text { agreed, } 35 \% \text { dis- } \\
\text { agreed } \\
\text { Less confident with TD than FtF } \\
\text { (CD) } \\
75 \% \text { agree, } 12.5 \% \text { disagree } \\
\text { TD consultation takes longer } \\
\text { (CD) } \\
\text { 100\% disagree }\end{array}$ & $\begin{array}{l}\text { IG: intervention group; CG: } \\
\text { control group; } \\
\text { TD: teledermatology; FtF: face- } \\
\text { to-face; CD: consulting derma- } \\
\text { tologists } \\
\text { GPs: } 4 \text { questions relating to } \\
\text { timeliness, information trans- } \\
\text { fer, education, and overall sat- } \\
\text { isfaction; score agree, neutral, } \\
\text { disagree } \\
\text { Referring GPs ( } \mathrm{N}=60) \\
\text { Dermatologists: confidence in } \\
\text { using TD for diagnostic } \\
\text { and management, resource } \\
\text { use, and overall satisfaction; } \\
\text { score agree, neutral, disagree } \\
\mathrm{CD}(\mathrm{N}=8 \text { ) }\end{array}$ \\
\hline
\end{tabular}


Analysis 5.2. Comparison 5: Mobile technologies used by primary care providers to consult with a hospital-based specialist compared to usual care: Acceptability or satisfaction, Outcome 2: Participant satisfaction with care

\begin{tabular}{|c|c|c|c|c|}
\hline Study & Population & Outcomes & Results & Notes \\
\hline Eminović 2009 & $\begin{array}{l}\text { General practitioners consult- } \\
\text { ing with dermatologists about } \\
\text { adults with skin condition }\end{array}$ & $\begin{array}{l}\text { General satisfaction } \\
\text { Interpersonal aspects of care }\end{array}$ & $\begin{array}{l}\text { IG: Mean } 3.8(\mathrm{SD} 0.59, \mathrm{~N}=191) \\
\text { CG: Mean } 3.8(\mathrm{SD} 0.59, \mathrm{~N}=159) \\
\text { MD: } 0.0(95 \% \mathrm{Cl}-0.12 \text { to } 0.12) \\
\text { IG: Mean } 4.13(\mathrm{SD} 0.62, \mathrm{~N}=191) \\
\text { CG: Mean } 4.15(\mathrm{SD} 0.73, \mathrm{~N}= \\
\text { 159) } \\
\text { MD: } 0.2(95 \% \mathrm{Cl}-0.12 \text { to } 0.16)\end{array}$ & $\begin{array}{l}\text { Shortened version of the Pa- } \\
\text { tient Satisfaction Question- } \\
\text { naire (PSQ III) } \\
1 \text { - } 5 \text {, higher scores indicate } \\
\text { more satisfaction with the care } \\
\text { received } \\
1 \text { month follow-up } \\
\text { IG: Intervention group; CG: } \\
\text { Control group; SD: standard } \\
\text { deviation; } \\
\text { MD: mean difference; CI: confi- } \\
\text { dence interval }\end{array}$ \\
\hline Piette 2017 & $\begin{array}{l}\text { General practitioner consult- } \\
\text { ing with dermatologists re- } \\
\text { garding adults with skin le- } \\
\text { sions }\end{array}$ & $\begin{array}{l}\text { Global satisfaction } \\
\text { Time to treatment satisfaction }\end{array}$ & $\begin{array}{l}\text { Similar proportion of partici- } \\
\text { pants in both groups were sat- } \\
\text { isfied or very satisfied (IG: } 85 \% \text {; } \\
\text { CG: } 94 \%) \\
\text { Higher proportion of partici- } \\
\text { pants in the IG considered the } \\
\text { time for resolution to be short } \\
\text { or very short, compared to the } \\
\text { CG }(46 \%)^{\star}\end{array}$ & $\begin{array}{l}\text { Response rate: } 100 \% \text { ( } N=103) \\
2 \text { questions with a Likert scale } \\
\text { response ( } 1 \text { very satisfied to } 4 \\
\text { very unsatisfied) } \\
\text { Results provided narratively } \\
P=0.20 \text {, as provided by the au- } \\
\text { thors }\end{array}$ \\
\hline Whited 2002 & $\begin{array}{l}\text { General practitioner consult- } \\
\text { ing with dermatologists re- } \\
\text { garding adults with skin condi- } \\
\text { tion }\end{array}$ & Satisfaction & $\begin{array}{l}\text { There was little or no differ- } \\
\text { ence between IG }(N=101) \text { and } \\
\text { CG }(N=93)^{\star}\end{array}$ & $\begin{array}{l}\text { Visit-specific satisfaction ques- } \\
\text { tionnaire (VSQ), } 1 \text { - } 5 \text {, higher } \\
\text { scores indicate more satisfac- } \\
\text { tion } \\
1 \text { month follow-up } \\
{ }^{*} \text { As reported by study authors, } \\
\text { no usable data }\end{array}$ \\
\hline Whited 2013 & $\begin{array}{l}\text { General practitioner consult- } \\
\text { ing with dermatologists re- } \\
\text { garding adults with skin condi- } \\
\text { tion }\end{array}$ & $\begin{array}{l}\text { Overall satisfied with the care } \\
\text { received for skin problem }\end{array}$ & $\begin{array}{l}\text { Agree/strongly agree: IG: } \\
86.8 \% \text {; CG: } 92 \% \\
\text { Neutral: IG: } 8.8 \% \text {; CG: } 6.7 \% \\
\text { Disagree/Strongly disagree: IG: } \\
\text { 4.5\%; CG: } 1.2 \%\end{array}$ & $\begin{array}{l}\text { Single question assessing } \\
\text { global satisfaction with the } \\
\text { care received } \\
9 \text { months follow-up } \\
\mathrm{N}=159 \text { (IG) and } 166 \text { (CG) }\end{array}$ \\
\hline
\end{tabular}

Comparison 6. Mobile technologies used by primary care providers to consult with a hospital-based specialist compared to usual care: Costs

\begin{tabular}{lllll}
\hline Outcome or subgroup title & $\begin{array}{l}\text { No. of stud- } \\
\text { ies }\end{array}$ & $\begin{array}{l}\text { No. of partici- } \\
\text { pants }\end{array}$ & Statistical method & Effect size \\
\hline 6.1 Costs & 6 & Other data & No numeric data \\
\hline
\end{tabular}

Analysis 6.1. Comparison 6: Mobile technologies used by primary care providers to consult with a hospital-based specialist compared to usual care: Costs, Outcome 1: Costs

\begin{tabular}{llll}
\hline Costs & & & \\
\hline Study & Population & Outcome & Results \\
\hline & & & Notes \\
\hline
\end{tabular}

Mobile technologies to support healthcare provider to healthcare provider communication and management of care (Review) 
Byamba 2015
General practitioners consulting with dermatologists about adults with skin lesions
Total mean costs

CG: USD 3174

IG: intervention group; CG: control group

Costs calculated in USD (2014) *Data as provided by the authors; no further information available

5 months follow-up

Note: there was no evidence of clustering taken into account in the analysis, and we were not able to re-analyse the data. It is possible there are potential unit of analysis errors.

\begin{tabular}{|c|c|c|c|c|}
\hline Eminović 2009 & $\begin{array}{l}\text { General practitioners consult- } \\
\text { ing with dermatologists about } \\
\text { adults with a skin condition }\end{array}$ & Total mean costs & $\begin{array}{l}\text { IG: EUR } 387(95 \% \mathrm{Cl} 281 \text { to } \\
\text { 502.5, N }=312) \\
\text { CG: EUR } 354(95 \% \mathrm{Cl} 228 \text { to } \\
\text { 484, } \mathrm{N}=293) \\
\text { MD: EUR } 32.5(95 \% \mathrm{Cl}-29.0 \text { to } \\
74.7)^{\star}\end{array}$ & $\begin{array}{l}\text { Costs calculated in EUR (2003) } \\
\text { 1-month follow-up } \\
\text { MD: mean difference; CI: confi- } \\
\text { dence interval } \\
\text { ^ Data as provided by authors }\end{array}$ \\
\hline Pak 2007 & $\begin{array}{l}\text { Primary care professional con- } \\
\text { sulting with dermatologist } \\
\text { about adults with skin condi- } \\
\text { tion }\end{array}$ & Total mean costs & $\begin{array}{l}\text { Total direct cost } \\
\text { IG: USD 103,043 (SD:294, N = } \\
\text { 351), CG: } 98,365(283, \mathrm{~N}=347) \\
\text { MD: USD }-4678(95 \% \mathrm{Cl}-4720 \\
\text { to -4635) } \\
\text { Lost productivity } \\
\text { IG: USD 16,359 (SD:47, N = 351) } \\
\text { CG: USD 30,768 (SD 89, N = } \\
\text { 347) } \\
\text { MD: USD 14,409 (95\% Cl 14,398 } \\
\text { to } 14,419)\end{array}$ & $\begin{array}{l}\text { Total direct costs include con- } \\
\text { sultations, } \\
\text { laboratory analyses and proce- } \\
\text { dures and medications } \\
\text { Costs calculated in USD (2006) } \\
\text { 4-month follow-up }\end{array}$ \\
\hline Van Gelder 2017 & $\begin{array}{l}\text { General practitioners consult- } \\
\text { ing with nephrologists about } \\
\text { adults with chronic kidney dis- } \\
\text { ease }\end{array}$ & Mean cost per participant & $\begin{array}{l}\text { IG: EUR 453.86 }(95 \% \mathrm{Cl} 392.98 \\
\text { to } 514.74 ; \mathrm{N}=1277) \\
\text { CG: EUR 433.74 }(95 \% \mathrm{Cl} 387.64 \\
\text { to } 479.84 ; \mathrm{N}=1727) \\
(\mathrm{P}=0.60)\end{array}$ & $\begin{array}{l}\text { Main related medical costs, in- } \\
\text { cluding number of contacts } \\
\text { between healthcare providers } \\
\text { and participant, as well as be- } \\
\text { tween healthcare providers; } \\
\text { lab costs; prescriptions; re- } \\
\text { ferrals to secondary for renal } \\
\text { care. } \\
\text { Costs calculated in EUR (2017) } \\
\text { Follow-up not specified }\end{array}$ \\
\hline Whited 2002 & $\begin{array}{l}\text { General practitioners consult- } \\
\text { ing with dermatologists about } \\
\text { adults with skin condition }\end{array}$ & $\begin{array}{l}\text { Mean expected cost per partic- } \\
\text { ipant per visit }\end{array}$ & $\begin{array}{l}\text { Using basic technology } \\
\text { IG: USD 40.35; CG: USD } 26.50 \\
\text { Using more advanced technol- } \\
\text { ogy } \\
\text { IG: USD 33.10; CG: USD } 21.40\end{array}$ & $\begin{array}{l}\text { Follow-up not specified } \\
\text { Costs calculated in USD (2002) } \\
N=275 \text { participants }\end{array}$ \\
\hline Whited 2013 & $\begin{array}{l}\text { General practitioners consult- } \\
\text { ing with dermatologists about } \\
\text { adults with skin condition }\end{array}$ & $\begin{array}{l}\text { Mean total costs per partici- } \\
\text { pant }\end{array}$ & $\begin{array}{l}\text { Healthcare system perspective* } \\
\text { IG: USD } 308 \text { (SD 298; } N=195) \\
\text { CG: USD } 338 \text { (SD 291; N = 196) } \\
\text { MD: USD } 30 \text { (95\% CI USD -79 to } \\
\text { 20) } \\
\text { Societal perspective }{ }^{\star \star} \\
\text { IG: USD } 460 \text { (SD 428; } N=195) \\
\text { CG: USD } 542 \text { (SD 403; N = 196) } \\
\text { MD USD -82 (95\% CI USD -12 } \\
\text { to -152) }\end{array}$ & $\begin{array}{l}\text { *Includes intervention costs } \\
\text { (healthcare providers input, } \\
\text { dermatology visits, medica- } \\
\text { tion, travel reimbursement) } \\
{ }^{\star \star} \text { Travel, loss of productivity, } \\
\text { other dermatology care } \\
\text { USD Follow-up } 9 \text { months } \\
\text { Costs calculated in USD (2011) }\end{array}$ \\
\hline
\end{tabular}

Comparison 7. Mobile technologies used by primary care providers to consult with a hospital-based specialist compared to usual care: Technical difficulties

\begin{tabular}{llll}
\hline Outcome or subgroup title & $\begin{array}{l}\text { No. of } \\
\text { studies }\end{array}$ & $\begin{array}{l}\text { No. of } \\
\text { partici- } \\
\text { pants }\end{array}$ & Statistical method \\
\hline 7.1 Technical difficulties & 4 & Other data & Other data numeric data \\
\hline 7.1 .1 Quality of the data transmitted & 4 & No numeric data \\
\hline
\end{tabular}


Analysis 7.1. Comparison 7: Mobile technologies used by primary care providers to consult with a hospital-based specialist compared to usual care: Technical difficulties, Outcome 1: Technical difficulties

\begin{tabular}{|c|c|c|c|c|}
\hline \multicolumn{5}{|c|}{ Technical difficulties } \\
\hline Study & Population & Outcome & Results & Notes \\
\hline \multicolumn{5}{|c|}{ Quality of the data transmitted } \\
\hline Pak 2007 & $\begin{array}{l}\text { Primary care providers con- } \\
\text { sulting with dermatologist } \\
\text { about adults referred to the } \\
\text { dermatology service from pri- } \\
\text { mary care clinics }\end{array}$ & Technical problems & $\begin{array}{l}\text { 20/528 participants' images } \\
\text { were lost }\end{array}$ & 10 images in each group \\
\hline Piette 2017 & $\begin{array}{l}\text { General practitioner consult- } \\
\text { ing with dermatologists about } \\
\text { adults with skin lesions }\end{array}$ & $\begin{array}{l}\text { Technical quality of the im- } \\
\text { ages received }\end{array}$ & $\begin{array}{l}11 / 53 \text { participants' images did } \\
\text { not have enough quality as to } \\
\text { allow diagnosis or treatment } \\
\text { or both }\end{array}$ & $\begin{array}{l}\text { Intervention group only } \\
\text { The dermatologist was able } \\
\text { to make a decision about the } \\
\text { need of an in-person appoint- } \\
\text { ment for } 8 \text { of the clients, based } \\
\text { on the clinical notes sent along } \\
\text { with the images }\end{array}$ \\
\hline Sutherland 2009 & $\begin{array}{l}\text { General practitioner consult- } \\
\text { ing with radiologists about } \\
\text { clients aged } \geq 13 \text { years requir- } \\
\text { ing a trans-abdominal or trans- } \\
\text { vaginal ultrasound }\end{array}$ & $\begin{array}{l}\text { Technical quality of the im- } \\
\text { ages received }\end{array}$ & $\begin{array}{l}\text { Mean } 4.6 \text { (standard deviation } \\
0.5 \text { ) } \\
\text { Procedural quality } \\
\text { Mean } 4.7 \text { (standard deviation } \\
0.6 \text { ) }\end{array}$ & $\begin{array}{l}\text { As rated by } 6 \text { radiologists } \\
\text { based on } 53 \text { scans, delivered } \\
\text { by email; } 1-5 \text {, higher scores } \\
\text { represent better quality of the } \\
\text { images and the procedure } \\
\text { Intervention group only }\end{array}$ \\
\hline Whited 2002 & $\begin{array}{l}\text { General practitioner consult- } \\
\text { ing with dermatologists about } \\
\text { adults referred to the derma- } \\
\text { tology service from primary } \\
\text { care clinics }\end{array}$ & $\begin{array}{l}\text { Technical quality of the im- } \\
\text { ages received }\end{array}$ & $\begin{array}{l}\text { Due to the bad quality of the } \\
\text { images transmitted, } 1 / 134 \\
\text { clients allocated to the IG re- } \\
\text { quired an in-person consulta- } \\
\text { tion }\end{array}$ & Intervention group only \\
\hline
\end{tabular}

Comparison 8. Mobile technologies for use in the emergency department compared to usual care: Time between presentation and management of the health condition

\begin{tabular}{lllll}
\hline Outcome or subgroup title & $\begin{array}{l}\text { No. of } \\
\text { studies }\end{array}$ & $\begin{array}{l}\text { No. of par- } \\
\text { ticipants }\end{array}$ & Statistical method Effect size \\
\hline 8.1 Time between presentation and management & 1 & Other data & No numeric data \\
\hline
\end{tabular}

Analysis 8.1. Comparison 8: Mobile technologies for use in the emergency department compared to usual care: Time between presentation and management of the health condition, Outcome 1: Time between presentation and management

\begin{tabular}{|c|c|c|c|c|}
\hline \multicolumn{5}{|c|}{ Time between presentation and management } \\
\hline Study & Population & Outcome & Results & Notes \\
\hline Gulacti 2017 & $\begin{array}{l}\text { Emergency physicians con- } \\
\text { sulting with specialists about } \\
\text { adults attending the emer- } \\
\text { gency department; duration } \\
\text { not provided }\end{array}$ & Median consult time ${ }^{\star}$ & $\begin{array}{l}\text { IG: } 158 \text { minutes (IQR: } 133 \text { to } \\
177.25,95 \% \mathrm{Cl}: 150 \text { to } 169, \mathrm{~N}= \\
\text { 173) } \\
\text { CG: } 170 \text { minutes (IQR: } 165 \text { to } \\
\text { 188.5, } 95 \% \mathrm{Cl}: 170 \text { to } 171, \mathrm{~N}= \\
\text { 172) } \\
\text { Median difference: }-12 \text { min- } \\
\text { utes }(95 \% \mathrm{Cl}:-19 \text { to }-7 \text { ), } \mathrm{P}< \\
0.0001^{\star \star}\end{array}$ & $\begin{array}{l}\text { * Time when consultation was } \\
\text { requested } \\
\text { minus time when a bed was re- } \\
\text { quested (for admission to hos- } \\
\text { pital) or discharge time } \\
\text { IG: intervention group; CG: } \\
\text { control group; Cl: confidence } \\
\text { interval } \\
{ }^{\star \star} \text { Data as provided by the au- } \\
\text { thors }\end{array}$ \\
\hline
\end{tabular}


Comparison 9. Mobile technologies for use in the emergency department compared to usual care: Healthcare use

\begin{tabular}{lllll}
\hline Outcome or subgroup title & $\begin{array}{l}\text { No. of stud- } \\
\text { ies }\end{array}$ & $\begin{array}{l}\text { No. of partici- } \\
\text { pants }\end{array}$ & Statistical method & Effect size \\
\hline 9.1 Healthcare use & 1 & Other data & No numeric data \\
\hline
\end{tabular}

Analysis 9.1. Comparison 9: Mobile technologies for use in the emergency department compared to usual care: Healthcare use, Outcome 1: Healthcare use

\begin{tabular}{|c|c|c|c|c|}
\hline \multicolumn{5}{|l|}{ Healthcare use } \\
\hline Study & Population & Outcome & Results & Notes \\
\hline Gulacti 2017 & $\begin{array}{l}\text { Emergency physicians con- } \\
\text { sulting with specialists about } \\
\text { adults attending the emer- } \\
\text { gency department }\end{array}$ & $\begin{array}{l}\text { Median emergency depart- } \\
\text { ment length of stay }\end{array}$ & $\begin{array}{l}\text { IG: } 240 \text { minutes (IQR: } 230 \text { to } \\
270,95 \% \mathrm{Cl}: 240 \text { to } 255.2, \mathrm{~N}= \\
\text { 173) } \\
\text { CG: } 277 \text { minutes (IQR: } 270 \text { to } \\
287.8,95 \% \mathrm{Cl}: 277 \text { to } 279, \mathrm{~N}= \\
\text { 172) } \\
\text { Median difference }-30 \text { min- } \\
\text { utes, } 95 \% \mathrm{Cl}-37 \text { to }-25^{\star}\end{array}$ & $\begin{array}{l}\text { IG: intervention group; CG: } \\
\text { control group; IQR: interquar- } \\
\text { tile range; CI: confidence inter- } \\
\text { val } \\
\text { Follow-up not specified } \\
\text { * Data provided by study au- } \\
\text { thors }\end{array}$ \\
\hline
\end{tabular}

Comparison 10. Mobile technologies for use in the emergency department compared to usual care: Technical difficulties

\begin{tabular}{lllll}
\hline Outcome or subgroup title & $\begin{array}{l}\text { No. of } \\
\text { studies }\end{array}$ & $\begin{array}{l}\text { No. of } \\
\text { partici- } \\
\text { pants }\end{array}$ & Statistical method Effect size \\
\hline 10.1 Technical difficulties & 1 & Other data & No numeric data \\
\hline 10.1 .1 Quality of the data transmitted & 1 & Other data & No numeric data \\
\hline
\end{tabular}

Analysis 10.1. Comparison 10: Mobile technologies for use in the emergency department compared to usual care: Technical difficulties, Outcome 1: Technical difficulties

\begin{tabular}{llll}
\hline Technical difficulties & & & Results \\
\hline Study & Population & Outcome & Notes \\
\hline Quality of the data transmitted & & & There were no problems re- \\
pulacti 2017 & $\begin{array}{l}\text { Emergency physicians con- } \\
\text { sulting with specialists about } \\
\text { adults attending the emer- } \\
\text { gency department }\end{array}$ & Technical problems & \\
\hline
\end{tabular}


Comparison 11. Mobile technologies used by community health workers or home-care workers compared to usual care: Healthcare use

\begin{tabular}{lllll}
\hline Outcome or subgroup title & $\begin{array}{l}\text { No. of } \\
\text { studies }\end{array}$ & $\begin{array}{l}\text { No. of partici- } \\
\text { pants }\end{array}$ & Statistical method & Effect size \\
\hline 11.1 Healthcare use & 2 & Other data & No numeric data \\
\hline
\end{tabular}

Analysis 11.1. Comparison 11: Mobile technologies used by community health workers or home-care workers compared to usual care: Healthcare use, Outcome 1: Healthcare use

\begin{tabular}{|c|c|c|c|c|}
\hline \multicolumn{5}{|l|}{ Healthcare use } \\
\hline Study & Population & Outcome & Results & Notes \\
\hline Iversen 2018 & $\begin{array}{l}\text { Community nurses consulting } \\
\text { with diabetes specialist nurses } \\
\text { and podiatrists about adults } \\
\text { aged } \geq 20 \text { years with new dia- } \\
\text { betes-related foot ulcers }\end{array}$ & $\begin{array}{l}\text { Outpatient clinic consultations } \\
\text { Community nurse consulta- } \\
\text { tions }\end{array}$ & $\begin{array}{l}\text { IG: Mean 2.8 (SD 1.9, } \mathrm{N}=94) \text {, } \\
\text { CG: Mean } 2.5(\mathrm{SD} 3.0, \mathrm{~N}=88) \\
\text { MD }-0.48(95 \% \mathrm{Cl}-1.46 \text { to } 0.49) \\
\text { IG: M } 6.7(\mathrm{SD} 3.4, \mathrm{~N}=94), \mathrm{CG}: \mathrm{M} \\
5.9(\mathrm{SD} 4.6, \mathrm{~N}=88) \\
\text { MD } 0.92(95 \% \mathrm{Cl}-0.70 \text { to } 2.53)\end{array}$ & $\begin{array}{l}\text { 12-month follow-up } \\
\text { SD: standard deviation; MD: } \\
\text { mean difference; } \mathrm{Cl} \text { : confi- } \\
\text { dence interval }\end{array}$ \\
\hline Orlandoni 2016 & $\begin{array}{l}\text { Home-visiting nursing staff } \\
\text { consulting with a hospital } \\
\text { physician about older adults } \\
\text { treated with home enteral nu- } \\
\text { trition }\end{array}$ & $\begin{array}{l}\text { Outpatient visits } \\
\text { Hospitalisations }\end{array}$ & $\begin{array}{l}\text { Incidence rate ratio } 95 \% \mathrm{Cl} \text { : } \\
0.65 \text { to } 1.30, \mathrm{P}=0.62 \\
\text { Incidence rate ratio } 95 \% \mathrm{Cl} \text { : } \\
0.54 \text { to } 1.19, \mathrm{P}=0.26^{\star}\end{array}$ & $\begin{array}{l}12 \text {-month follow-up } \\
{ }^{\star} \text { Data as provided by the au- } \\
\text { thors }\end{array}$ \\
\hline
\end{tabular}

Comparison 12. Mobile technologies used by community health workers or home-care workers compared to usual care: Participant's healthcare status and well-being

\begin{tabular}{lllll}
\hline Outcome or subgroup title & $\begin{array}{l}\text { No. of } \\
\text { studies }\end{array}$ & $\begin{array}{l}\text { No. of par- } \\
\text { ticipants }\end{array}$ & Statistical method Effect size \\
\hline 12.1 Participant healthcare status and well-being & 3 & Other data & No numeric data \\
\hline
\end{tabular}

Analysis 12.1. Comparison 12: Mobile technologies used by community health workers or home-care workers compared to usual care: Participant's healthcare status and well-being, Outcome 1: Participant healthcare status and well-being

\begin{tabular}{|c|c|c|c|c|}
\hline \multicolumn{5}{|c|}{ Participant healthcare status and well-being } \\
\hline Study & Population & Outcome & Results & Notes \\
\hline Chang 2011 & $\begin{array}{l}\text { Community-based peer health } \\
\text { workers consulting with clinic } \\
\text { staff about adults who were } \\
\text { receiving or started receiving } \\
\text { antiretroviral therapy }\end{array}$ & Mortality & $\begin{array}{l}\text { IG: } 37 / 446 ; \text { CG: } 53 / 524 \\
\text { RR } 0.82,95 \% \text { CI } 0.55 \text { to } 1.22\end{array}$ & Average follow-up: 103 weeks \\
\hline Iversen 2018 & $\begin{array}{l}\text { Community nurses consulting } \\
\text { with diabetes specialist nurses } \\
\text { and podiatrists about adults } \\
\text { aged } \geq 20 \text { years with new dia- } \\
\text { betes-related foot ulcers }\end{array}$ & Mortality & $\begin{array}{l}\text { IG: } 5 / 99 ; \text { CG } 5 / 88 \\
\text { RR } 0.94,95 \% \text { CI } 0.28 \text { to } 3.12\end{array}$ & 12 months follow-up \\
\hline Taylor-Gjevre 2018 & $\begin{array}{l}\text { Rural-based physical ther- } \\
\text { apists consulting with ur- } \\
\text { ban-based rheumatologists } \\
\text { about adults with a clinical di- } \\
\text { agnosis of rheumatoid arthritis }\end{array}$ & $\begin{array}{l}\text { Disease activity } \\
\text { Health-related quality of life }\end{array}$ & $\begin{array}{l}\text { DAS28-CRPa } \\
\text { MD 0.9 }(95 \% \mathrm{Cl}-1.2 \text { to } 3.1, \mathrm{P}= \\
0.33) \\
\text { mHAQ } \\
\text { MD } 0.2(95 \% \mathrm{Cl}-0.1 \text { to } 0.5, \mathrm{P}= \\
0.14)\end{array}$ & $\begin{array}{l}\text { aDisease activity score for } \\
\text { rheumatoid arthritis, higher } \\
\text { scores represent greater dis- } \\
\text { ease activity } \\
\text { b Modified health assessment } \\
\text { questionnaire, } 0-3 \text {, higher }\end{array}$ \\
\hline
\end{tabular}

Mobile technologies to support healthcare provider to healthcare provider communication and management of care (Review) 


\section{RADAIC}

MD $0.9(95 \% \mathrm{Cl}-0.5$ to $2.4, \mathrm{P}=$

$$
\text { 0.19) }
$$

EQ5Dd

$\mathrm{MD}-0.1(95 \% \mathrm{Cl}-0.4$ to $0.1, \mathrm{P}$

$=0.29)^{\star}$ scores represent greater impairment

'Rheumatoid arthritis disease activity index, 0 - 10, higher scores represent greater disease activity

dEuroQol 5 dimensions questionnaire (EQ5D), 0 - 1, higher scores represent better healthrelated quality of life

Mean difference (MD) between groups, (Control ( $\mathrm{N}=31)$, Intervention $(N=54))$, from base-

line to 9-month follow-up All data as provided by the study authors

Comparison 13. Mobile technologies used by community health workers or home-care workers compared to usual care: Acceptability or satisfaction

\begin{tabular}{|c|c|c|c|c|}
\hline Outcome or subgroup title & $\begin{array}{l}\text { No. of } \\
\text { studies }\end{array}$ & $\begin{array}{l}\text { No. of partici- } \\
\text { pants }\end{array}$ & Statistical method & Effect size \\
\hline 13.1 Participant satisfaction with care & 2 & & Other data & No numeric data \\
\hline
\end{tabular}

Analysis 13.1. Comparison 13: Mobile technologies used by community health workers or home-care workers compared to usual care: Acceptability or satisfaction, Outcome 1: Participant satisfaction with care

\begin{tabular}{|c|c|c|c|c|}
\hline \multicolumn{5}{|c|}{ Participant satisfaction with care } \\
\hline Study & Population & Outcome & Results & Notes \\
\hline Iversen 2018 & $\begin{array}{l}\text { Community nurses consulting } \\
\text { with diabetes specialist nurses } \\
\text { and podiatrists about adults } \\
\text { aged } \geq 20 \text { years with new dia- } \\
\text { betes-related foot ulcers }\end{array}$ & Experience with healthcare & $\begin{array}{l}\text { IG: M } 4.4(\mathrm{SD} 0.5, \mathrm{~N}=67) \\
\text { CG: } \mathrm{M} 4.4(\mathrm{SD} 0.5, \mathrm{~N}=57) \\
\text { MD: } 0.0(95 \% \mathrm{Cl}-0.18 \text { to } 0.18)\end{array}$ & $\begin{array}{l}\text { Generic Short Patient Experi- } \\
\text { ences Questionnaire (GS-PEQ), } \\
1 \text { - 5, higher scores indicate } \\
\text { more satisfaction } \\
\text { 12-month follow-up }\end{array}$ \\
\hline Taylor-Gjevre 2018 & $\begin{array}{l}\text { Rural-based physical ther- } \\
\text { apists consulting with ur- } \\
\text { ban-based rheumatologists } \\
\text { about adults with a clinical di- } \\
\text { agnosis of rheumatoid arthritis }\end{array}$ & Participant satisfaction & $\begin{array}{l}\text { There was little or no differ- } \\
\text { ence between IG }(N=31) \text { and } \\
C G(N=23)^{\star}\end{array}$ & $\begin{array}{l}\text { Visit specific satisfaction ques- } \\
\text { tionnaire (VSQ9), } 1 \text { - } 5 \text {, higher } \\
\text { scores indicate more satisfac- } \\
\text { tion } \\
\text { 9-month follow-up } \\
{ }^{*} \text { As reported by study authors, } \\
\text { no usable data }\end{array}$ \\
\hline
\end{tabular}

Comparison 14. Mobile technologies used by community health workers or home-care workers compared to usual care: Costs

\begin{tabular}{llll}
\hline Outcome or subgroup title & $\begin{array}{l}\text { No. of stud- } \\
\text { ies }\end{array}$ & $\begin{array}{l}\text { No. of partici- } \\
\text { pants }\end{array}$ & Statistical method \\
\hline 14.1 Costs & 1 & Other data \\
\hline
\end{tabular}

Analysis 14.1. Comparison 14: Mobile technologies used by community health workers or home-care workers compared to usual care: Costs, Outcome 1: Costs 


\begin{tabular}{|c|c|c|c|c|}
\hline Study & Population & Outcome & Results & Notes \\
\hline Chang 2011 & $\begin{array}{l}\text { Community-based peer health } \\
\text { workers consulting with clinic } \\
\text { staff about adults who were } \\
\text { receiving or started receiving } \\
\text { antiretroviral therapy }\end{array}$ & $\begin{array}{l}\text { Yearly total cost of running the } \\
\text { mHealth intervention } \\
\text { Cost per participant }\end{array}$ & $\begin{array}{l}\mathrm{N}=29 \text { clusters, } 970 \text { partici- } \\
\text { pants. } \\
\text { USD } 1046 \\
\text { USD } 2.35\end{array}$ & $\begin{array}{l}\text { Intervention arm only, costs } \\
\text { calculated in Ugandan } \\
\text { shillings and converted to USD } \\
\text { (2011). } \\
\text { Does not include cost of a pre- } \\
\text { viously set-up intervention } \\
\text { to train peer health workers, } \\
\text { to which the mHealth was an } \\
\text { add-on } \\
\text { Average follow-up: } 103 \text { weeks }\end{array}$ \\
\hline
\end{tabular}

Comparison 15. Mobile technologies used by community health workers or home-care workers compared to usual care: Technical difficulties

\begin{tabular}{lllll}
\hline Outcome or subgroup title & $\begin{array}{l}\text { No. of } \\
\text { studies }\end{array}$ & $\begin{array}{l}\text { No. of } \\
\text { partici- } \\
\text { pants }\end{array}$ & $\begin{array}{l}\text { Statistical } \\
\text { method }\end{array}$ & Effect size \\
\hline 15.1 Technical difficulties & 2 & Other data & No numeric data \\
\hline $\begin{array}{l}\text { 15.1.1 Quality of the data transmitted } \\
\begin{array}{l}\text { 15.1.2 Technical difficulties reported by the healthcare pro- } \\
\text { fessionals }\end{array}\end{array}$ & 1 & Other data & No numeric data \\
\hline
\end{tabular}

Analysis 15.1. Comparison 15: Mobile technologies used by community health workers or homecare workers compared to usual care: Technical difficulties, Outcome 1: Technical difficulties

\begin{tabular}{|c|c|c|c|c|}
\hline \multicolumn{5}{|l|}{ Technical difficulties } \\
\hline Study & Population & Outcomes & Results & Notes \\
\hline \multicolumn{5}{|c|}{ Quality of the data transmitted } \\
\hline Taylor-Gjevre 2018 & $\begin{array}{l}\text { Community nurses consulting } \\
\text { with diabetes specialist nurses } \\
\text { and podiatrists about adults } \\
\text { aged } \geq 20 \text { years with new dia- } \\
\text { betes-related foot ulcers }\end{array}$ & Technical problems & $\begin{array}{l}\text { For } 10 \text { video-conferencing vis- } \\
\text { its images were not transmit- } \\
\text { ted and only an audio-link was } \\
\text { available }\end{array}$ & $\begin{array}{l}\text { Unclear how many visits were } \\
\text { conducted in total } \\
\text { Intervention group only }\end{array}$ \\
\hline Chang 2011 & $\begin{array}{l}\text { Community-based peer health } \\
\text { workers consulting with clinic } \\
\text { staff about adults who were } \\
\text { receiving or started receiving } \\
\text { antiretroviral therapy }\end{array}$ & Problems with the equipment & $\begin{array}{l}\text { Healthcare professionals were } \\
\text { not always able to charge the } \\
\text { mobile phone } \\
\text { Some mobile phones were } \\
\text { stolen }\end{array}$ & $\begin{array}{l}\text { Qualitative outcomes based } \\
\text { on a small number of inter- } \\
\text { views (4) } \\
\text { Intervention group only }\end{array}$ \\
\hline
\end{tabular}

\section{ADDITIONAL TABLES}

Table 1. Intervention components

\begin{tabular}{lll}
\hline Study & Incentives & Specific training \\
\hline Armstrong 2018 & $\begin{array}{ll}\text { Participants were paid } \\
\text { for participating in the } \\
\text { study, through gift cards }\end{array}$ & $\begin{array}{l}\text { Participants and their carers were taught how to take standardised images of } \\
\text { skin lesions, as well as how to communicate with the dermatologist using a se- } \\
\text { cure web-based system. PCPs also had access to the training materials. (Protocol, } \\
\text { p.19, 2nd paragraph) }\end{array}$ \\
\hline
\end{tabular}

Mobile technologies to support healthcare provider to healthcare provider communication and management of care (Review) 
Table 1. Intervention components (Continued)

(main paper, p.3, end

1st paragraph)

\begin{tabular}{|c|c|c|}
\hline Byamba 2015 & - & $\begin{array}{l}\text { GPs attended a 2-day training session to learn how to take images and use the } \\
\text { medical record system and software on mobile phones ( } p .1 \text {, top } 2^{\text {nd }} \text { column) }\end{array}$ \\
\hline Chang 2011 & $\begin{array}{l}\text { PHWs were given a bi- } \\
\text { cycle, t-shirts, basic } \\
\text { supplies, and an ini- } \\
\text { tial monthly allowance } \\
\text { (parent trial) }\end{array}$ & $\begin{array}{l}\text { PHWs allocated to the intervention group were given a mobile phone, and at- } \\
\text { tended a 1-day residential training and a brief field-based practical training on } \\
\text { the intervention (main paper, p.3, 2nd paragraph) }\end{array}$ \\
\hline Eminović 2009 & - & $\begin{array}{l}\text { GPs allocated to the intervention group received detailed instructions on how to } \\
\text { take digital images and use the web-based form (main paper, p.559, bottom 1st } \\
\text { column) }\end{array}$ \\
\hline Iversen 2018 & - & $\begin{array}{l}\text { All staff received training in the use of the web-based system, as well as in-person } \\
\text { access to hospital clinics to improve their practical skills (main paper, pp.97-8) }\end{array}$ \\
\hline Liddy 2019a & $\begin{array}{l}\text { Specialists received fi- } \\
\text { nancial incentives for } \\
\text { each eConsult they un- } \\
\text { dertook (support paper, } \\
\text { under 8. Payment) }\end{array}$ & - \\
\hline Mansberger 2015 & $\begin{array}{l}\text { Participants received } \\
\text { monetary incentive to } \\
\text { complete follow-up } \\
\text { questionnaire (associat- } \\
\text { ed paper, p.524, bottom } \\
\text { 1st column) }\end{array}$ & $\begin{array}{l}\text { Technicians performing imaging attended a 3-day training session to learn how } \\
\text { to take images and ongoing feedback as needed (main paper, p.943, bottom 1st } \\
\text { column) }\end{array}$ \\
\hline Piette 2017 & - & $\begin{array}{l}\text { GPs received training and a workbook on how to take photographs (p.2, top 2nd } \\
\text { column) }\end{array}$ \\
\hline Sutherland 2009 & - & $\begin{array}{l}\text { The on-site investigator received sonographic training over a 2-month period, as } \\
\text { well as practice guidelines for trans-abdominal ultrasound scanning (P. 192, mid } \\
\text { 1st column and top } 2 \text { nd column) }\end{array}$ \\
\hline Taylor-Gjevre 2018 & - & $\begin{array}{l}\text { Physical therapists and rheumatologists received an orientation and education } \\
\text { session about rheumatoid arthritis and the study protocol and methods (main } \\
\text { paper, p.2, top 2nd column) }\end{array}$ \\
\hline
\end{tabular}

GP: general practitioner; PCP: primary care provider; PHW: peer health workers

Table 2. Equity considerations

\begin{tabular}{llll}
\hline Study ID & Population & $\begin{array}{l}\text { Disadvantaged populations included/exclud- } \\
\text { ed? }\end{array}$ & Notes \\
\hline $\begin{array}{l}\text { Armstrong } \\
\mathbf{2 0 1 8}\end{array}$ & $\begin{array}{l}\text { General practitioner consulting with der- } \\
\text { matologists about adults with psoriasis }\end{array}$ & $\begin{array}{l}\text { Participants without access to the Internet and } \\
\text { a digital camera or smartphone with camera fea- } \\
\text { tures were excluded }\end{array}$ & $\begin{array}{l}\text { - } \\
\text { Azogil-López }\end{array}$ \\
$\begin{array}{llll}\mathbf{2 0 1 9} \\
\text { GP consulting with hospital physicians }\end{array}$ & $\begin{array}{l}\text { Participants deemed as complex were not eligible } \\
\text { for receiving the intervention }\end{array}$ & $\begin{array}{l}\text { Complex partic- } \\
\text { ipants defined } \\
\text { ab those lacking }\end{array}$
\end{tabular}


Table 2. Equity considerations (Continued)

a specific diagnosis or requiring further clinical assessment

\begin{tabular}{ll} 
Byamba 2015 & $\begin{array}{l}\text { GP consulting with dermatologists about } \\
\text { adults with skin lesions }\end{array}$ \\
\hline Chang 2011 & $\begin{array}{l}\text { Community-based peer health workers } \\
\text { consulting with clinic staff about adults } \\
\text { who were receiving or started receiving } \\
\text { antiretroviral therapy }\end{array}$
\end{tabular}

Intervention was set in rural health clinics in Mongolia

Specifically targeted HIV-positive participants in rural Uganda. However, many participants had limited access to mobile phones ${ }^{\star}$, which might have limited the benefits of the intervention.

For the healthcare providers, the costs of the intervention were also a factor, as although they were given a monthly stipend it was not always enough

Charging the mobile phone was often challenging, as access to electricity was limited

\begin{tabular}{|c|c|c|c|}
\hline Davis 2003 & $\begin{array}{l}\text { PCPs at the rural primary practice con- } \\
\text { sulting with ophthalmologist in the uni- } \\
\text { versity setting about adults with Type } 2 \\
\text { diabetes }\end{array}$ & $\begin{array}{l}\text { Specifically targeted rural-based ethnic minori- } \\
\text { ties, 35\% of whom did not have health insurance }\end{array}$ & - \\
\hline Gulacti 2017 & $\begin{array}{l}\text { Emergency physicians consulting with } \\
\text { specialists about adults attending the } \\
\text { emergency department }\end{array}$ & $\begin{array}{l}\text { Only consultants who owned a smartphone and } \\
\text { were familiarised with the secure messaging ser- } \\
\text { vice were included }\end{array}$ & - \\
\hline $\begin{array}{l}\text { Mansberger } \\
2015\end{array}$ & $\begin{array}{l}\text { PCPs consulting with experienced inves- } \\
\text { tigators based at an eye institute about } \\
\text { adults with Type } 2 \text { diabetes }\end{array}$ & $\begin{array}{l}\text { Primary clinics that served a large number of eth- } \\
\text { nic minorities, including a high percentage of par- } \\
\text { ticipants with transient housing }\end{array}$ & - \\
\hline Piette 2017 & $\begin{array}{l}\text { General practitioners consulting with der- } \\
\text { matologists about adults with skin le- } \\
\text { sions }\end{array}$ & $\begin{array}{l}\text { Participants who were not able to attend in-per- } \\
\text { son appointments at the dermatologist office } \\
\text { were excluded, i.e. participants unable to travel or } \\
\text { those residing in nursing homes. }\end{array}$ & - \\
\hline $\begin{array}{l}\text { Sutherland } \\
2009\end{array}$ & $\begin{array}{l}\text { GP consulting with radiologists about } \\
\text { participants aged } \geq 13 \text { years requiring a } \\
\text { trans-abdominal or trans-vaginal ultra- } \\
\text { sound }\end{array}$ & $\begin{array}{l}\text { Sample was composed mainly of low-skilled } \\
\text { workers relying on government-supported prima- } \\
\text { ry clinics for their health care }\end{array}$ & - \\
\hline $\begin{array}{l}\text { Taylor-Gjevre } \\
2018\end{array}$ & $\begin{array}{l}\text { Community nurses consulting with dia- } \\
\text { betes specialist nurses and podiatrists } \\
\text { about adults aged } \geq 20 \text { years with new di- } \\
\text { abetes-related foot ulcers }\end{array}$ & Specifically targeted rural-based adults & - \\
\hline Whited 2013 & $\begin{array}{l}\text { GP consulting with dermatologists about } \\
\text { adults with skin condition }\end{array}$ & $\begin{array}{l}\text { Participants who could not speak or read English } \\
\text { or who failed a single-question literacy assess- } \\
\text { ment }^{*} \text { were excluded }\end{array}$ & $\begin{array}{l}\text { *Single-Item } \\
\text { Literacy } \\
\text { Screener (SILS), } \\
\text { which identifies } \\
\text { limited reading } \\
\text { ability (Morris } \\
\text { 2006) }\end{array}$ \\
\hline
\end{tabular}

GP: General practitioner; PCP: primary care provider; PHW: Peer health workers 


\section{APPENDICES}

\section{Appendix 1. Search strategies and results}

Ovid MEDLINE(R) In-Process \& Other Non-Indexed Citations, Ovid MEDLINE(R) Daily and Ovid MEDLINE(R) <1946 to Present> Searched 25 September 2018

\begin{tabular}{|c|c|}
\hline 1 & exp Health Personnel/ \\
\hline 2 & $\begin{array}{l}\left.\left.\text { (((health or medical or healthcare) adj (personnel or worker }{ }^{\star} \text { or auxiliar* or staff or professional }{ }^{\star}\right)\right) \\
\text { or doctor }^{\star} \text { or physician }^{\star} \text { or GP or general practitioner? or family doctor or nurse } \text { or midwi }^{\star} \text { or clin- } \\
\text { ical officer } \text { or pharmacist }^{\star} \text { or dentist* or ((birth or childbirth or labor or labour) adj (attendant? or } \\
\text { assistant?))).ti,ab,kw. }\end{array}$ \\
\hline
\end{tabular}

3 ((lay or voluntary or volunteer? or untrained or unlicensed or nonprofessional? or non professional?) adj5 (worker? or visitor? or attendant? or aide or aides or support\$ or person\$ or helper? or carer? or caregiver? or care giver? or consultant? or assistant? or staff)).ti,ab,kw.

(paraprofessional? or paramedic or paramedics or paramedical worker? or paramedical personnel or allied health personnel or allied health worker? or support worker? or home health aide?).ti,ab,kw.

\begin{tabular}{|c|c|}
\hline 5 & $\begin{array}{l}\text { ((community or village? or lay) adj3 (health worker? or health care worker? or healthcare work- } \\
\text { er?)).ti,ab,kw. }\end{array}$ \\
\hline 6 & (doula? or douladural? or barefoot doctor?).ti,ab,kw. \\
\hline 7 & 1 or 2 or 3 or 4 or 5 or 6 \\
\hline 8 & Cell Phones/ \\
\hline 9 & Smartphone/ \\
\hline 10 & MP3-Player/ \\
\hline 11 & Computers, Handheld/ \\
\hline 12 & $\left(\left(\right.\right.$ cell $^{\star}$ or mobile $\left.{ }^{\star}\right)$ adj1 (phone ${ }^{\star}$ or telephone ${ }^{\star}$ or technolog ${ }^{\star}$ or device $\left.)\right) . t i, a b, k w$. \\
\hline 13 & (handheld or hand-held).ti,ab,kw. \\
\hline 14 & (smartphone ${ }^{\star}$ or smart-phone* or cellphone ${ }^{\star}$ or mobiles).ti,ab,kw. \\
\hline 15 & 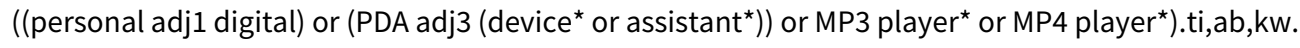 \\
\hline 16 & (samsung or nokia).ti,ab,kw. \\
\hline 17 & (windows adj3 (mobile* or phone*)).ti,ab,kw. \\
\hline 18 & android.ti,ab,kw. \\
\hline 19 & 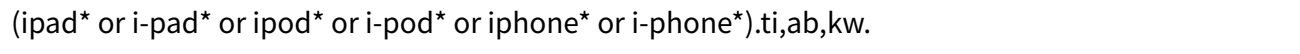 \\
\hline 20 & (tablet ${ }^{\star}$ adj3 (device* or computer $\left.^{\star}\right)$ ).ti,ab,kw. \\
\hline 21 & Telemedicine/ \\
\hline
\end{tabular}

Mobile technologies to support healthcare provider to healthcare provider communication and management of care (Review) 


22 Videoconferencing/ or Webcasts as topic/

\begin{tabular}{|c|c|}
\hline 23 & Text Messaging/ \\
\hline 24 & Telenursing/ \\
\hline 25 & (mhealth or m-health or "mobile health" or ehealth or e-health or "electronic health").ti,ab,kw. \\
\hline 26 & $\begin{array}{l}\text { (telemedicine or tele-medicine or telehealth or tele-health or telecare or tele-care or telenursing or } \\
\text { tele-nursing or telepsychiatry or tele-psychiatry or telemonitor }{ }^{\star} \text { or tele-monitor }{ }^{\star} \text { or teleconsult* or } \\
\left.\text { tele-consult* or telecounsel* or tele-counsel }{ }^{*} \text { or telecoach }{ }^{\star} \text { or tele-coach }\right) . t i, a b, k w .\end{array}$ \\
\hline 27 & (videoconferenc ${ }^{\star}$ or video-conferenc ${ }^{\star}$ or webcast $^{\star}$ or web-cast*).ti,ab,kw. \\
\hline 28 & $\begin{array}{l}\left.\text { (((text }{ }^{\star} \text { or short or voice or multimedia or multi-media or electronic or instant) adj1 messag }{ }^{\star}\right) \text { or in- } \\
\text { stant messenger).ti,ab,kw. }\end{array}$ \\
\hline 29 & $\begin{array}{l}\text { (texting or texted or texter }{ }^{\star} \text { or ((sms or mms) adj (service* or messag*)) or interactive voice re- } \\
\text { sponse }^{\star} \text { or IVR or voice call* or callback* or voice over internet or VOIP).ti,ab,kw. }\end{array}$ \\
\hline 30 & $\begin{array}{l}\text { (Facebook or Twitter or Whatsapp* or Skyp* or YouTube or "You Tube" or Google Hang- } \\
\text { out }^{\star} \text { ).ti,ab,kw. }\end{array}$ \\
\hline 31 & Mobile Applications/ \\
\hline 32 & "mobile app*".ti,ab,kw. \\
\hline 33 & Social Media/ \\
\hline 34 & (social adj (media or network $\left.{ }^{\star}\right)$ ).ti,ab,kw. \\
\hline 35 & Reminder Systems/ \\
\hline 36 & $\left(\right.$ remind $^{\star}$ adj3 (text* or system ${ }^{\star}$ or messag $\left.\left.{ }^{\star}\right)\right) . t i, a b, k w$. \\
\hline 37 & Electronic Mail/ \\
\hline 38 & (electronic mail* or email* or e-mail or webmail).ti,ab,kw. \\
\hline 39 & Medical informatics/ or Medical informatics applications/ \\
\hline 40 & Nursing informatics/ or Public health informatics/ \\
\hline 41 & ((medical or clinical or health or healthcare or nurs $\left.{ }^{\star}\right)$ adj3 informatics).ti,ab,kw. \\
\hline 42 & Multimedia/ \\
\hline 43 & Hypermedia/ \\
\hline 44 & Blogging/ \\
\hline 45 & $\begin{array}{l}\text { (multimedia or multi-media or hypermedia or hyper-media or blog }{ }^{\star} \text { or } \operatorname{llog}^{\star} \text { or weblog }{ }^{\star} \text { or web- } \\
\log ^{\star} \text { ).ti,ab,kw. }\end{array}$ \\
\hline 46 & Interactive Tutorial/ \\
\hline
\end{tabular}




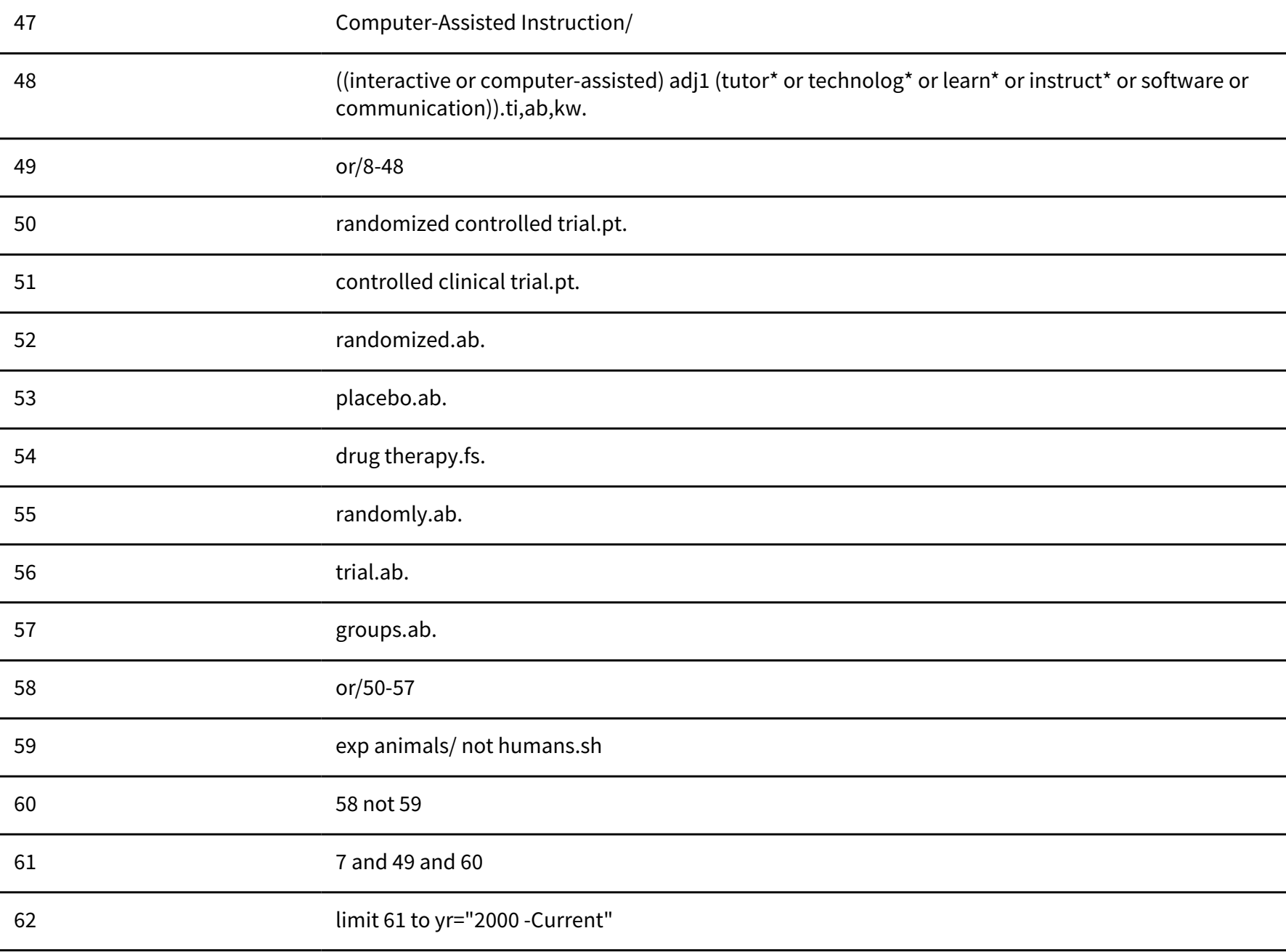

Embase (Ovid) - Searched 25 September 2018

\begin{tabular}{|c|c|}
\hline 1 & mobile phone/ or smartphone/ \\
\hline 2 & mp3 player/ \\
\hline 3 & ((cell ${ }^{\star}$ or mobile*) adj1 (phone* or telephone* or technolog* or device*)).ti,ab,kw. \\
\hline 4 & (handheld or hand-held).ti,ab,kw. \\
\hline 5 & (smartphone ${ }^{\star}$ or smart-phone* or cellphone* or mobiles).ti,ab,kw. \\
\hline 6 & ((personal adj1 digital) or (PDA adj3 (device* or assistant $\left.\left.^{\star}\right)\right)$ or MP3 player ${ }^{\star}$ or MP4 player $\left.{ }^{\star}\right) . t i, a b, k w$. \\
\hline 7 & (samsung or nokia).ti,ab,kw. \\
\hline 8 & (windows adj3 (mobile* or phone $\left.e^{\star}\right)$ ).ti,ab,kw. \\
\hline
\end{tabular}


$10 \quad$ (ipad ${ }^{\star}$ or i-pad ${ }^{\star}$ or ipod ${ }^{\star}$ or i-pod $^{\star}$ or iphone or i-phone $^{\star}$ ).ti,ab,kw.

11 (tablet ${ }^{\star}$ adj3 (device* or computer $\left.^{\star}\right)$ ).ti,ab,kw.

telemedicine/ or telecardiology/or teleconsultation/ or teledermatology/ or telediagnosis/or telemonitoring/ or telepathology/or telepsychiatry/ or teleradiotherapy/ or telesurgery/ or teletherapy/

\begin{tabular}{|c|c|}
\hline 13 & videoconferencing/ or webcast/ \\
\hline 14 & text messaging/ \\
\hline 15 & telenursing/ \\
\hline 16 & (mhealth or m-health or "mobile health" or ehealth or e-health or "electronic health").ti,ab,kw. \\
\hline 17 & $\begin{array}{l}\text { (telemedicine or tele-medicine or telehealth or tele-health or telecare or tele-care or telenursing or } \\
\text { tele-nursing or telepsychiatry or tele-psychiatry or telemonitor }{ }^{\star} \text { or tele-monitor } \text { or teleconsult }^{\star} \text { or } \\
\text { tele-consult }{ }^{\star} \text { or telecounsel }{ }^{\star} \text { or tele-counsel }{ }^{\star} \text { or telecoach }{ }^{*} \text { or tele-coach }{ }^{\star} \text { ).ti,ab,kw. }\end{array}$ \\
\hline 18 & (videoconferenc ${ }^{\star}$ or video-conferenc ${ }^{\star}$ or webcast $^{\star}$ or web-cast $^{\star}$ ).ti,ab,kw. \\
\hline 19 & $\begin{array}{l}\left.\text { (((text* or short or voice or multimedia or multi-media or electronic or instant) adj1 messag }{ }^{\star}\right) \text { or in- } \\
\text { stant messenger).ti,ab,kw. }\end{array}$ \\
\hline 20 & $\begin{array}{l}\left.\left.\text { (texting or texted or texter }{ }^{\star} \text { or ((sms or mms) adj (service* or messag }{ }^{\star}\right)\right) \text { or interactive voice re- } \\
\text { sponse }^{\star} \text { or IVR or voice call }{ }^{\star} \text { or callback* or voice over internet or VOIP).ti,ab,kw. }\end{array}$ \\
\hline 21 & $\begin{array}{l}\text { (Facebook or Twitter or Whatsapp* or Skyp* or YouTube or "You Tube" or Google Hang- } \\
\text { out }^{\star} \text { ).ti,ab,kw. }\end{array}$ \\
\hline 22 & mobile application/ \\
\hline 23 & "mobile app*".ti,ab,kw. \\
\hline 24 & social media/ \\
\hline 25 & (social adj (media or network $\left.{ }^{\star}\right)$ ).ti,ab,kw. \\
\hline 26 & reminder system/ \\
\hline 27 & $\left(\right.$ remind $^{\star} \operatorname{adj}\left(\right.$ text $^{\star}$ or system ${ }^{\star}$ or messag $\left.\left.{ }^{\star}\right)\right) \cdot \mathrm{ti}, \mathrm{ab}, \mathrm{kw}$. \\
\hline 28 & e-mail/ \\
\hline 29 & (electronic mail ${ }^{\star}$ or email* or e-mail or webmail).ti,ab,kw. \\
\hline 30 & medical informatics/ \\
\hline 31 & nursing informatics/ \\
\hline 32 & ((medical or clinical or health or healthcare or nurs*) adj3 informatics).ti,ab,kw. \\
\hline 33 & multimedia/ \\
\hline 34 & hypermedia/ \\
\hline
\end{tabular}




\begin{tabular}{|c|c|}
\hline 35 & blogging/ \\
\hline 36 & $\begin{array}{l}\text { (multimedia or multi-media or hypermedia or hyper-media or blog }{ }^{\star} \text { or vlog }{ }^{\star} \text { or weblog }{ }^{\star} \text { or web- } \\
\log ^{\star} \text { ).ti,ab,kw. }\end{array}$ \\
\hline 37 & teaching/ \\
\hline 38 & $\begin{array}{l}\text { ((interactive or computer-assisted) adj1 (tutor }{ }^{\star} \text { or technolog* or learn }{ }^{\star} \text { or instruct }{ }^{\star} \text { or software or } \\
\text { communication)).ti,ab,kw. }\end{array}$ \\
\hline
\end{tabular}

\begin{tabular}{|c|c|}
\hline 39 & or/1-38 \\
\hline 40 & exp health care personnel/ \\
\hline 41 & 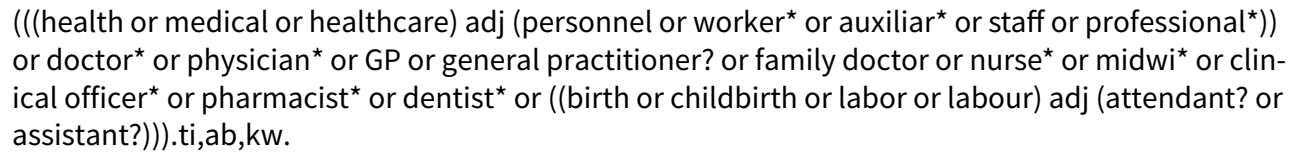 \\
\hline
\end{tabular}

$42 \quad$ ((lay or voluntary or volunteer? or untrained or unlicensed or nonprofessional? or non profession-
al?) adj5 (worker? or visitor? or attendant? or aide or aides or support\$ or person\$ or helper? or car-
er? or caregiver? or care giver? or consultant? or assistant? or staff)).ti,ab,kw.

$\begin{array}{ll}43 & \text { (paraprofessional? or paramedic or paramedics or paramedical worker? or paramedical per- } \\ & \text { sonnel or allied health personnel or allied health worker? or support worker? or home health } \\ & \text { aide?).ti,ab,kw. }\end{array}$

\begin{tabular}{|c|c|}
\hline 44 & $\begin{array}{l}\text { ((community or village? or lay) adj3 (health worker? or health care worker? or healthcare work- } \\
\text { er?)).ti,ab,kw. }\end{array}$ \\
\hline 45 & (doula? or douladural? or barefoot doctor?).ti,ab,kw. \\
\hline 46 & or/40-45 \\
\hline 47 & 39 and 46 \\
\hline 48 & crossover procedure/ \\
\hline 49 & double blind procedure/ \\
\hline 50 & randomized controlled trial/ \\
\hline 51 & single-blind procedure/ \\
\hline 52 & random\$.tw. \\
\hline 53 & factorial\$.tw. \\
\hline 54 & (crossover\$ or cross over\$ or cross-over\$).tw. \\
\hline 55 & placebo\$.tw. \\
\hline 56 & (doubl\$ adj blind\$).tw. \\
\hline 57 & (singl\$ adj blind\$).tw. \\
\hline 58 & assign\$.tw. \\
\hline
\end{tabular}

Mobile technologies to support healthcare provider to healthcare provider communication and management of care (Review) 


\begin{tabular}{ll}
59 & allocat\$.tw. \\
\hline 60 & volunteer\$.tw. \\
\hline 61 & or/48-60 \\
\hline 62 & 47 and 61 \\
\hline 63 & limit 62 to yr="2000 -Current" \\
\hline 64 & limit 63 to embase \\
\hline
\end{tabular}

\section{CENTRAL Register of Trials (Cochrane Library) - Searched 25 September 2018}

\begin{tabular}{|c|c|}
\hline \#1 & MeSH descriptor: [Health Personnel] explode all trees \\
\hline \#2 & $\begin{array}{l}\left.\left.\text { (((health or medical or healthcare) near (personnel or worker* or auxiliar* or staff or professional }{ }^{\star}\right)\right) \\
\text { or doctor } \text { or physician }^{\star} \text { or GP or general practitioner? or family doctor or nurse* or midwi* or clini- } \\
\text { cal officer }{ }^{\star} \text { or pharmacist }{ }^{\star} \text { or dentist* or ((birth or childbirth or labor or labour) near (attendant? or } \\
\text { assistant?))):ti,ab,kw }\end{array}$ \\
\hline \#3 & $\begin{array}{l}\text { ((lay or voluntary or volunteer? or untrained or unlicensed or nonprofessional? or non profession- } \\
\text { al?) near } / 5 \text { (worker? or visitor? or attendant? or aide or aides or support }{ }^{\star} \text { or person* or helper? or } \\
\text { carer? or caregiver? or care giver? or consultant? or assistant? or staff)):ti,ab,kw }\end{array}$ \\
\hline \#4 & $\begin{array}{l}\text { (paraprofessional? or paramedic or paramedics or paramedical worker? or paramedical per- } \\
\text { sonnel or allied health personnel or allied health worker? or support worker? or home health } \\
\text { aide?):ti,ab,kw }\end{array}$ \\
\hline \#5 & $\begin{array}{l}\text { ((community or village? or lay) near/3 (health worker? or health care worker? or healthcare work- } \\
\text { er?)):ti,ab,kw }\end{array}$ \\
\hline \#6 & (doula? or douladural? or barefoot doctor?):ti,ab,kw \\
\hline \#7 & \{or \#1-\#6\} \\
\hline \#8 & MeSH descriptor: [Cell Phones] this term only \\
\hline \#9 & MeSH descriptor: [Smartphone] this term only \\
\hline \#10 & MeSH descriptor: [MP3-Player] this term only \\
\hline \#11 & MeSH descriptor: [Computers, Handheld] this term only \\
\hline \#12 & $\left(\left(\right.\right.$ cell $^{\star}$ or mobile $\left.{ }^{\star}\right)$ near $/ 1$ (phone ${ }^{\star}$ or telephone* or technolog* or device $\left.\left.{ }^{\star}\right)\right):$ ti,ab,kw \\
\hline \#13 & (handheld or hand-held):ti,ab,kw \\
\hline \#14 & (smartphone* or smart-phone* or cellphone ${ }^{\star}$ or mobiles):ti,ab,kw \\
\hline \#15 & $\begin{array}{l}\left.\text { ((personal near/1 digital) or (PDA near/3 (device* or assistant }{ }^{\star}\right) \text { ) or MP3 player }{ }^{\star} \text { or MP4 play- } \\
\left.\mathrm{er}^{\star}\right): \text { ti,ab,kw }\end{array}$ \\
\hline
\end{tabular}




\begin{tabular}{|c|c|}
\hline \#16 & (samsung or nokia):ti,ab,kw \\
\hline$\# 17$ & (windows near/3 (mobile* or phone $\left.{ }^{\star}\right)$ ):ti,ab,kw \\
\hline \#18 & android:ti,ab,kw \\
\hline \#19 & (ipad* or i-pad* or ipod* or i-pod* or iphone* or i-phone*):ti,ab,kw \\
\hline \#20 & (tablet* near/3 (device* or computer $\left.\left.{ }^{\star}\right)\right): t i, a b, k w$ \\
\hline \#21 & MeSH descriptor: [Telemedicine] this term only \\
\hline \#22 & MeSH descriptor: [Videoconferencing] this term only \\
\hline \#23 & MeSH descriptor: [Webcasts as Topic] this term only \\
\hline \#24 & MeSH descriptor: [Text Messaging] this term only \\
\hline \#25 & MeSH descriptor: [Telenursing] this term only \\
\hline \#26 & (mhealth or m-health or "mobile health" or ehealth or e-health or "electronic health"):ti,ab,kw \\
\hline \#27 & $\begin{array}{l}\text { (telemedicine or tele-medicine or telehealth or tele-health or telecare or tele-care or telenursing or } \\
\text { tele-nursing or telepsychiatry or tele-psychiatry or telemonitor }{ }^{\star} \text { or tele-monitor } \text { or teleconsult* }^{\star} \text { or } \\
\text { tele-consult }^{\star} \text { or telecounsel }{ }^{\star} \text { or tele-counsel }{ }^{\star} \text { or telecoach }{ }^{\star} \text { or tele-coach } \text { ):ti,ab,kw }\end{array}$ \\
\hline
\end{tabular}

\begin{tabular}{|c|c|}
\hline \#28 & $\left(\right.$ videoconferenc $^{\star}$ or video-conferenc ${ }^{\star}$ or webcast $^{\star}$ or web-cast $\left.{ }^{\star}\right):$ ti,ab,kw \\
\hline \#29 & $\begin{array}{l}\text { (((text* or short or voice or multimedia or multi-media or electronic or instant) near/1 messag*) or } \\
\text { instant messenger) .ti,ab,kw }\end{array}$ \\
\hline \#30 & $\begin{array}{l}\left.\left.\text { (texting or texted or texter }{ }^{\star} \text { or ((sms or mms) near (service* or messag }{ }^{\star}\right)\right) \text { or interactive voice re- } \\
\text { sponse }^{\star} \text { or IVR or voice call* or callback* or voice over internet or VOIP):ti,ab,kw }\end{array}$ \\
\hline \#31 & 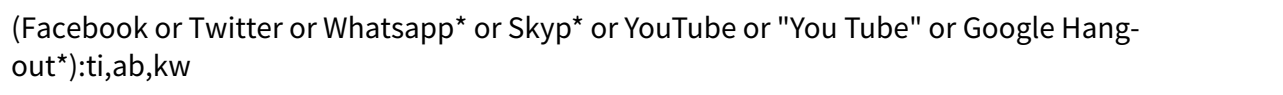 \\
\hline \#32 & MeSH descriptor: [Mobile Applications] this term only \\
\hline \#33 & "mobile app*":ti,ab,kw \\
\hline \#34 & MeSH descriptor: [Social Media] this term only \\
\hline \#35 & (social near (media or network*)):ti,ab,kw \\
\hline \#36 & MeSH descriptor: [Reminder Systems] this term only \\
\hline \#37 & $\left(\right.$ remind $^{\star}$ near/3 (text ${ }^{\star}$ or system ${ }^{\star}$ or messag $\left.\left.{ }^{\star}\right)\right): t i, a b, k w$ \\
\hline \#38 & MeSH descriptor: [Electronic Mail] this term only \\
\hline \#39 & (electronic mail ${ }^{\star}$ or email* or e-mail or webmail):ti,ab,kw \\
\hline \#40 & MeSH descriptor: [Medical Informatics] this term only \\
\hline \#41 & MeSH descriptor: [Medical Informatics Applications] this term only \\
\hline
\end{tabular}


(Continued)

\begin{tabular}{ll} 
\#42 & MeSH descriptor: [Nursing Informatics] this term only \\
\hline$\# 43$ & MeSH descriptor: [Public Health Informatics] this term only \\
\hline$\# 44$ & MeSH descriptor: [Multimedia] this term only \\
\hline$\# 45$ & MeSH descriptor: [Hypermedia] this term only \\
\hline$\# 46$ & MeSH descriptor: [Blogging] this term only \\
\hline$\# 47$ & $\left(\right.$ multimedia or multi-media or hypermedia or hyper-media or blog ${ }^{\star}$ or vlog ${ }^{\star}$ or weblog or web- \\
\hline$\# 48$ & log*):ti,ab,kw \\
\hline$\# 49$ & MeSH descriptor: [Interactive Tutorial] this term only \\
\hline$\# 50$ & MeSH descriptor: [Computer-Assisted Instruction] this term only
\end{tabular}

\#51

((interactive or computer-assisted) near/1 (tutor ${ }^{\star}$ or technolog* or learn* or instruct* or software or communication)):ti,ab,kw

\section{Popline - Searched 25 September 2018}

Keyword:(TEXT MESSAGING OR MOBILE DEVICES OR INFORMATION COMMUNICATION TECHNOLOGY OR CELLULAR PHONE) OR AIl FIeIdS: ((cell OR cellular OR mobile) AND (phone OR phones OR telephone OR telephones OR technology OR technologies OR device OR devices)) OR smartphone OR smartphones OR smart-phone OR smart-phones OR cellphone OR cellphones OR mobiles OR mhealth OR m-health OR "mobile health" OR ehealth OR e-health OR "electronic health" OR telemedicine OR tele-medicine OR telehealth OR tele-health OR telecare OR tele-care OR telenursing OR tele-nursing OR telepsychiatry OR tele-psychiatry OR telemonitor OR telemonitoring OR telemonitor OR tele-monitoring OR teleconsult OR teleconsulting OR tele-consult OR tele-consulting OR telecounsel OR telecounseling OR tele-counsel OR tele-counseling OR telecoach OR telecoaching OR tele-coach OR tele-coaching OR videoconference OR videoconferences OR videoconferencing OR video-conference OR video-conferences OR video-conferencing OR webcast OR webcasts OR webcasting OR web-cast OR web-casts OR web-casting OR ((text OR texts OR texting OR short OR voice OR multimedia OR multi-media OR electronic OR instant) AND (message OR messages OR messaging)) OR "instant messenger" OR texting OR texted OR texter OR texters OR ((sms OR mms) AND (service OR services OR message OR messages OR messaging)) OR "interactive voice response" OR "interactive voice responses" OR ivr OR "voice call" OR "voice calls" OR callback OR "voice over internet" OR voip OR "mobile app" OR "mobile apps" OR "mobile application" OR "mobile applications" OR "social media" OR ((medical OR clinical OR health OR healthcare OR nurse OR nurses OR nursing) AND informatics)

\section{AND}

Keyword: (QUANTITATIVE RESEARCH OR RESEARCH METHODOLOGY OR CLINICAL TRIALS OR CONTROL GROUPS) OR All Fields: (randomised OR randomized OR "randomly allocated" OR "random allocation" OR "controlled trial" OR "control group" OR "control groups" OR trial) (2000-2018)

\section{WHO Global Health Library (Regional Indexes only) - 25 September 2018}

(mh:(("cell phones" OR smartphone OR mp3-player OR "Computers, Handheld" OR telemedicine OR Videoconferencing OR "Text Messaging" OR Telenursing OR "Mobile Applications" OR "Reminder Systems" OR "Electronic Mail" OR "Medical Informatics" OR "Nursing Informatics" OR "Public Health Informatics" OR Multimedia OR Hypermedia OR Blogging OR Telemedicine))) OR (tw:(("cell phone" OR "cell phones" OR "cellular phone" OR "cellular phones" OR "mobile phone" OR "mobile phones" OR "mobile devices" OR "mobile devices" OR smartphone OR smartphones OR smart-phone OR smart-phones OR cellphone OR cellphones))) AND (mh:(("Controlled Clinical Trials, Randomized" OR "Controlled Clinical Trials as Topic" OR "Controlled Clinical Trial" OR "Clinical Trial"))) OR (tw:((randomised OR 
randomized OR "randomly allocated" OR "random allocation" OR "controlled trial" OR "control group" OR "control groups" OR trial))) 598 hits $(2000-2018)$

\section{ClinicalTrials.gov - 25 September 2018}

Field search: Other Terms: (telemedicine OR telehealth OR telecare OR telenursing OR telepsychiatry OR mhealth OR ehealth) AND ("mobile phone" OR "mobile phones" OR "mobile devices" OR mobiles OR smartphone OR smartphones) | Studies received on or after 01/01/2000 | Studies updated on or before 25/09/2018

\section{WHO ICTRP - 25 September 2018}

\section{Search 1:}

Title: telemedicine OR telehealth OR telecare OR telenursing OR telepsychiatry OR mhealth OR ehealth

AND

Intervention: mobile device OR mobiles OR smartphone OR phone OR cellphone

Search 2:

Title: mobile device OR mobiles OR smartphone OR phone OR cellphone

AND

Intervention: telemedicine OR telehealth OR telecare OR telenursing OR telepsychiatry OR mhealth OR ehealth

\section{H I S T O R Y}

Protocol first published: Issue 1, 2018

Review first published: Issue 8, 2020

\section{CONTRIBUTIONSOF AUTHORS}

Conceiving and designing the review: MF, DGB, CG, SL, GM, SS, TT

Co-ordinating the review: DGB

Searching, selecting studies and completing the data extraction and grading: ARM, BB, DGB, GV, IRC, MF, NH, TT

Writing the review: DGB, SS

Providing general advice and feedback: ARM, BB, CG, DGB, GM, GV, IRC, MF, NH, SL, SS, TT

Securing funding for the review: GM, TT

\section{DECLARATIONS OF INTEREST}

ARM: Consultancy from Infarmed - national authority of medicines and health products. Health Technology Assessment Commission. Payment for development of education presentations from Portuguese Institute of Oncology - Lisbon.

BB: none known.

CG: none known.

DGB: "I was commissioned by the WHO to conduct this review."

GM: owns stock in Apple Computer.

GV: "Since October 2017 I have been employed by Cochrane Response, an evidence services unit operated by the Cochrane Collaboration and contracted by the WHO to produce this review."

IRC: none known.

MF: none known.

$\mathrm{NH}$ : "Since June 2016 I have been employed by Cochrane Response, an evidence services unit operated by the Cochrane Collaboration and contracted by the WHO to produce this review".

SL: "I am the Joint Co-ordinating Editor for the Cochrane Effective Practice and Organisation of Care Review Group. I am also a member of the WHO Executive Guideline Steering Group on maternal and perinatal health recommendations".

SS: "I am the Joint Co-ordinating Editor for the Cochrane Effective Practice and Organisation of Care Review Group."

TT: none known.

\section{SOURCES OF SUPPORT}

\section{Internal sources}

- National Institute of Medical Research, UK 


\section{External sources}

- UNDP-UNFPA-UNICEF-WHO-World Bank Special Programme of Research, Development and Research Training in Human Reproduction (HRP), a cosponsored program executed by the World Health Organization (WHO), Switzerland

Provided funding for the review.

\section{DIFFERENCES BETWEEN PROTOCOLANDREVIEW}

We stated in the protocol that there would be one 'Summary of findings' table per comparison, and that we would group the trials by health condition. We did not do this due to the low number of included trials and the large number of different health conditions. Following discussion among the authors we agreed that stratifying the included studies by setting (community, primary, secondary care) would provide relatively homogenous groups of studies and that reporting findings by setting would improve the usability of the evidence.

We changed the title from "Mobile-based technologies to support healthcare provider to healthcare provider communication and management of care" to "Mobile technologies to support healthcare provider to healthcare provider communication and management of care".

For the outcome 'Healthcare provider and participant acceptability of and satisfaction with the intervention', the protocol stated that both objective and subjective measures would be included, the former being the number lost to follow-up not explained by other reasons. We did not measure acceptability or satisfaction using loss to follow-up data, due to insufficient information.

We split the outcome 'Resource use' into two outcomes ('Healthcare use' and 'Cost').

For the 'Summary of findings' tables, we included participant acceptability and satisfaction alongside healthcare provider acceptability and satisfaction. The former was already a prespecified outcome in the protocol, but not for the 'Summary of findings' table.

One of the authors left the team (Nicola Maayan); we added new authors (Ana Rita Maria, Ignacio Ricci-Cabello, Gemma Villanueva).

\section{N O T E S}

This review is based on standard text and guidance provided by Cochrane Effective Practice and Organisation of Care (EPOC). 